\title{
Population and Community Ecology of the Rare Plant Amsinckia grandiflora
}

Tina Marie Carlsen

PhD Thesis

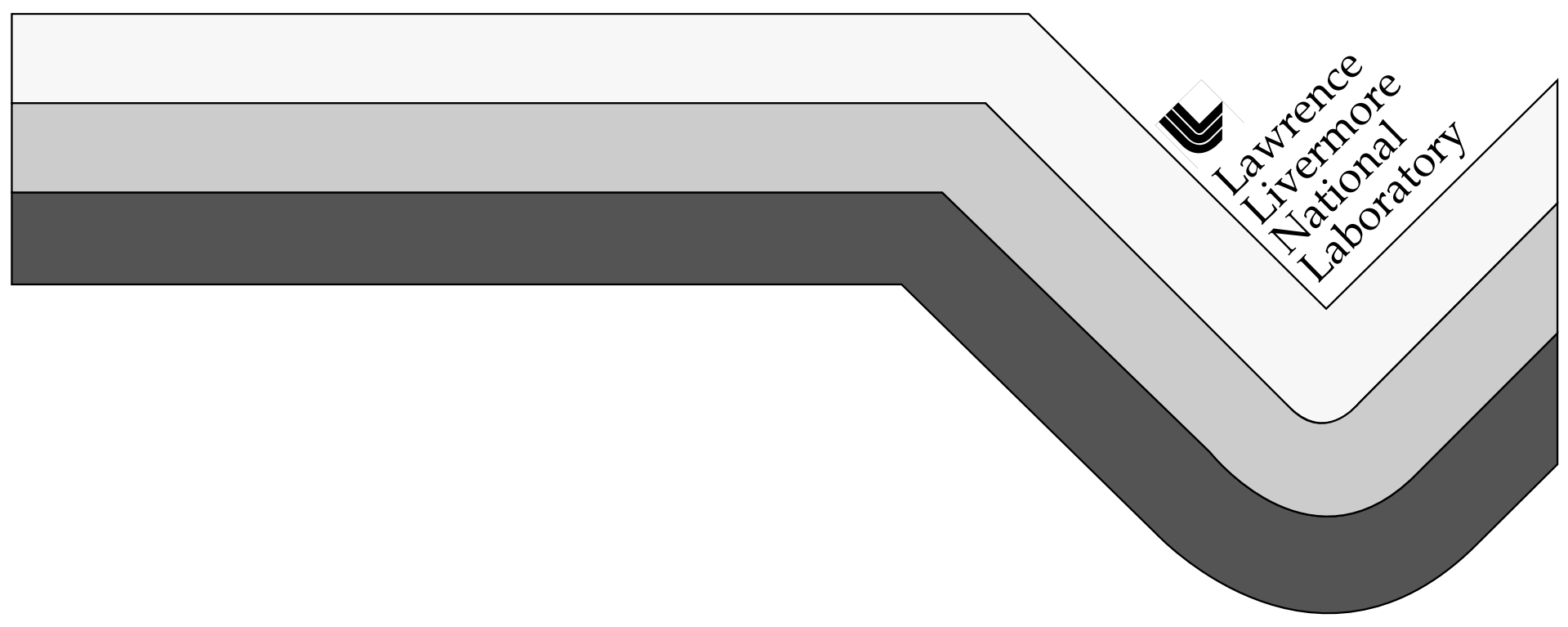




\section{DISCLAIMER}

This document was prepared as an account of work sponsored by an agency of the United States Government. Neither the United States Government nor the University of California nor any of their employees, makes any warranty, express or implied, or assumes any legal liability or responsibility for the accuracy, completeness, or usefulness of any information, apparatus, product, or process disclosed, or represents that its use would not infringe privately owned rights. Reference herein to any specific commercial product, process, or service by trade name, trademark, manufacturer, or otherwise, does not necessarily constitute or imply its endorsement, recommendation, or favoring by the United States Government or the University of California. The views and opinions of authors expressed herein do not necessarily state or reflect those of the United States Government or the University of California, and shall not be used for advertising or product endorsement purposes.

This report has been reproduced directly from the best available copy.

Available to DOE and DOE contractors from the Office of Scientific and Technical Information P.O. Box 62, Oak Ridge, TN 37831

Prices available from (615) 576-8401, FTS 626-8401

Available to the public from the National Technical Information Service

U.S. Department of Commerce 5285 Port Royal Rd., Springfield, VA 22161

Work performed under the auspices of the U.S. Department of Energy by Lawrence Livermore National Laboratory under Contract W-7405-ENG-48. 
UCRL-LR-127218

Distribution Category UC-702

\title{
Population and Community Ecology of the Rare Plant Amsinckia grandiflora
}

\author{
Tina Marie Carlsen
}

Doctor of Philosophy

Thesis

Manuscript date: November 1996

LAWRENCE LIVERMORE NATIONAL LABORATORY 



\section{Population and Community Ecology \\ of the Rare Plant Amsinckia grandiflora}

BY

Tina Marie Carlsen

B. A. (California State University, Stanislaus) 1984

M. S. (University of San Francisco) 1990

\section{DISSERTATION}

Submitted in partial satisfaction of the requirements for the $c$ DOCTOR OF PHILOSOPHY

in
Ecology
in the
OFFICE OF GRADUATE STUDIES
Of the
OF CALIFORNIA
DAVIS

Approved:

Committee in Charge

1996

$-i-$ 
TABLE OF CONTENTS

ACKNOWLEDGMENTS

iii

ABSTRACT

$\mathrm{V}$

INTRODUCTION AND OVERVIEW

1

Competitive Suppression of a Rare Annual Forb

by Native Perennial and Exotic Annual Grasses

8

The Role of Intrinsic Factors in the Reproductive Ecology of an Endangered Plant

Effect of Litter and Seed Predation on the Germination of a Rare Annual Forb 


\section{ACKNOWLEDGMENTS}

It is impossible to undertake a project such as this without tr support of many people. In a very real sense, this degree belong them. I would first of all like to acknowledge the various organ Lawrence Livermore National Laboratory (LLNL) which supported me through this process. The three years of funding from the Labor Directed Research and Development Program made the research poss In addition, I am grateful for the encouragement and support I $r$ from the management of the Environmental Restoration Division (ER especially that from Albert Lamarre. They allowed me to work, ta classes, and conduct the research, without going totally crazy. would like to thank the members of the Environmental Chemistry an Biology Group, particularly steven Gregory, Erin Espeland, Eric h Peter Beesley, Mary Bean and Valerie Dibley. Their long hours of work in the field and greenhouse were essential to the successfu] completion of this research.

I would also like to express my deeply felt gratitude to member guidance committee. My major advisor, Dr. John Menke, was able. provide valuable guidance although located in the far reaches of California. I am very grateful to Dr. Bruce Pavlik of Mills Coll agreed to serve on my committee, and was an invaluable collaborat research. His previous work on Amsinckia grandiflora added immeasurably to the quality of the research. And special thanks Kevin Rice for his careful review of all portions of the manuscri from the outback of Australia. His thoughtful critiques and helf 
suggestions in the statistical analyses were invaluable. I also Jim Richards and Lisa Donovan for their advice and guidance in t] use of thermocouple psychrometers.

I would like to make special recognition of Dr. Theodore Foin, chair of the Ecology Graduate Group (EGG) during most of my gradu career at UC Davis. His enthusiasm for his work, and interest ir. students, was amazing. I have benefited immensely from my inter with Dr. Foin over the past five years. I will greatly miss our Species Act Working Group. I would also like to thank Silvia Hil EGG. As a long-distance student, her logistical support helped $\mathrm{m}$ several tight spots.

I found my graduate experience at UC Davis to be a very positiv a commuter student working full time at LLNL and living in Modest was only able to be on campus two days a week (even when taking t] day-a-week classes) while completing the course work, and had to innumerable logistical details. Without exception, everyone, frc instructors, to my guidance committee, to the EGG, helped make tr possible. They were all understanding of my circumstances, and me in many ways. While I cannot recommend it as a path for othe: students, I can at least tell them it is possible, and most at UC very accommodating of such circumstances.

Most of all, I would like to thank my husband, Fred Kelly. His support, and patience through the many long, lonely nights when occupied with school or work provided me with a solid foundation. such a foundation, the focus required to reach such a goal would been possible. I now look forward to making it up to him. 
ABSTRACT

Research was conducted between the fall of 1992 and the spring , on the population and community ecology of the rare annual plant Amsinckia grandiflora (Gray) Kleeb. ex Greene (Boraginaceae). $T$. research goal was to investigate the causes of the species rarity data useful to restoration efforts. The work focused on examinat competitive suppression by exotic annual grasses; comparisons wi. common, weedy congener; and the role of litter cover and seed pre nutlet germination and seedling establishment.

Annual exotic grasses reduced A. grandiflora reproductive outp greater extent than did the native perennial bunch grass P. secur. intermediate densities when compared on a biomass per area basis. response of A. grandiflora nutlet production to grass biomass was the amount of cover and was linear for P. secunda biomass, where; same response to the annual exotic grass biomass was logarithmic

Comparative studies between A. grandiflora and A. tessellata s nutlet germination responses to be similar between the two specie grandiflora greenhouse pollination studies revealed A. grandiflor completely self-incompatible, and floral seed cache (nutlets/flor approached that of the self-compatible A. tessellata. A. grandij output could fully compensate for lower floral seed cache, result nutlet output between A. grandiflora and A. tessellata in the grt but could not fully equal A. tessellata nutlet output in the fiel، 
Manual removal of litter was shown to alter A. grandiflora nut microclimate. Depending on the ambient temperature at the time $c$ germination subsequent to litter removal, nutlet germination and establishment were reduced. Nutlet predation also significantly seedling establishment. The existing climatic conditions at the litter removal and the timing of the initiation of germination de which factor exerted the primary controlling influence. 


\author{
Population and Community Ecology \\ of the Rare Plant Amsinckia grandiflora
}

\begin{abstract}
Research was conducted between the fall of 1992 and the spring , on the population and community ecology of the rare annual plant Amsinckia grandiflora (Gray) Kleeb. ex Greene (Boraginaceae). $\mathrm{T}$. research goal was to investigate the causes of the species rarity data useful to restoration efforts. The work focused on examinat competitive suppression by exotic annual grasses; comparisons wi. common, weedy congener; and the role of litter cover and seed pre nutlet germination and seedling establishment.

Annual exotic grasses reduced A. grandiflora reproductive outp greater extent than did the native perennial bunch grass P. secur. intermediate densities when compared on a biomass per area basis. response of A. grandiflora nutlet production to grass biomass was the amount of cover and was linear for P. secunda biomass, where; same response to the annual exotic grass biomass was logarithmic

Comparative studies between A. grandiflora and A. tessellata s nutlet germination responses to be similar between the two specie grandiflora greenhouse pollination studies revealed A. grandiflor completely self-incompatible, and floral seed cache (nutlets/flor approached that of the self-compatible A. tessellata. A. grandij output could fully compensate for lower floral seed cache, result
\end{abstract}


nutlet output between A. grandiflora and A. tessellata in the grt but could not fully equal A. tessellata nutlet output in the fiel، Manual removal of litter was shown to alter A. grandiflora nut microclimate. Depending on the ambient temperature at the time $c$ germination subsequent to litter removal, nutlet germination and establishment were reduced. Nutlet predation also significantly seedling establishment. The existing climatic conditions at the litter removal and the timing of the initiation of germination de which factor exerted the primary controlling influence. 


\section{INTRODUCTION}

AND OVERVIEW

I conducted research between the fall of 1992 and the spring of the population and community ecology of the rare plant Amsinckia grandiflora (Gray) Kleeb. ex Greene (Boraginaceae). I performed greenhouse studies to investigate ecological factors which could affect fitness components of A. grandiflora, and thus may be cont the extreme rarity of this plant. The goal of my research was to information which could be used in restoration efforts on this sk

A. grandiflora is a federally-listed endangered species; an an that is part of the California winter annual grassland. Origina: by Gray in 1876 as a variety of A. vernicosa, it was recognized a species by Greene in 1894. Over one hundred years later, at the $t$ listing in 1985, A. grandiflora was known from only one populatic had declined from several thousand individuals to less than one: It is currently known from three natural populations containing individuals numbering from fewer than 30 to several thousand. Tr populations occur in grasslands which border on blue oak woodlan. coastal sage scrub on steep, well-drained, north-facing slopes o: intermediate $(300 \mathrm{~m})$ elevations. All three populations are locat، Altamont Hills of the Diablo range, about 50 miles east of San Fr California on or near Site 300. Site 300 is a Lawrence Livermore Laboratory high-explosive testing facility, operated by the Univer California for the U.S. Department of Energy. A heterostylous SF A. grandiflora produces two different flower forms (also known a morphs); pin and thrum flowers. Each individual plant has only ( 
of flower. Pin flowers are characterized by having a stigma exs $\epsilon$ the anthers within the corolla tube. Thrum flowers have the oppc morphology, with anthers exserted and the stigma within the coro] Prior to the initiation of my research, two main hypotheses hac proposed as the cause of this species rarity. First, some eviden that suggested A. grandiflora was competing poorly with exotic al grasses. Second, there was evidence that the inefficient heteros mating system of $A$. grandiflora was resulting in competitive dis of A. grandiflora by sympatric, weedy congeneric species. It shc noted that these two primary hypotheses are not necessarily mutua exclusive. And they are not the only possible causes for the rar plant. For example, little previous work had focused on factors germination. It is possible that environmental (such as temperat biological (such as predation) factors could be controlling the , and establishment of this species in the field. At a minimum, $g$ controls could have significant implications during restoration at creating additional A. grandiflora populations. My research these three hypotheses concerning the rarity of A. grandiflora.

The first research paper, "Competitive Suppression of a Rare A Forb by Native Perennial and Exotic Annual Grasses", describes my research on the role of competitive suppression by exotic grasses decline of A. grandiflora. I reasoned that if exotic grass compt contributing to the decline of this plant, then its performance $s$ enhanced in a matrix of native perennial bunch grasses. To test hypothesis, during the 1993-94 California wet season, I conducted competition experiment in which A. grandiflora seedlings were transplanted into $0.64 \mathrm{~m}^{2}$ experimental plots. The plots consisted 
3-cm-dia. plants of the native perennial bunch grass Poa secunda in three densities, or exotic annual grasses established in four through manual removal of existing plants. All plots were arran randomized, complete-block design. Both grass types significant] the production of A. grandiflora inflorescences (which is correl nutlet output). The annual grasses reduced A. grandiflora inflo number to a greater extent than did P. secunda when compared on $\bar{c}$ biomass per area basis. The response of A. grandiflora nutlet pr P. secunda biomass was linear, whereas the same response to the grass biomass was logarithmic, and appeared to be related to the grass cover. This may be due to the different morphologies exhib: two grass types. I concluded that A. grandiflora performance, a by inflorescence number, was greatest in a community dominated b! intermediate densities of $\mathrm{P}$. secunda when compared with a commun dominated by exotic annual grasses, at least under the conditions during this single growing season experiment.

The second research paper, "The Role of Intrinsic Factors in $t$ Reproductive Ecology of an Endangered Plant", presents a set of $f$ greenhouse experiments I conducted to evaluate intrinsic limitati fitness of A. grandiflora as compared to A. tessellata, a weedy, relative. A greenhouse pollination study was conducted in which flowers on 20 pin plants and 20 thrum plants received one of four pollination treatments, 1) no manual pollination, 2) manually-ass pollination, 3) manually-assisted intramorph pollination, and 4) assisted intermorph pollination. Results of this study indicated distylous A. grandiflora is not completely self-incompatible. Tr floral seed cache (seeds/flower) was observed in the intramorph 
pollinations, and was comparable to that observed in field grown A. tessellata. Germination trials consisted of germinating nutl' plates containing moistened filter paper, or in steuwe tubes cont from one of the natural field populations. The results indicated A. grandiflora and A. tessellata have germination responses typi many annual species found in the California grasslands. Similar germination responses were observed for both species. Interspec: comparisons of survivorship and nutlet production were conducted greenhouse-grown and field-grown plants. In the field, mortalit for both species, although it was greater for A. tessellata at on In the greenhouse, A. grandiflora can compensate for low floral by increasing floral output (flowers/plant) as compared to A. te through increasing the number of flowers per inflorescence. Alt statistically significant, A. grandiflora floral output was also A. tessellata in the field, but it did not fully compensate for $t$ seed cache. The presence of exotic annual grasses in the field $\mathrm{r}$ affected A. grandiflora to a greater extent than A. tessellata. concluded that under conditions of unlimited resources, it appea: unlikely that A. grandiflora fitness was intrinsically limited w] compared to its weedy relative A. tessellata. However, under fie conditions, the reproductive ecology of A. grandiflora may result seed output.

In the third and final research paper, "Effect of Litter and $S \in$ Predation on the Germination of a Rare Annual Forb", I present m: investigations into the role of microclimate and predation on the germination of A. grandiflora. I had observed very poor A. gran germination during the fall of 1992 subsequent to a controlled bu 
suggesting microclimate or predation may control A. grandiflora establishment. I therefore conducted a field experiment over twc seasons to investigate these possible controls on A. grandiflora germination. During the 1993-94 growing season, two main plots v established within a single field site. The main treatments cons either manually clearing all litter, or leaving the litter intact main treatments, two sub-treatments were established. In the cle main treatment plot, sub-treatments consisted of either covering plot with aviary netting, or leaving the sub-plot open. Within tht treatment plot, sub-treatments consisted of clipping the standing replacing on to the sub-plot, or leaving the standing litter intar treatment plots were replicated three times, the main treatment $p$ not replicated. A single replicate of sub-treatment plots were $i$ with thermocouples to measure soil temperature at a depth of $1 \mathrm{~cm}$ During the 1994-95 growing season, the experiment was conducted a sites. This time, the main treatments were replicated three time sub-treatments replicated three times within each main treatment replicate. All sub-treatment plots at one site were instrumented thermocouples. During the 1993-94 growing season, litter cover significantly increased A. grandiflora germination. Soil temper indicated litter cover moderated soil temperature. Some evidence predation was detected, as indicated by increased germination in plots, but was not significant. In contrast, during the 1994-95 season, germination success was greatly affected by predation, as highest amount of germination was observed in the netted sub-trea In addition, soil temperature extremes were not as great during 1 growing season. These data suggest that both microclimate alterc 
predation can affect A. grandiflora germination, with the existi conditions at the time of litter removal and the timing of the in: germination determining which factor exerts the primary controll influence.

As a result of this research, I can conclude the following wit the population and community ecology of A. grandiflora. First, A. grandiflora competes poorly with exotic annual grasses, and $t$ competitive suppression is contributing to its rarity. A corolla A. grandiflora performs best in a matrix of intermediate densiti perennial bunch grass P. secunda. Second, A. grandiflora has th to equal the reproductive output of its weedy relative A. tesselli particularly under conditions of unlimited resources. Therefore A. grandiflora fitness is not inherently limited. However, under conditions, A. grandiflora's reproductive ecology apparently con nutlet output as compared to A. tessellata. This may also be the poor competition with annual exotic grasses. Finally, I conclude germination of A. grandiflora can be controlled by microclimate. predation, with the predominance of one over the other changing 1 to year. The results described in this dissertation provides inf which should be considered during any restoration work conducted A. grandiflora. 
THE RESEARCH PAPERS 


\title{
COMPETITIVE SUPPRESSION OF A \\ RARE ANNUAL FORB BY NATIVE PERENNIAL \\ AND EXOTIC ANNUAL GRASSES
}

\author{
TINA M. CARLSEN \\ Environmental Restoration Division, Lawrence Livermore Nation \\ Laboratory, Livermore, CA 94551 USA
}

JOHN W. MENKE

Department of Agronomy and Range Science, University of Califo Davis, CA 95616 USA

BRUCE M. PAVLIK

Department of Biology, Mills College, Oakland, CA 94613 USA

Prepared for submission to Ecology 
Abstract. Populations of the California winter annual forb Am: grandiflora may be declining because of competitive suppression b annual grasses, and may perform better in a matrix of native perı bunch grasses. To test this hypothesis, we conducted a field com experiment in which A. grandiflora seedlings were transplanted $i$ $0.64 \mathrm{~m}^{2}$ experimental plots. The plots consisted of mature 3-cm-di of the native perennial bunch grass Poa secunda planted in three or exotic annual grasses established in four densities through $\mathrm{m}$ removal of existing plants. All plots were arranged in a random complete-block design. Both grass types significantly reduced th production of A. grandiflora inflorescences. At low and interme densities, the annual grasses reduced A. grandiflora inflorescer. to a greater extent than did P. secunda when compared on a biomas area basis. The response of A. grandiflora nutlet production to $\mathrm{F}$ biomass was linear, whereas the same response to the annual gras biomass is logarithmic, and appeared to be related to the amount cover. This may be due to the different morphologies exhibited by grass types.

Key words: A. grandiflora, P. secunda, rare plants, native plé plants, interspecific plant competition, light competition, water 


\section{INTRODUCTION}

The native bunch grass communities of California have undergor. major transformation since the arrival of the first Europeans (Ba Grasslands occur in several California plant communities. They primary component in the valley grassland community, and form th understory in oak woodland (also known as foothill woodland) and cismontane woodland communities of the California Floristic Prov (Barbour and Major 1990). During exploration and intensive settl annual grasses native to the Mediterranean area were either inter introduced as cereal or forage crops, or inadvertently introducer impurities in crop seed and in packing material (Murphy and Ehrl 1989). By the 1850's, European plants had largely displaced natir and perennial grassland species, particularly in the valley gras oak woodland communities, resulting in the California winter ann grasslands of today. These grasslands, now dominated by alien s] have more recently been fragmented due to agricultural conversior suburban sprawl (Huenneke 1989).

In recent years, the decline of locally-restricted native plant been observed within California winter annual grasslands. Many taxa are now of conservation concern, and some have been formally as threatened and endangered. In their most recent inventory of endangered vascular plants of California (Skinner and Pavlik 1994 California Native Plant Society (CNPS) listed 454 taxa found in va

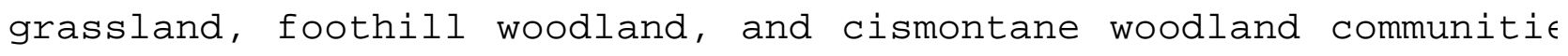
Annual plants comprised 48\% of this total (216 taxa). Of these 21 are on the CNPS list of most threatened plants, with 9 taxa federc as threatened or endangered. Many of the 121 highly threatened ti 
occur in valley grassland or foothill woodland communities. Con research on the role of annual exotic grasses in the decline of $r$ species, both annual and perennial, can determine the mechanisms decline, and provide recommendations required to maintain biodiv $\epsilon$ annual grasslands. Several authors have shown that competition i annual exotic grasses reduces some measure of fecundity in the $n$. species (Gordon and Rice 1993, Guerrant 1992).

The large-flowered fiddleneck, Amsinckia grandiflora (Gray) Kl Greene (Boraginaceae), is a rare forb native to the California gr which there is concern that competitive suppression by its exotic may have contributed to its decline (Knudsen and Tarp 1994). Dur: reintroduction efforts, Pavlik et al. (1993) found that competitic grasses reduced fecundity of A. grandiflora. They also found the management of one of the native populations using a grass-select: herbicide for several years resulted in the numbers in this popul rebounding from fewer than 100 individuals to its present number 1500 individuals (Pavlik 1995).

The evidence that the presence of annual exotic grasses has ner impacted the reproductive performance of A. grandiflora implies. A. grandiflora would perform better in a matrix of native species assumption has not been explicitly tested. Should it be true, it reaching management implications, given that much of the Califor grasslands are now composed primarily of exotic species. Intens management to restore and maintain native grass communities woul' required in the effort to sustain many rare native plants. There out to test the hypothesis that this particular California native forb, A. grandiflora, would perform better in a matrix of native 
bunch grasses than in a matrix of annual exotic grasses. We selt native bunch grass P. secunda J. S. Presl (formerly P. scabrella: test, since it is abundant at the site where A. grandiflora is na

METHODS

The study species

Of the fifteen species in the genus recognized by Ray and Chisa and 1957b), A. grandiflora is one of four heterostylous species w restricted distributions that are probably ancestors of the weedy, widespread, and homostylous congeners (Ray and Chisaki 1957a and 1957b). As a heterostylous species, A. grandiflora produces pin flower forms (or morphs). Each individual plant has only one tyk flower. Pin flowers are characterized by having an exserted stic anthers within the corolla tube. Thrum flowers have the opposinc morphology, with exserted anthers and the stigma within the coro] As a member of the California winter annual grassland, A. grandi germinates with the onset of fall or winter rains, grows vegetati throughout the winter, flowers in the early spring, sets seed anc to the summer drought (Heady 1990). It is currently known from o natural populations containing individuals numbering from fewer to several thousand. All natural populations occur on steep, we north-facing slopes in the Altamont Hills, about $30 \mathrm{~km}$ southeast Francisco, California. The populations occur at low elevations , m) and border on blue oak woodland and coastal sage scrub commun Two of the natural populations of A. grandiflora occur on Lawr Livermore National Laboratory Site 300, a high-explosive testing $f$ operated by the University of California for the United States Dep 
Energy. This largely undeveloped 2711 ha site has been protected livestock grazing and many other human activities since the early Its grasslands are managed with annual controlled burns to reduc threat of wildfire. The burns are typically conducted in June ea summer. This management practice has resulted in large expanses native perennial bunch grass Poa secunda (formerly Poa scabrella: and Davilla 1986). Although the populations of A. grandiflora do in areas undergoing the annual controlled burns, there is a sign amount of $\mathrm{P}$. secunda cover at the sites where the natural populat found. However, annual exotic grasses consisting of Bromus horc L., B. diandrus Roth, B. madritensis ssp. rubens (L.) Husnot, Av barbata Link and Vulpia myuros (L.) C. Gmelin, and annual exotic such as Erodium cicutarium (L.) L'Hér still form the primary con matrix in which A. grandiflora occurs.

\section{Site selection}

The experimental site was selected in the fall of 1992. This s same canyon on Site 300 property as the originally described natu population. The experimental site was selected to mimic the site A. grandiflora occurs naturally as closely as possible. It is il grassland bordered by blue oak woodland and coastal sage scrub. elevation is approximately $320 \mathrm{~m}$. The aspect is northwest facing slope ranging from 25\% to 72\% (average 56\%). The soil consists 0 drained, deep (about $1 \mathrm{~m}$ ) sandy clay loam. Herbaceous cover cons primarily of the annual exotic grasses Bromus hordeaceus and Vul myuros, with lesser amounts of B. diandrus, B. madritensis ssp. Avena barbata, and the exotic forb Erodium cicutarium. Native sk 
include the perennial bunch grass P. secunda as well as several legumes, including Clarkia spp., miniature lupine (Lupinus bico] Lindley), and purple owl's clover (Castilleja exserta (A. A. Hel $\&$ Heckard).

To clear the litter from the site for the experiment, a contro] conducted on October 26, 1992. Wind, slope and vegetation moistur were used in a model to predict fire intensity (Andrews 1983, Bur Rothermal 1983). The predicted heat per unit area was 625 Btu/ft $^{3}$ fireline intensity was $48 \mathrm{Btu} / \mathrm{ft} / \mathrm{s}$.

\section{Treatment assignments}

The experimental method consisted of treatments on 40 plots me $0.64 \mathrm{~m}^{2}$ each $(0.8 \mathrm{~m} \times 0.8 \mathrm{~m})$. All 40 plots were sited and were as treatments in the fall of 1992. All P. secunda tussocks were man removed from the plots that received the annual grass treatments. plot contained 4 equally spaced target plants (A. grandiflora) wi selected treatment. The treatments included three densities of $P$ (subsequently identified as the P. secunda treatments), four dens annual grasses (identified as the annual grass treatments), and 1 treatments which were plots containing only A. grandiflora. All treatments were replicated five times, with plots arranged in a complete block design (Little and Hills 1978).

\section{P. secunda treatment establishment}

Between February 5 and February 10, 1993, the P. secunda treatm were established. Healthy, mature P. secunda tussocks were excar from land surrounding the experimental site. The tussocks were, 
into 3-cm-dia.. plugs and transplanted into the plots in a hexagc arrangement at densities of 11, 22 and 45 plugs per plot (17, 34 a: plugs $\left./ \mathrm{m}^{2}\right)$. The high density treatment corresponds to densities 0 areas of Site 300 that undergo annual controlled burns (unpublish Four P. secunda transplants that were damaged by gopher activity the first month were replaced. The transplanted plugs were allow grow through the remainder of the season. All annual plants wer manually removed from the $P$. secunda plots throughout the growin season

\section{A. grandiflora transplantation}

In the fall of 1993, A. grandiflora nutlets were germinated in greenhouse for subsequent transplantation into the field. Nutlet. present experiment were obtained from a 1988 common garden study conducted at the University of California at Davis by Drs. Daniel and Ronald Kelley (Pavlik et al. 1993). These nutlets can be trac nutlets collected from the Site 300 native population by Dr. Rober the University of California at Berkeley in the mid-1960s. On Nov 1993, with the onset of winter rains, A. grandiflora nutlets were Petri dishes containing Whatman 40 filter paper saturated with di water at 20 nutlets per dish. Each dish was then covered with fo maintained at approximately $25^{\circ} \mathrm{C}$. In an ambient temperature greenhouse, steuwe tubes measuring $2.5 \mathrm{~cm}$ in diameter by $15 \mathrm{~cm} d \epsilon$ were filled with native soil collected from the field site and we with distilled water. Of the A. grandiflora nutlets sown on the 84\% germinated. A. grandiflora germinules were transplanted int، prepared steuwe tubes as soon as the pericarps were shed and eacr. 
germinule possessed a noticeable hypocotyl and a root length of 1 Transplantation occurred over a period of four days, with the maj germinules transplanted on December 2, 1993. Transplant success over 95\%. Distilled water was used to irrigate the tubes.

On December 9, 1993, A. grandiflora seedlings were transplantec the field plots. We selected seedlings from the December 2, 1993, greenhouse transplantation that were uniform in size, had well df cotyledons and the first true leaves beginning to emerge. Upon transplantation into the field, the soil was packed around each $s$ well wetted with distilled water. Four A. grandiflora seedlings transplanted into the center of each plot in a 30-cm-square arrar Two seedlings sustained rodent damage and were replaced on Decem] $29,1993$.

Annual grass treatment establishment

During A. grandiflora transplantation, Bromus hordeaceus seedi added to the annual grass treatments to ensure a range of exotic Depending on the assigned treatment target density, seeds were ad $500,1000,2000$ and 4000 seeds per $0.64 \mathrm{~m}^{2}$ plot. An equal amount o grass thatch was placed on all of the plots to moderate soil temp Plots were manually thinned to target annual grass densities on , 13-14, 1994, and again on January 31-February 1, 1994. These targ* densities were 900, 1800, 2700 and 3600 grass individuals per $\mathrm{m}^{2}$. non-grass monocots were removed from the plots. After February 1 only the control and $\mathrm{P}$. secunda treatments were routinely weeded. the lack of significant natural rainfall, on January 19, 1994, al received supplemental watering with $0.16 \mathrm{~cm}$ of distilled water pe 
Psychrometer installation and use

A total of 64 screen-caged Peltier thermocouple psychrometers calibrated in the laboratory using the Brown and Bartos model (Br Bartos 1982). Two psychrometers were installed within each plot the five blocks, which spanned the range of the slope observed in site. Psychrometers were installed at depths of 10 and $75 \mathrm{~cm}$. Tc disturbing the plot, a 1-m-deep trench was excavated directly dow the plot. The psychrometer was installed by going to the desired the trench, then using a wooden dowel to create a hole reaching $\mathrm{l}$ into the plot at the same slope as the plot. The psychrometer was through this hole, the excavation was filled, and the leads to th psychrometer were directed to one of six common stations. All psychrometer cable was buried. A Campbell CR-7 datalogger was us read all psychrometers. In early February of 1993, 30 of the psy were installed, and the remaining 34 were installed in February 0

Pre-dawn (4 am) soil water potential measurements were obtaine both depths in two to three blocks throughout the month of April 1 addition, midday soil water potential measurements were obtained two depths from each plot on April 21, 1994, which was near the el flowering period.

Field observations and nutlet harvest

Phenological observations for all species, and measurements on height and number of flowering branches (inflorescences) on each A. grandiflora plant were obtained throughout the 1993/1994 growil season. Calibrated ocular estimates of grass cover were made for 
on March 17 and April 1, 1994. On March 22, 1994, twenty A. granc plants (10 pin and 10 thrum) spanning the observed size range wer selected and flagged for nutlet collection. Every 2 to 3 days, mé were manualy collected from each flagged plant.

\section{Biomass harvest}

At the end of the 1992/1993 growing season, above-ground plant from all of the plots was clipped and removed. In addition, bion collected from each of the five blocks from a randomly selected $p$ been assigned an annual grass treatment. This biomass was separi species and weighed to establish initial species composition witr. community, exclusive of $P$. secunda.

Between May 3 and May 5, 1994, biomass from plants other than A. grandiflora (termed neighbor biomass) was collected from each A. grandiflora plants were not harvested, and were thus allowed $t$ seed. For the annual grass treatments, the center $0.6 \times 0.6 \mathrm{~m}$ of was harvested. Four randomly placed sub-samples were collected within this area (the area of each subsample was delineated by a $\mathrm{cm}$ to a side), and the individual plants were counted and separat species for subsequent dry weight determination. For the P. secl treatments, P. secunda biomass was harvested from the entire plot Species other than $\mathrm{P}$. secunda remaining in the plot were collect $\epsilon$ separately. Of the $15 \mathrm{P}$. secunda treatment plots, one medium den one high density plot was lost to gopher damage, and thus was not harvested. All 20 annual grass treatment plots survived the expe intact. 
All neighbor biomass was oven dried at $65{ }^{\circ} \mathrm{C}$ for 5 days and wei the five control treatment plots, the manual thinning of two plot adequate, resulting in unacceptably high levels of neighbor biome plots were excluded from subsequent analysis.

\section{Data analysis}

Due to the rarity of A. grandiflora, we wanted to allow the maj plants to senesce naturally, hopefully reseeding a new populatior Therefore, it was necessary to determine the best predictor of nut for use in subsequent analysis of the effects of grass competitio Therefore, shoot length in centimeters and the number of inflore recorded on April 12, 1994 for each of the twenty harvested A. gri plants were correlated with total nutlet production per plant to the best predictor of nutlet output. Both single and multiple co were performed. The predictor or combination of predictors with highest correlation was selected for use in subsequent analysis o grass competition on A. grandiflora.

The annual grass densities varied greatly within each of the p: received an annual grass treatment, which caused the grass bioma collected from these plots to vary as well. We therefore analyzer resulting data using both regression analyses on a per plot basis analysis of variance (ANOVA) analyses on a per treatment basis, appropriate. Caution must be used in interpreting the results of ANOVA analysis, as the treatment classification variable is some artificial, due to the large degree of variation within each trea classification. Mortality data as percentages were transformed l arcsin transformation prior to ANOVA (Krebs 1989). A single degr 
freedom F-test (also known as an orthogonal contrast) was used tc the combined $\mathrm{P}$. secunda treatments to the combined annual grass treatments. Mean separation subsequent to an ANOVA to compare le within a grass treatment was conducted using a Tukey-Kramer pair comparison. ANOVA analyses, orthogonal contrasts and mean separations were conducted using the GLM procedure of SAS (SAS 19 Little and Hills 1978). Regression analyses were conducted using procedure of SAS and Statview II (Feldman et al. 1988, Afifi and 1990). Linear and logarithmic simple regression models were exa The model with the largest $R^{2}$ was considered to have the best fit. logarithmic models, the significance of the curvature in the mod estimated by fitting a multiple regression in which the second te model was the squared independent variable (i.e., a quadratic moc examining the significance of the quadratic term. The significa for all statistical tests was set at alpha $=0.05$.

\section{RESULTS}

Species composition manipulation

To investigate the effect of exotic annual grasses and native $k$ grasses on the demography of A. grandiflora, we manipulated the natural community to create two artificial communities; one comp primarily of exotic annual grasses, and one comprised of native grasses (Figure 1). In the annual grass treatment plots, the ma increased the proportion of annual grasses, with B. hordeaceus a V. myuros remaining the dominant species. Annual grass species comprised 95\% of the biomass in the annual grass treatment plots. P. secunda treatment plots, P. secunda comprised an average of $8 \mathrm{C}$ 
biomass collected from the field plots. The remaining $20 \%$ of the was comprised primarily of annual grasses growing within the tus although some dicots were also present in the plots. Control tre plots contained primarily A. grandiflora, although a small amoun neighbor biomass was present (less than $10 \mathrm{~g} / \mathrm{m}^{2}$ ), consisting prin annual grasses.

\section{Phenological Observations}

The first significant rain of the season $(1.8 \mathrm{~cm})$ occurred on 17, 1993. This stimulated germination of the annual grasses and grandiflora, and broke the dormancy of P. secunda tussocks (as et by greening of the tussocks) on November 19, 1993 (Table 1). Howe date of first flowering was much earlier for A. grandiflora and compared to the exotic annual grasses $(21$ and 35 days earlier, re P. secunda was dormant by April 19, 1994, and A. grandiflora had senesced by May 1, 1994, whereas the annual grasses were still gr producing seed at the time of the May 1994, harvest.

Characteristics of the grass treatment plots

The range of peak standing biomass obtained within the annual treatments $\left(54-111 \mathrm{~g} / \mathrm{m}^{2}\right)$ and the $\mathrm{P}$. secunda treatments $(67-135$ were very similar (Table 2). We were able to maintain the P. sec density classes with a high degree of precision. However, it was maintain the annual grass density classes at a given level. Whil significant difference between the low and high density treatment achieved, there was no real separation between the two medium den annual grass treatments. 
Both grass treatments affected pre-dawn (4 am) soil water poten depth of $10 \mathrm{~cm}$ measured between April 13 and May 3, 1994 (Figures 2b). Soil water potential recovered for the P. secunda and contri between April 25 and May 2. Approximately $1.2 \mathrm{~cm}$ of rainfall occ April 26. At this time, P. secunda was fully dormant, but the ar grasses were in full flower. A. grandiflora had completed flowe was still filling seed (Table 1 ). The rate of soil moisture depl. greatest between April 14 and April 21, 1994. During this time pe rate of soil water potential change was related in a linear fashi biomass, and was independent of grass type (Figure 2c). Both gra treatments also reduced midday soil water potential at the $10-\mathrm{cm}$, measured on April 21, 1994, but this reduction was not significan different between the two grass types (Figure 2d). No significan soil water potential was observed at the $75 \mathrm{~cm}$ depth, therefore, $t$ are not presented.

Maximum grass cover as estimated on April 1, 1994, exceeded 70: both grass treatments (Figure 3). The amount of cover in the $P$. treatments was linearly related to the biomass of $\mathrm{P}$. secunda, whe amount of annual grass cover was logarithmically related to annu biomass. The quadratic term in the fitted quadratic model was si for the annual grass biomass (Table 3). The quadratic model resu larger $\mathrm{R}^{2}$ term than the linear model, and was similar to the $\mathrm{R}^{2} \mathrm{C}$ the logarithmic model (Figure 3). This indicates that the curvat significant component of the fitted model. 
A. grandiflora nutlet output predictor

From the twenty A. grandiflora plants from which nutlets were collected, correlations on several plant attributes were conducte Inflorescence number was highly correlated with nutlet productiol Figure 4), as was inflorescence number combined with the natural logarithmic transformation of shoot length $(r=0.97)$. Because of interpretation, the total number of inflorescences per plot (i.e. the number of inflorescences of the four individual A. grandiflo: as well as the average number of inflorescences per plant per plc subsequently used to analyze the effects of grass neighbor compet A. grandiflora.

\section{A. grandiflora response to grass treatments}

A. grandiflora mortality was very low (Table 5), with an overa] mortality of $6.9 \%$. Mortality was highest in the $\mathrm{P}$. secunda treat increased with $\mathrm{P}$. secunda density (over $30 \%$ in the high density treatments). Mortality did not appear to be related to annual gr. in the annual grass treatments. Mortality was zero in the contrc

Using A. grandiflora inflorescence number as an index of nutle we examined the reproductive response of $A$. grandiflora to the g] treatments (Figure 5). A. grandiflora inflorescence number only responded to soil water potential in the two grass treatments as on April 21, 1994 (Figure 5a). In addition, the slopes of the twc significantly different. A. grandiflora inflorescence number di، cover (Figure 5b). A. grandiflora responded in a linear fashion P. secunda cover, but in a logarithmic fashion to the annual gra The quadratic term in the fitted quadratic model was significant 
annual grass cover (Table 3). The quadratic model resulted in a term compared to the linear model, but was not as large as that o the logarithmic model (Figure 5b). Thus, the curvature is a sigl component of the fitted model, with the logarithmic model providi best fit. When the overall response of A. grandiflora infloresc $\epsilon$ to neighbor biomass was examined, A. grandiflora again responded P. secunda biomass in a linear fashion, but to annual grass biom. logarithmic fashion (Figures 5c). The quadratic model fitted to biomass again indicated the curvature to be a significant compone fitted model (Table 3), with the logarithmic model having the lar. (Figure 5c). At the highest densities, competitive suppression c A. grandiflora inflorescence number by $P$ secunda and the exotic was equally severe. However, at low and intermediate densities, grasses suppressed A. grandiflora inflorescence number to a grea on a per biomass basis than P. secunda.

An ANOVA on these treatments verifies that there are significa differences between treatments (Table 6), but also reveals a sign: effect. This effect occurred because the two blocks in the more sloping portion of the study site contained more annual grass bic compared to those plots in the steeper portion of the study site. contrasts revealed that inflorescence number in the combined P. : treatments was significantly different from the combined annual treatments (Table 6). Besides the increased mortality observed ir highest density $P$. secunda plots (Table 5), the grass treatments A. grandiflora fecundity by both reducing the growth of the shoot individual plants (Figure 6a) and reducing the number of inflore per plant (Figure 6b). Again, at the highest densities, the effe, 
P. secunda and the exotic grasses on A. grandiflora growth was $s$ but at low and intermediate densities, the exotic annual grasses A. grandiflora growth to a greater extent than P. secunda.

\section{DISCUSSION}

The results of this experiment suggest that A. grandiflora per (as indicated by inflorescence number) is greatest in a communit! dominated by intermediate densities of $\mathrm{P}$. secunda when compared V community dominated by exotic annual grasses, at least under the conditions found during this single growing season experiment. Surprisingly, water did not appear to be the limiting resource in competition between A. grandiflora and its grass neighbors. Othe either suggested (Menke, 1992) or demonstrated (Gordon and Rice 1! Momen et al. 1994) that competition for water can be important bet exotic and native California grassland species. Indeed, we founc grass types reduced soil water potential throughout the growing s This appeared to be linearly related to the amount of grass bioma A. grandiflora did respond to soil water potential, but only weak possible that the variation in our data masked any competition fo that may have occurred. There was a recovery in soil water poten during A. grandiflora's seed filling period in the P. secunda an treatment plots as a result of rainfall during this period. The moisture in these plots could have resulted in either a greater A. grandiflora seed number per inflorescence or greater seed wei Unfortunately, we did not collect the data required to test this $\mathrm{r}$ In contrast, the annual grasses were able to utilize this soil mo which kept the soil water potential low. This indicated that the 
grasses were more metabolically active than $\mathrm{P}$. secunda during th Both seed number and seed weight of California annuals can be aff drought during seedfill (Ewing and Menke 1983). However, it is $\mathrm{n}$ from our data that A. grandiflora is so affected.

A. grandiflora responded much more strongly to the amount of $\subseteq$ cover, which in turn was related to neighbor biomass. While A. grandiflora total inflorescence number was reduced by both gré a per unit amount of annual grass cover or biomass more severely inflorescence number compared with $P$. secunda cover or biomass, the highest grass densities. In addition, the annual grasses af: A. grandiflora in a logarithmic fashion, versus a linear effect c P. secunda. The linear effect of P. secunda is highly unusual, typically the effect of increasing neighbor biomass or density on plant is strongly non-linear, with a large decrease in target pla to the presence of any neighbors, and smaller effects of adding $\bar{c}$ neighbors (Goldberg and Fleetwood 1987, Silander and Pacala 1985). differing effect on A. grandiflora by $P$. secunda and the annual. may be a result of the different community structure exhibited by grass types. Spacing patterns can have a marked effect on densit dependence (Silander and Pacala 1985, Fowler 1984), as well as on interspecific competition (Mack and Harper 1977). A community of grasses forms a more or less solid sward of plant material, whic likely have an effect on the amount and quality of light reaching A. grandiflora seedling (Taiz and Zeiger 1991), which in turn cor seedling growth. A community in which $P$. secunda is the dominar. the other hand, will have the majority of the biomass and leaf ar concentrated in well defined tussocks, resulting in well lighted, 
open spaces. Our results suggest that A. grandiflora can readily advantage of these open spaces.

As our results show, however, P. secunda can strongly compete native forbs at higher densities. In addition, data collected on 300 where annual controlled burns have resulted in thick stands o $100 \%$ cover of $\mathrm{P}$. secunda reveal these communities to be species $\mathrm{p}$ (Taylor and Davilla 1986). Properly timed fires have been frequen a means of reducing annual grass competition and promoting nativ perennial bunch grass communities (Menke 1992, George et al. 1992 However, aggressive land management techniques aimed at creating density bunch grass communities that can withstand invasion of a exotic grasses may not result in a habitat which is favorable for forbs. In addition, P. secunda's early phenology is also very s: A. grandiflora, as shown here. This suggests that a community w adequate disturbance to maintain $\mathrm{P}$. secunda at an intermediate de with minimal amounts of exotic annual grasses would result in a community with the highest species richness, and the most favorak A. grandiflora. Indeed, data from site 300 show that stands with intermediate density of $\mathrm{P}$. secunda are species rich (Taylor and I 1986). Others have also suggested that forbs do not establish wel bunch grass communities, with good forb-bunch grass associations typically occurring where environmental factors combine to keep $t$ grasses well spaced (Edwards 1994).

It is difficult to speculate on what comprised the pristine Ca grassland community. It is likely that perennial bunch grass cc with numerous native annuals filling the interspaces formed a st: climax community on well-drained upland sites (such as the locat: 
Site 300 experimental site), with annual herbaceous plants domina intermediate and early successional stages (Heady 1990). The cur annual grasslands are dominated by a small number of exotic annu species with a few widespread natives present. In the pristine $v$ grassland, the community was probably dominated by those same widespread natives (such as Nassella pulchra associated with oth perennial grasses like P. secunda), but also contained native fc limited distribution, resulting in a greater regional heterogenei (Huenneke 1989, Heady 1990). The dominance of P. secunda at Site likely a consequence of the late spring/early summer timing of tr unusually frequent annual controlled burns, as opposed to the nat occurring lightning-caused fires of late summer/early fall timin intermittent frequency (Heady 1990). At the time of the Site 300 ] P. secunda is already dormant, where as N. pulchra is still phys active (Laude 1953; note: Laude's P. scabrella is equivalent to or P. secunda). Our results suggest that a pristine "stable" bunch community may have required some type of disturbance at an interm frequency to maintain the open spaces. It is also possible that bunch grass community with grasses of both early (P. secunda) anı (Nassella pulchra) phenology may have provided a more heterogener community favorable to native forbs.

While this and other studies (Pavlik et al. 1993) have demonstri A. grandiflora is negatively affected by annual grass competitior cannot say that competition with exotic grasses is the primary $\mathrm{m}$ in the decline of this species. And although the fact that A. gr performs better in a native bunch grass community supports this hypothesis, it is not sufficient to prove it. Ornduff (1976) has 
A. grandiflora is being competitively displaced by its more weedy homostylous congeners as a result of an inefficient heterostylous system reported to be self-incompatible (Weller and Ornduff 1977, Indeed, A. grandiflora produces fewer seeds per flower than its i relatives (Ornduff 1976, Pantone et al. 1995). While these factor A. grandiflora are undoubtedly important, again, their presence c prove they are the cause in this species decline. Pantone et al. that fitness component compensation (i.e., the production of few $\epsilon$ flower results in more flowers per inflorescence being produced) occur within either A. grandiflora or A. menziesii var. intermer However, this analysis was made within species, not between them. determine if A. grandiflora is being displaced by A. menziesii V intermedia, it is important to conduct a comparison between the: For example, if A. grandiflora produces fewer seeds per flower $t$ A. menziesii var. intermedia (which it does), does A. grandiflor more flowers per plant than its relative, resulting in similar se per plant? Pantone et al. (1995) suggests that an increased amour inflorescence production by A. grandiflora could not completely , for the low seed set per flower when compared to A. menziesii va: intermedia, indicating an intrinsic limit to fecundity in A. gra Further field and greenhouse experiments should be conducted to $t$ assertion. Assuming A. grandiflora could compensate for the lon number of seeds per flower by producing more flowers, it is possi effects of competition on A. grandiflora would be more severe as to its weedy relatives, since the larger floral structures (i.e., inflorescences) would necessarily require more resources. Panto Pavlik (1996) could not demonstrate a significant difference in c' 
ability between A. grandiflora and A. menziesii when the two sper grown in mixture. A field competition study comparing the effect competition on A. grandiflora and A. menziesii var. intermedia, be extremely useful in assessing the relative ability of A. grand weedy relatives in competing with introduced annual grasses.

\section{ACKNOWLEDGMENTS}

The authors thank Steve Gregory, Erin Espeland, Eric Walters, E Goodrich, Marvin Lima and Valerie Dibley for extraordinary field assistance. We also thank Drs. Jim Richards and Lisa Donovan fo: technical assistance in the use of thermocouple psychrometers. addition, we thank Dr. Kevin Rice for technical input throughout project, as well as for review of the manuscript. Work performec auspices of the U. S. Department of Energy by Lawrence Livermore National Laboratory under Contract W-7405-Eng-48 and funded by a $\subseteq$ from the Laboratory Directed Research and Development program. Publication number UCRL-ID-123355. 


\section{LITERATURE CITED}

Afifi, A. A. and V. Clark. 1990. Computer-aided multivariate a Second edition. Pages 88-195. Van Nostrand Reinhold Company, York, New York, USA.

Andrews, Patricia L. 1983. BEHAVE: fire behavior prediction and modeling system - BURN subsystem, Part 1. Gen. Tech. Rep. INT130 p. U.S. Dept. of Agriculture, Forest Service, Intermounta: Research Station, Ogden, Utah, USA.

Baker, H. G. 1989. Sources of the Naturalized Grasses and Herbs California. Pages 29-36 in L. F. Huenneke and H. A. Mooney, e Grassland Structure and Function: California Annual Grassland Tasks for Vegetation Science 20. Kluwer Academic Publishers, Dordrecht, The Netherlands.

Barbour, M. G. and J. Major, editors. 1990. Terrestrial Vegeta California. Pages 223-515. California Native Plant Society, Sacramento, California, USA.

Brown, R. W. and D. L. Bartos. 1982. A calibration model for sc peltier thermocouple psychrometers. Research Paper INT-293. 1982. U.S. Dept. of Agriculture, Forest Service, Intermountair and Range Experiment Station, Ogden, Utah, USA.

Burgan, Robert E. and Richard C. Rothermal. 1983. BEHAVE: fire behavior prediction and fuel modeling system - FUEL subsystem. Tech. Rep. INT-167, 126 p. U.S. Dept. of Agriculture, Forest s Intermountain Research Station, Ogden, Utah, USA.

Edwards, S. W. 1994. Creating an authentic California meadow. Season $9(4): 4-16$. 
Ewing, A. L. and J. W. Menke. 1983. Reproductive potential of Br mollis and Avena barbata under drought conditions. Madrono 30 159-167.

Feldman, D., J. Gagnon, R. Hoffmann and J. Simpson. 1988. Stat The solution for Data Analysis and Presentation Graphics, v1.0: September 15, 1988. Abacus Concepts Inc., Berkeley, Californic Fowler, N. L. 1984. The role of germination date, spatial arrar. and neighbourhood effects in competitive interactions in Linum Journal of Ecology 72: 307-318.

George, M. R., J. R. Brown and W. J. Clawson. 1992. Applicatior nonequilibrium ecology to management of Mediterranean grasslar Journal of Range Management 45(5):436-440.

Goldberg, D. E. and L. Fleetwood. 1987. Competitive effect and I four annual plants. Journal of Ecology 75:1131-1143.

Gordon, D. R. and K. J. Rice. 1993. Competitive effects of gras annuals on soil water and blue oak (Quercus douglasii) seedlir. Ecology $74(1): 68-82$.

Guerrant, E. O. 1992. Genetic and demographic considerations ir. sampling and reintroduction of rare plants. Pages $321-344$ in I Fiedler and S. K. Jain, editors. Conservation Biology: the the practice of nature conservation, preservation and management. Chapman and Hill, New York, New York, USA.

Heady, H. F. 1990. Valley grassland. Pages 491-514 in M. G. Baj J. Major, editors. Terrestrial Vegetation of California. Cal Native Plant Society, Sacramento, California, USA. Hickman, J. C., ed. 1993. The Jepson Manual: Higher Plants of California. University of California Press, Berkeley, Califor 
Huenneke, L. F. 1989. Distribution and Regional Patterns of Cal Grasslands. Pages 1-10 in L. F. Huenneke and H. A. Mooney, ed Grassland Structure and Function: California Annual Grassland Tasks for Vegetation Science 20. Kluwer Academic Publishers, Dordrecht, The Netherlands.

Knudsen, M. and K. Tarp. 1994. Draft large-flowered fiddleneck (Amsinckia grandiflora (Gray) Kleeb. ex Greene) Recovery Plan. 1. U. S. Fish and Wildlife Service Portland, Oregon, USA.

Krebs, C. J. 1989. Ecological Methodology. Pages 449-451. Harpe New York, New York, USA.

Laude, H. M. 1953. The nature of summer dormancy in perennial Botanical Gazette, March :284-292.

Little, T. M. and F. J. Hills. 1978. Agricultural experimentatj and analysis. Pages 54-60. John Wiley and Sons, New York, NY Mack, R. N. and John L. Harper. 1977. Interference in dune ann spatial pattern and neighbourhood effects. Journal of Ecology 363.

Menke, J. 1992. Grazing and fire management for native perennic restoration in California grassland. Fremontia 20(2):22-25.

Momen, B., J. W. Menke, J. M. Welker, K. J. Rice and F. S. Chapi 1994. Blue-oak regeneration and seedling water relations in fc within a California oak savanna. International Journal of Pla Science $155(6): 744-749$. 
Murphy, D. D., and P. R. Ehrlich. 1989. Conservation Biology of California's Remnant Native Grasslands. Pages 201-212 in L. F Huenneke and H. A. Mooney, editors. Grassland Structure and Function: California Annual Grassland. Tasks for Vegetation : 20. Kluwer Academic Publishers, Dordrecht, The Netherlands. Ornduff, R. 1976. The reproductive system of Amsinckia grandifl distylous species. Systematic Botany 1: 57-66.

Pantone, D. J. and B. M. Pavlik. 1996. Plant population ecology endangered plant and a weedy congener: relative competitive abj reproductive biology. Submitted to Biological Conservation.

Pantone, D. J., B. M. Pavlik and R. B. Kelly. 1995. The reproduc attributes of an endangered plant as compared to a weedy conges Biological Conservation 71:305-311.

Pavlik, B. M. 1995. The recovery of an endangered plant. II. A phased approach to restoring populations. Pages 49-69 in K. M Urbanska and K. Grodzinska, editors. Restoration Ecology in E Geobotanical Institute SFIT, Zurich, Switzerland.

Pavlik, B. M., D. L. Nickrent and A. M. Howald. 1993. The recov endangered plant. I. Creating a new population of Amsinckia grandiflora. Conservation Biology $7(3): 510-526$.

Ray, P. M. and H. F. Chisaki. 1957a. Studies of Amsinckia. I. I of the genus, with a study of heterostyly in it. American Jours Botany $44: 524-536$.

Ray, P. M. and H. F. Chisaki. 1957b. Studies of Amsinckia. II. Relationships among primitive species. American Journal of Bot $537-544$ 
SAS. 1990. SAS/STAT ${ }^{\circledR}$ User's Guide, Version 6, Fourth Edition, V 2. Pages 891-996. SAS Institute Inc., Cary, North Carolina, I Silander, J. A. and S. W. Pacala. 1985. Neighborhood predictors performance. Oecologia 66:256-263.

Skinner, M. and B. M. Pavlik. 1994. Inventory of rare and endan vascular plants of California, 5th edition. California Native Society, Sacramento, California, USA.

Taiz, L and E. Zeiger. 1991. Plant Physiology. Pages 497-499. Benjamin/Cummings Publishing Company, Inc., Redwood City, California, USA.

Taylor, D. W. and W. Davilla. 1986. Vegetation of Site 300 Lawre Livermore National Laboratory San Joaquin County, California. Prepared for Lawrence Livermore National Laboratory by Biosyst $\epsilon$ Analysis, Inc., Santa Cruz, California, USA.

Weller, S. G. and R. Ornduff. 1977. Cryptic self-incompatibilit Amsinckia grandiflora. Evolution 31: 47-51.

Weller, S. G. and R. Ornduff. 1989. Incompatibility in Amsinckj grandiflora (Boraginaceae): Distribution of callose plugs and tubes following inter- and intramorph crosses. American Jourr Botany 76: 277-282. 
TABLE 1. Phenology at the Site 300 experimental site, November 1993 to May 1994

\begin{tabular}{|c|c|c|c|}
\hline Stage & Annual grasses & P. secunda & grandiflora \\
\hline Germination & \multirow{2}{*}{$\begin{array}{c}11-19-93^{a} \\
N A\end{array}$} & $\mathrm{NA}$ & \multirow{3}{*}{$\begin{array}{c}11-19-93^{a} \\
N A\end{array}$} \\
\hline Tussock greening & & $11-17-93^{a}$ & \\
\hline \multirow{3}{*}{ Flowering } & \multirow{3}{*}{\multicolumn{2}{|c|}{$\begin{array}{l}12-9-93^{b} \\
2-24-94^{a}\end{array}$}} & \\
\hline & & & $3-9-94^{a}$ \\
\hline & & & $4-20-94 b$ \\
\hline \multirow{3}{*}{$\begin{array}{l}\text { Senescence } \\
\text { Tussock dormancy }\end{array}$} & \multirow{3}{*}{$\begin{array}{l}>5-1-94 \\
\mathrm{NA}\end{array}$} & $\mathrm{NA}$ & \multirow{3}{*}{$\begin{array}{c}5-1-94 \mathrm{~b} \\
\mathrm{NA}\end{array}$} \\
\hline & & $3-31-94^{a}$ & \\
\hline & & $4-19-94^{b}$ & \\
\hline
\end{tabular}

a) First observed. b) Complete. c) Full flower. NA = Not applicable.

TABLE 2. Summary of neighbor biomass and estimated density by treatment at the Site 300 experimental site, May 1994.

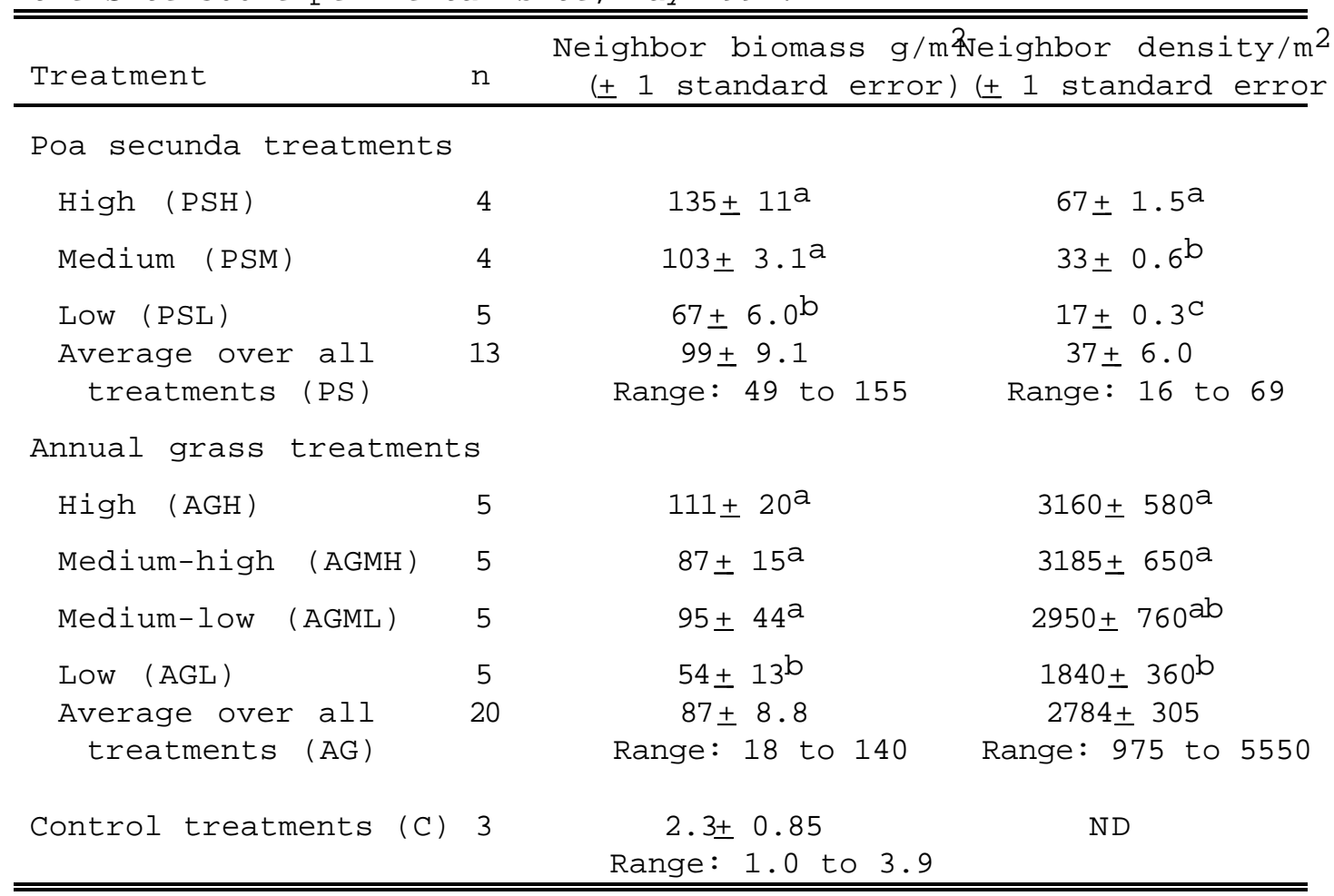

$\mathrm{ND}=$ not determined. Within each grass type, treatments with different letter: significantly different at $p=0.05$. 
TABLE 3. Significance of independent variables in simple regressions and multiple quadratic regressions.

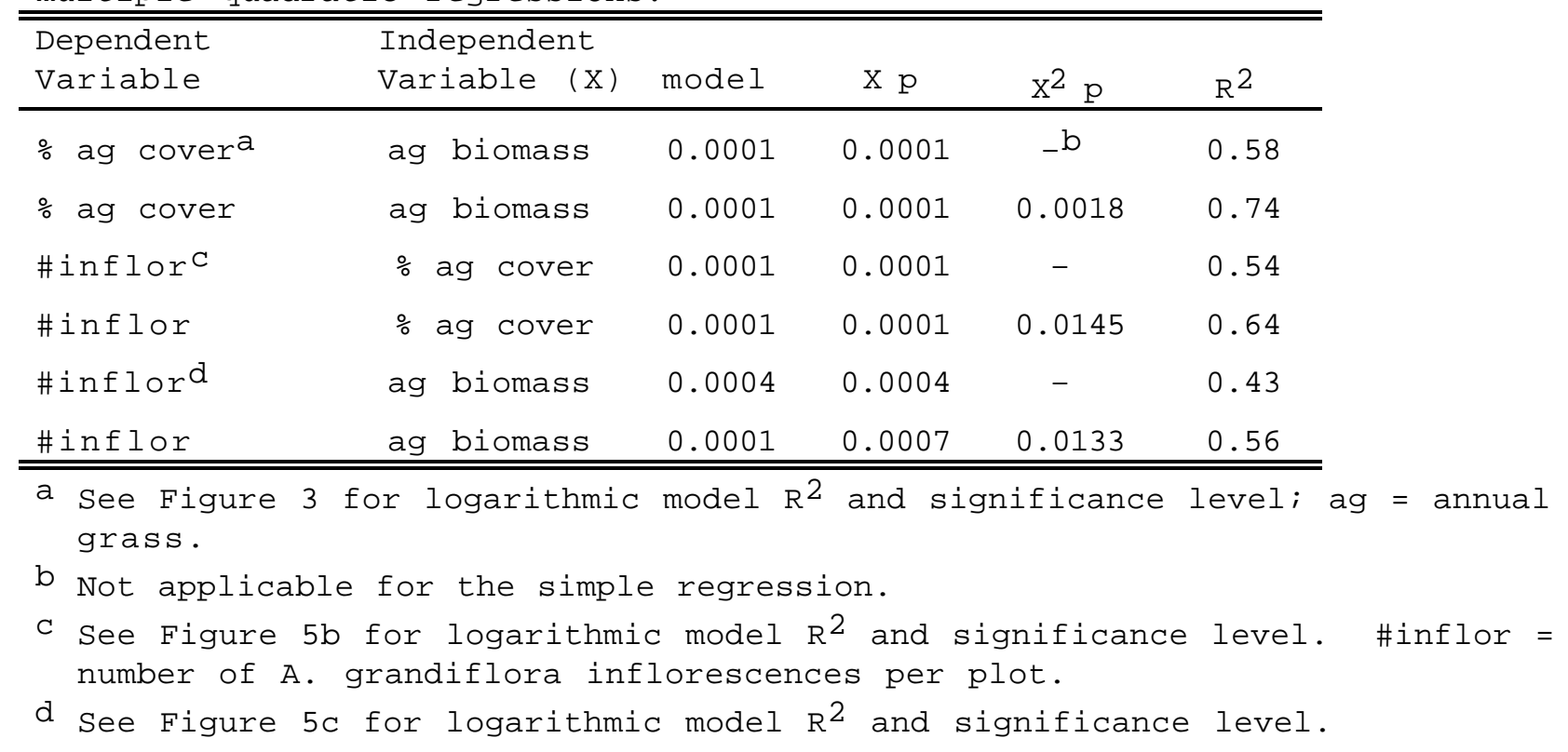

TABLE 4. Correlations between measures of plant size and reproductive output p individual A. grandiflora from the Site 300 experimental site, April 12, 1994;

\begin{tabular}{|c|c|c|c|c|}
\hline $\mathrm{x}_{1}^{\mathrm{a}}$ & $\mathrm{x}_{2}{ }^{\mathrm{a}}$ & $\mathrm{Y}$ & $r$ & $\mathrm{p}$ \\
\hline $\ln ($ shoot lgth) & \#inflor & \# nutlets & 0.97 & 0.0001 \\
\hline \#inflor & $-\mathrm{C}$ & \# nutlets & 0.96 & 0.0001 \\
\hline $\ln ($ shoot lgth) & \#inflor & ln (\# nutlets) & 0.94 & 0.0001 \\
\hline \#inflor & - & ln (\# nutlets) & 0.93 & 0.0001 \\
\hline ln (shoot lgth) & $\ln (\# i n f l o r)$ & ln (\# nutlets) & 0.90 & 0.0001 \\
\hline $\ln (\# \ln f \operatorname{lor})$ & - & ln (\# nutlets) & 0.90 & 0.0001 \\
\hline ln (shoot lgth) & $\ln (\# \ln f \operatorname{lor})$ & \# nutlets & 0.80 & 0.0001 \\
\hline $\ln (\# \operatorname{inflor})$ & - & \# nutlets & 0.80 & 0.0001 \\
\hline ln (shoot lgth) & - & ln (\# nutlets) & 0.80 & 0.0001 \\
\hline shoot lgth & - & $\ln (\#$ nutlets) & 0.78 & 0.0001 \\
\hline $\ln ($ shoot lgth) & - & \# nutlets & 0.67 & 0.0011 \\
\hline shoot lgth & - & \# nutlets & 0.67 & 0.0012 \\
\hline
\end{tabular}

a \#inflor $=$ number of inflorescences per plant; shoot lgth = length of shoot: centimeters (i.e., total height of plant); ln = natural logarithm. 
TABLE 5. A. grandiflora mortality at the site 300 experimental site, November 1993 to May 1994.

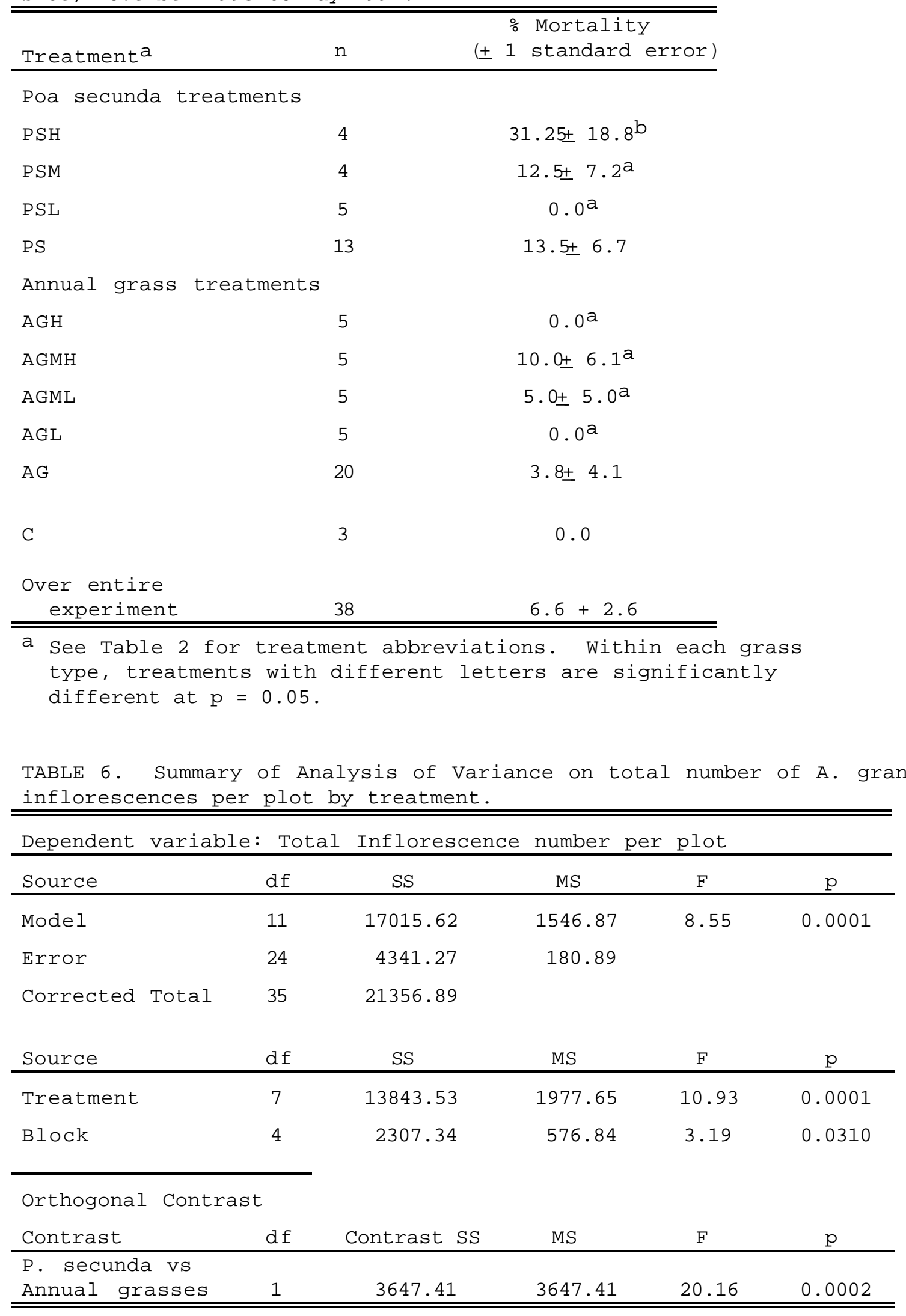



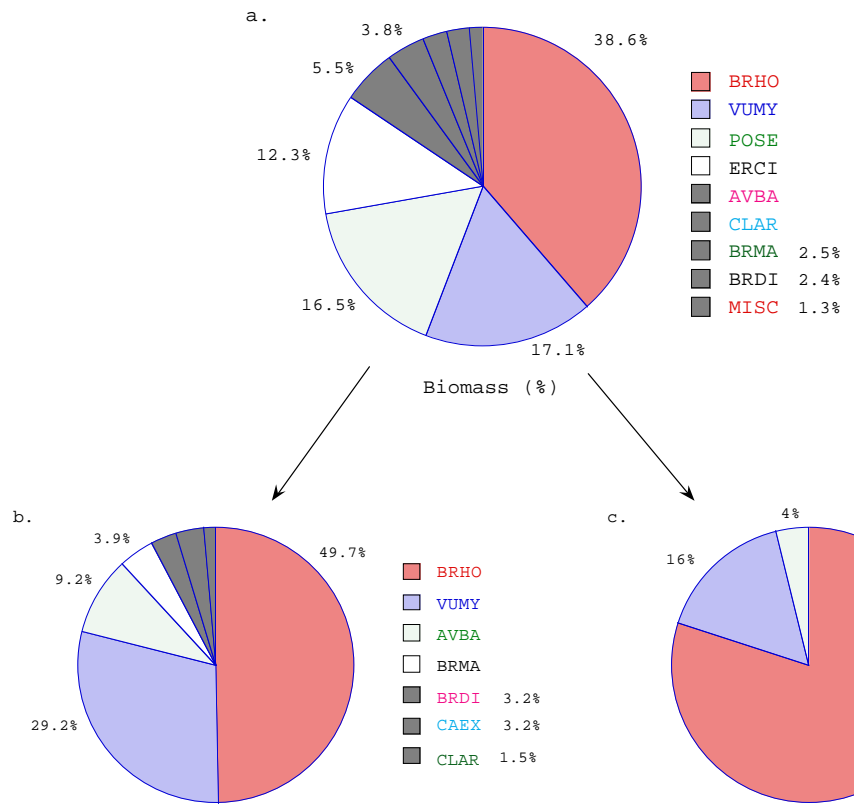

Biomass (\%)

c.

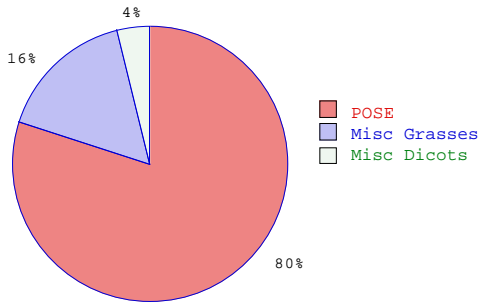

Biomass (8)

FIG. 1. Mean species composition of the Site 300 experimental site (a) in the spring of 1993 prior to manip ment plots in the spring of 1994 after manipuldtiogcuadereatment plots in the spring of 1994 after manipulat identification (after Hickman, 1993R: BestunelaVBA = Avena barbata; CAEXCastilleja exse CHAR = Clarkisap.; VUMY Vulpia myurqs BRMA =Bromus madritensis sspbens; BRDI B= diandrus BRHO =B. hordeaceus; ERCErødium cicutari,umISC

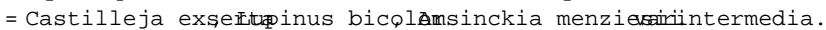



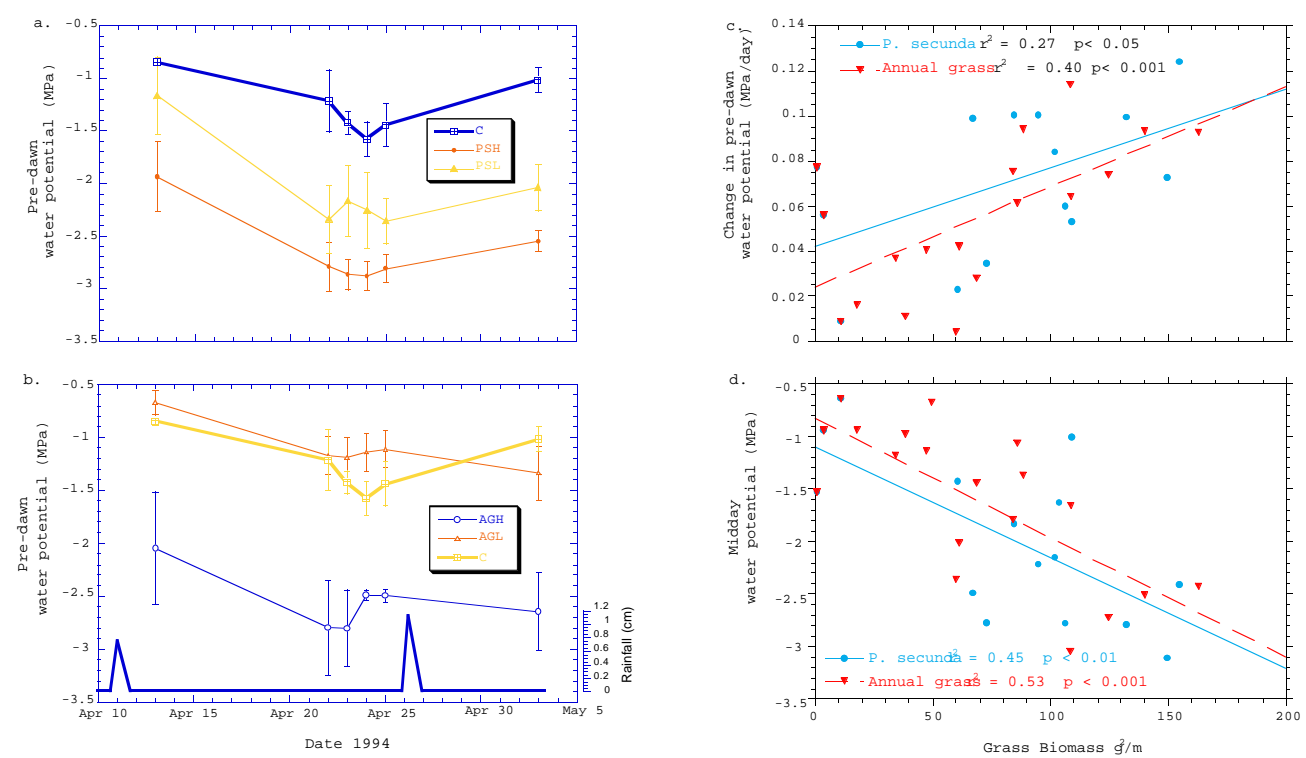

FIG. 2. Effect of (a) Fingeculmóa biomass and (b) final dry annual grass biomass by treatment on pre-dawn (4 tial at $10 \mathrm{~cm}$ between April 13 and May 3, 1994 (intermediate densities omitted for clarity); (c) final dry g soil water potential change per plot at $10 \mathrm{~cm}$ between April 13 and April 28, 1994; and d) final dry grass bi on midday soil water potential at $10 \mathrm{~cm}$ as measured on Apribb2t, 21 qo4 tseathent abbreviations); $\mathrm{n}=2$; error standard error 


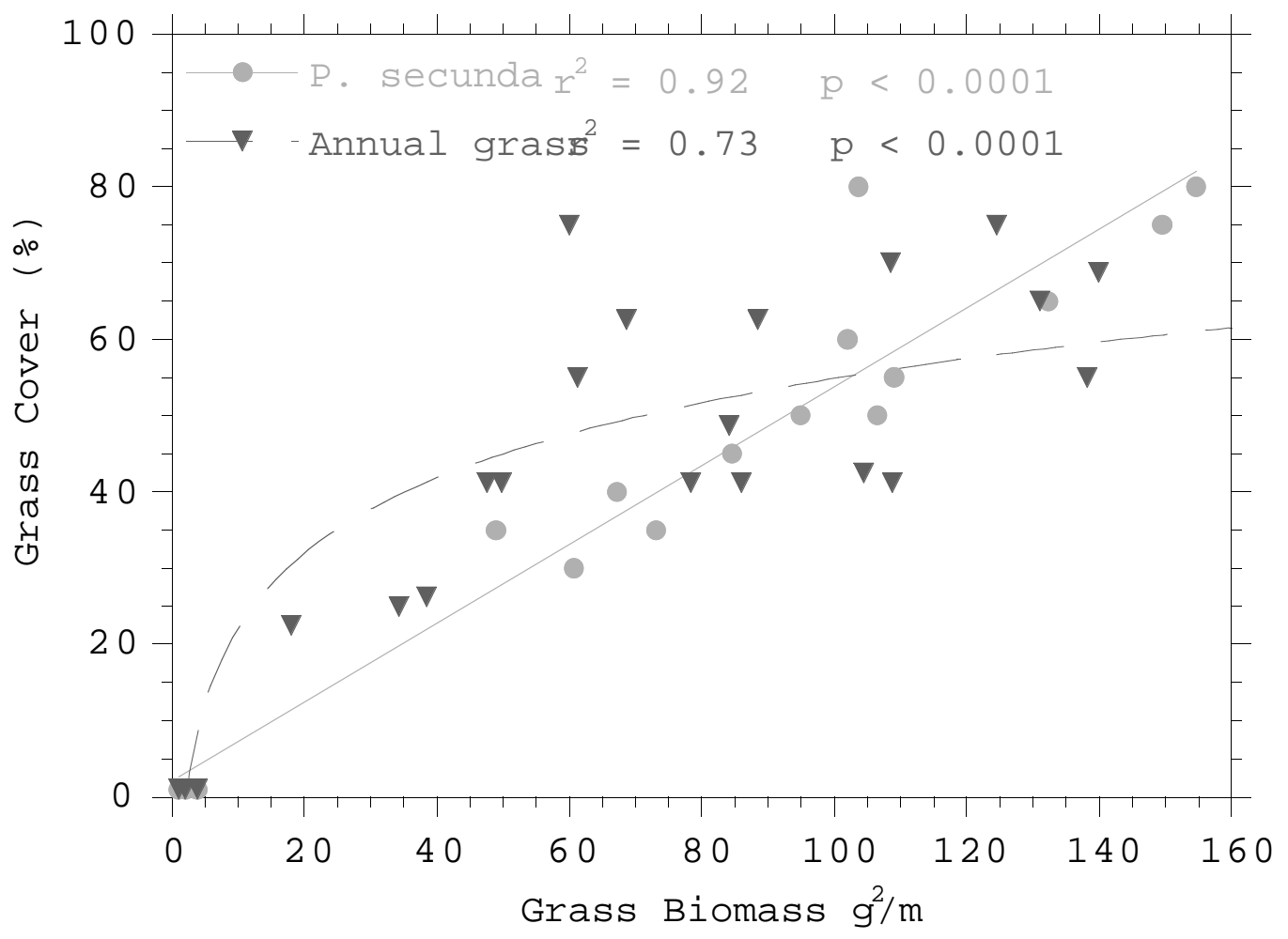

FIG. 3. Effect of final dry grass biomass (collected on May 1, 1994) on percent gra measured o用pril 1, 1994 .

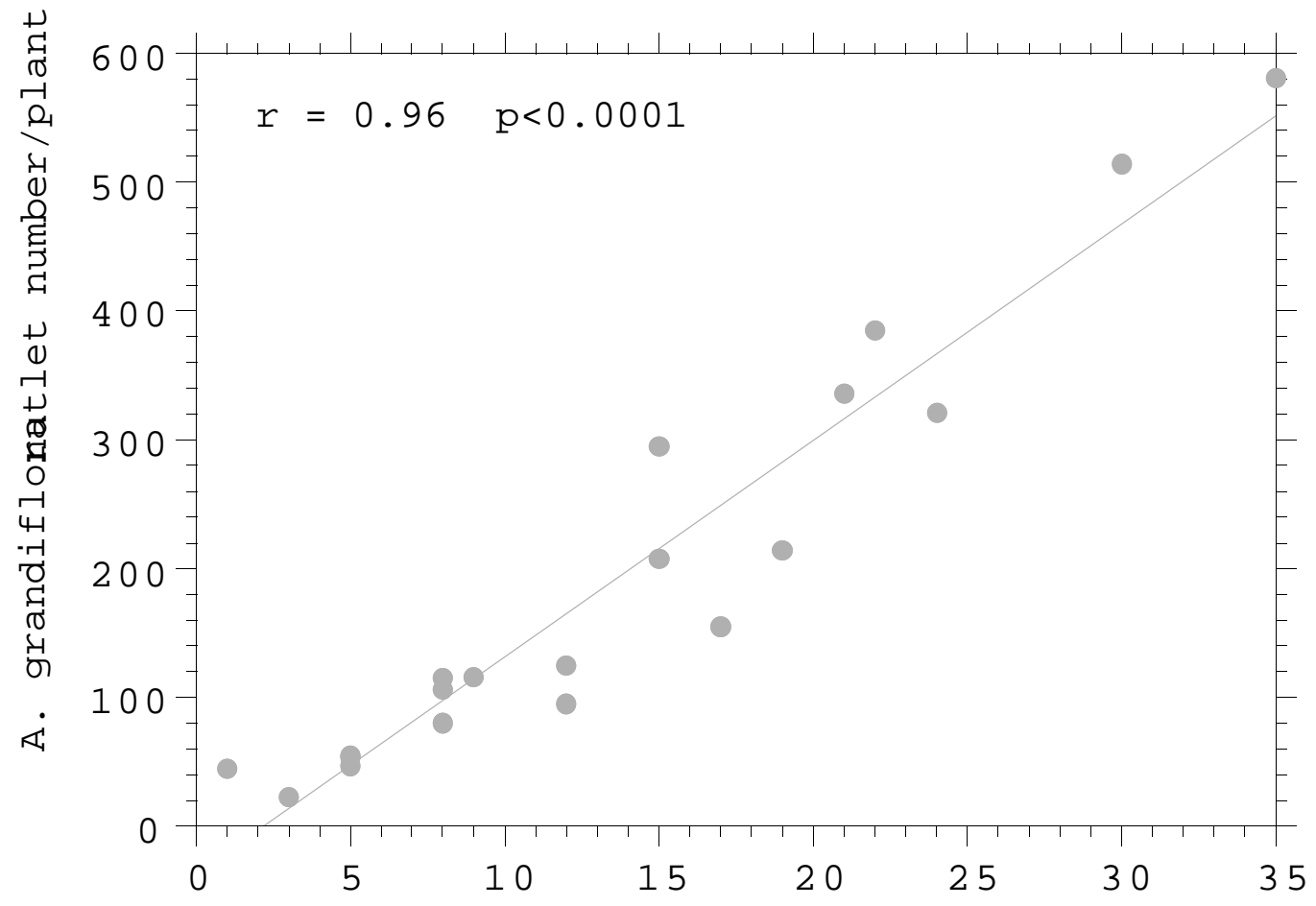

A. grandiflainaflorescence number/plant

FIG. 4. Nutlet out .ut gorindiflpoints at the site 300 experimental site as a functiol of the number of inflorescences meafspmield loh, 1994. 

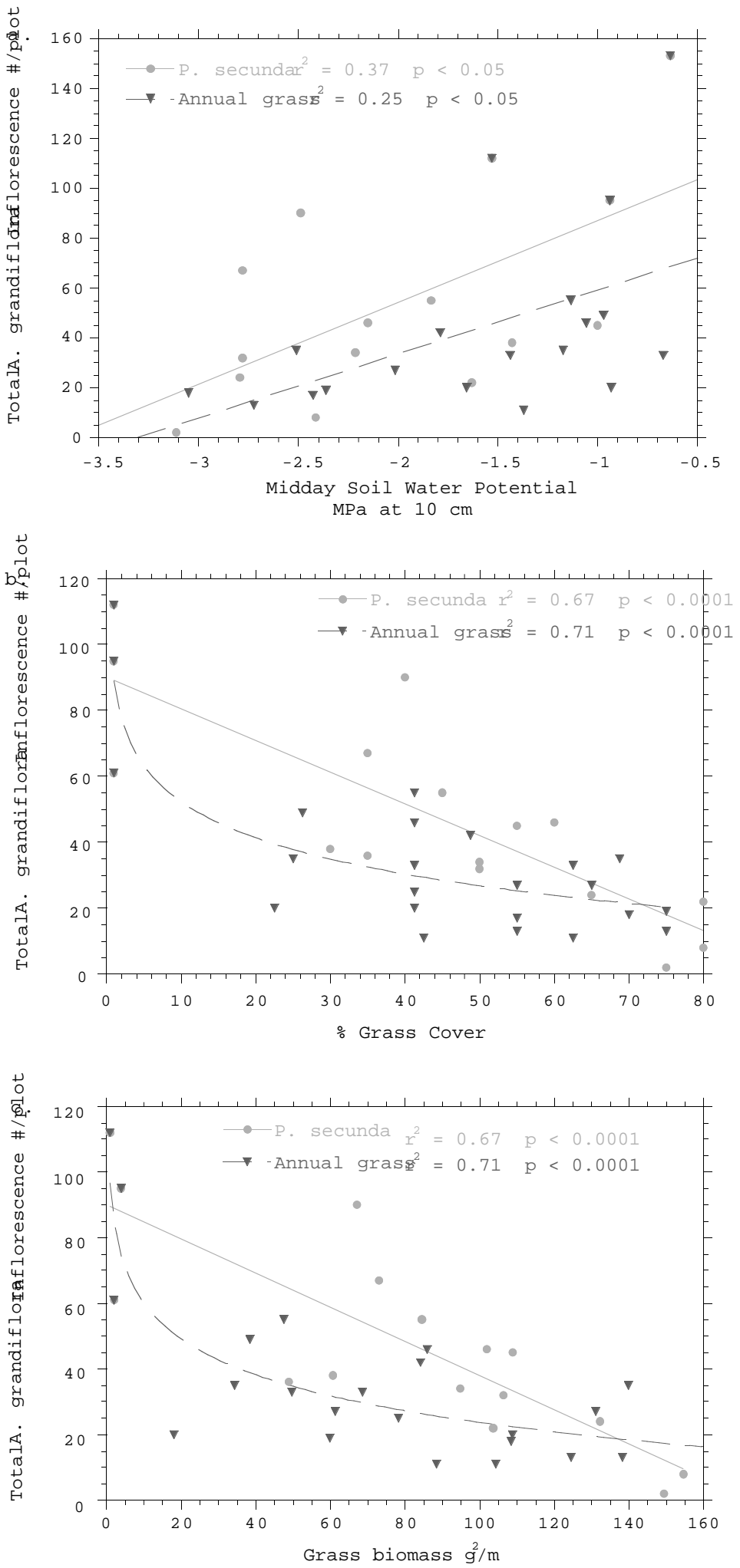

FIG. 5. Respons\$. ofrandiflotatal inflorescence number per plot (as measired on 12, 1994) to (a) midday soil water potential at $10 \mathrm{~cm}$ A(parsi meals,urleg9 40)n, (Ho) per cent grass cover (as measuAedibnl, 1994), and (c) final dry grass biomass (collected May 1, 1994); selele 2 for abbreviations. 

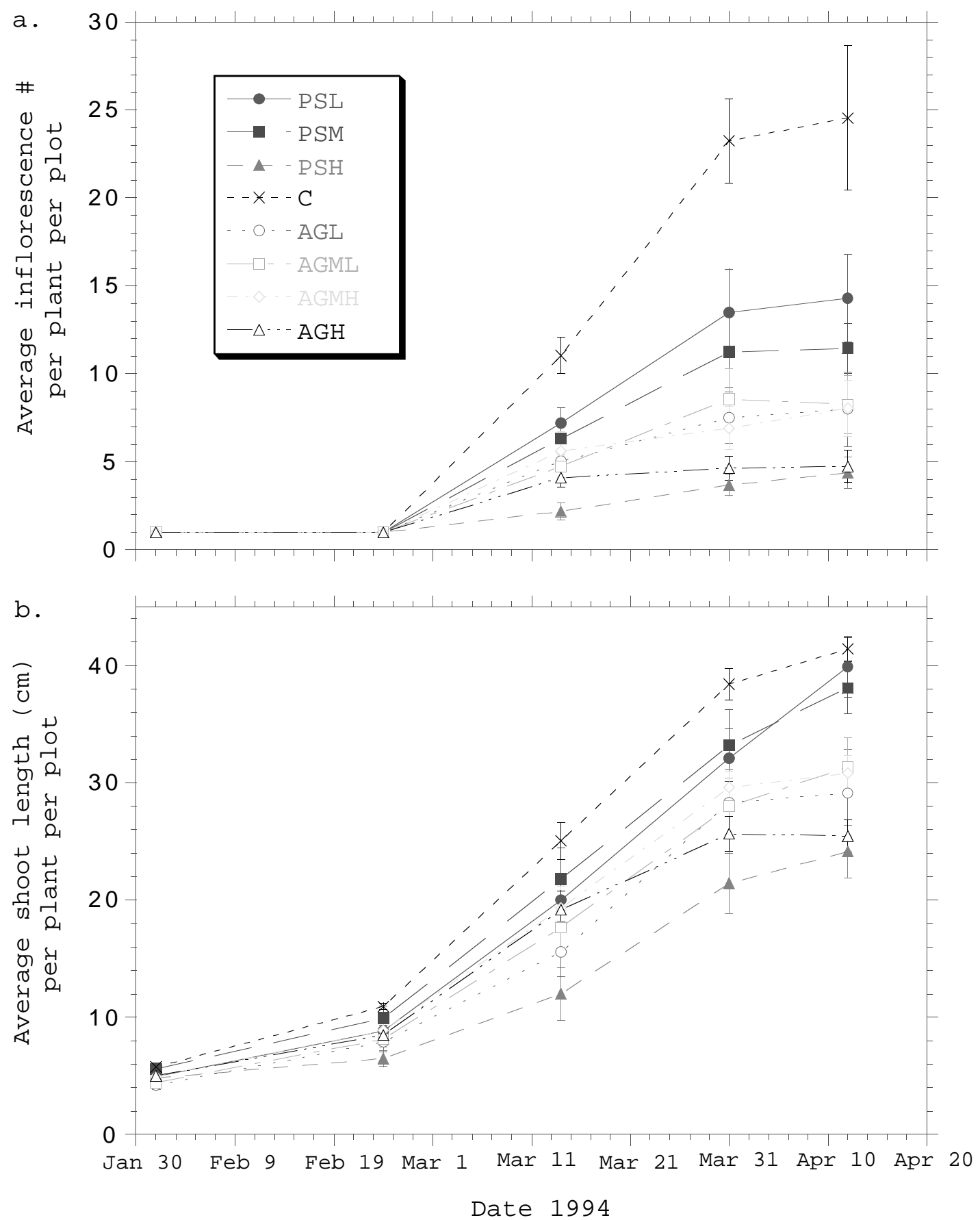

FIG. 6. Increase in (a) Aavemelifloraflorescence number per plant per plot by treatment and (b) average shoot length in centimeters per plant per plot by treatmen Table 2 for treatment abbreviations); error bars are one nstandtuod 5error 
THE ROLE OF INTRINSIC FACTORS IN THE REPRODUCTIVE ECOLOGY OF AN ENDANGERED PLANT

Tina M. Carlsen

Environmental Restoration Division, Lawrence Livermore Nation Laboratory Livermore, CA 94551 USA

Bruce M. Pavlik

Department of Biology, Mills College, Oakland, CA 94613 USA

Prepared for submission to Biological Conservation 
Abstract. A set of field and greenhouse experiments were cond compare intrinsic limitations in fitness components of the rare heterostylous forb A. grandiflora and its weedy homostylous cong $\epsilon$ A. tessellata. The highest floral seed cache (seeds/ flower) wa: with intermorph pollinations (although intramorph pollinations a produced significant seed set), and was comparable to that observ grown A. tessellata. Pin progeny nutlets (seeds) of A. grandifl' up to $1.14 \mathrm{mg} /$ nutlet more than thrum nutlets in both greenhouse a experiments. Three greenhouse germination trials showed germinć responses of both species to be similar regardless of breeding sy typical of many annual species found in California grasslands. Interspecies comparisons of adult plants suggested that in the $g$ A. grandiflora can compensate for low floral seed cache by incre output (flowers/plant) with a greater number of flowers per infl, In the field, A. grandiflora floral output was also greater than but without full compensation for lower floral seed cache. A. t; average seed weight was lower than A. grandiflora, which along w lower number of flowers produced, indicated lower maternal inves per nutlet than A. grandiflora. Thus, competition by exotic ann in the field could affect A. grandiflora reproduction to a greate A. tessellata. Under conditions of unlimited resources, it appe, A. grandiflora fitness is not intrinsically limited when comparec weedy relative A. tessellata. However, under field conditions, $t$ heterostylous breeding system of A. grandiflora may result in lon output.

Keywords: A. grandiflora, A. tessellata, rare plants, weedy ] intrinsic limitations, pollination biology, heterostyly 


\section{INTRODUCTION}

To conservation biologists, rarity has traditionally been cause $f$ Rare species have a greater likelihood of extinction than do mort species (Rabinowitz, 1981; Gaston, 1994). Because of limited dist small population sizes, or unusual habitat requirements, Darwin noted that rarity is a necessary precursor to extinction, with it underlying patterns and causes (Fiedler and Ahouse, 1992). Becau link between extinction and rarity, a great deal of effort has bet towards developing a scientific framework within which to unders those patterns and causes (Gaston, 1994; Fiedler and Ahouse, 1992 1986; Rabinowitz, 1981). These studies typically focused on those characteristics or factors responsible for the occurrence of nat "intrinsically" rare species, although Cody (1986) briefly mentio anthropogenic or "extrinsic" rarity, and Fiedler and Ahouse (1992 some discussion of the interaction between intrinsic and extrins: As more habitats become degraded or modified due to human influe is becoming increasingly important to identify those intrinsic (r occurring) and extrinsic (anthropogenically influenced) factors contribute to the rarity of a given species. Indeed, it may be tl with anthropogenic factors that pushes a naturally rare species c edge to extinction.

Amsinckia grandiflora (Gray) Kleeb. ex Greene (Boraginaceae) i annual plant for which both intrinsic and extrinsic factors have invoked to explain its extreme rarity. Extrinsic limits may have imposed as the native species of its grassland habitat were reduc native species, and as livestock grazing and fire suppression ber widespread in Northern California. There has been particular co 
that A. grandiflora may be poorly competing with its exotic grass neighbors (Knudsen and Tarp, 1994). During reintroduction exper: Pavlik et al. (1993) found that competition with non-native annua significantly reduced the fecundity of A. grandiflora. In additi management of a declining natural population of A. grandiflora u grass-selective herbicide has caused a rebound from less than $10 \mathrm{C}$ individuals to its present number of over 1500 (Pavlik, 1995). Na. perennial grasses were subsequently shown to have less detrimenta on fecundity than annual grasses (Carlsen et al., 1996), suggesti A. grandiflora would perform better within a community more clos resembling the original California grasslands in which it presum evolved.

Possible intrinsic limitations on A. grandiflora could result breeding system, or from genetic limitations as a result of low $\mathrm{k}$ density. Of the fifteen species in the genus recognized by Ray a (1957a and 1957b), A. grandiflora is one of four rare heterostylor with highly restricted distributions from which the more weedy homostylous congeners are thought to have evolved (Ray and Chisak and 1957b). Ornduff (1976) has suggested that A. grandiflora is $k$ competitively displaced by the weedy homostylous congeners becaus heterostyly and partial self-incompatibility greatly reduce effect transfer and seed set (Weller and Ornduff, 1977, 1989). Pantone e found that fitness-component compensation (i.e.., fewer seeds pe compensated by more flowers per inflorescence) did not occur witl A. grandiflora or the widespread A. menziesii var. intermedia (F C. Meyer) Ganders. They also suggested that increased floral prc A. grandiflora could not compensate for its low seed set per flow 
to A. menziesii var. intermedia), thus indicating an intrinsic 1 fecundity

In order for a weedy relative to displace A. grandiflora, it m. higher degree of fitness. We conducted a set of field and greent. experiments to evaluate intrinsic limitations in the fitness of $P$ as compared with A. tessellata A. Gray, a weedy, sympatric relat: exhibit a fitness advantage, A. tessellata must have either (1) $\bar{c}$ fecundity (seed output), or (2) higher germination rates and/or ] seedling mortality, resulting in a greater number of reproducing plants. We conducted greenhouse germination trials to compare t] germinability of the two congeners. We also compared survivorshj output, and field performance. This included an evaluation of tr distinctive breeding systems of these two congeners. We discuss in the context of the intrinsic limitations on the fitness of thi as well as the potential interaction between intrinsic and extrin which may affect A. grandiflora fitness.

\section{MATERIALS AND METHODS \\ The Study Species}

A. grandiflora and A. tessellata are both members of the Califor: annual grassland. As such, both species germinate with the onset winter rains, grow vegetatively throughout the winter, flower in spring, set seed, and die prior to the summer drought (Heady, 198 Precise information concerning seed banks of both species is not although it is likely that only a small percentage of seed carry year to year (Evans and Young, 1989). The historic range of A. 9 apparently ranged from the hills near Antioch to the north (on tr. 
Sacramento-San Joaquin River Delta), south through the Diablo Ran (including the city of Livermore) to northern San Joaquin County. A. grandiflora is currently known from only three natural popula containing individuals numbering from fewer than 30 to several t: These populations occur in grasslands which border on blue oak w and coastal sage scrub on steep, well-drained, north-facing slopt intermediate $(300 \mathrm{~m})$ elevations. All three populations are locat، Altamont Hills of the Diablo range, about 50 miles east of San Fr California, on or near site 300. Site 300 is a Lawrence Livermort Laboratory high-explosive testing facility, operated by the Univer California for the U.S. Department of Energy. Site 300 contains $t$ three known natural populations of A. grandiflora; the original ] (known as the Drop Tower population) which currently contains ar, 1500 individuals, and a second, much smaller population (known as Draney Canyon population) which contains around 30 individuals. third natural population is located adjacent to site 300 and is $\mathrm{kr}$ Carnegie Canyon population. This population contains several th، individuals.

A. grandiflora exhibits a form of heterostyly known as distyly pin and thrum flower forms (or "morphs") are produced (Ganders, 1979). Each individual plant has only one floral morph. Pin flo characterized by having a stigma exserted and the anthers within corolla tube. Thrum flowers have the opposing morphology, with. exserted and the stigma within the corolla tube. This morphology a type of outcrossing known as phenotypic disassortative mating ( pollinate thrums, and thrums pollinate pins). Many distylous sp، not self-compatible (do not exhibit assortative mating or self-po 
and may be "morph"-incompatible (pollination by a separate plant ] same floral morph is unsuccessful). Distyly appears to be contro pair of alleles. Pin plants have the genotype recessive ss and $t$ have the genotype Ss or SS. Under conditions of complete disassor mating (no self- or intramorph pollination), the sS genotype does and the phenotypic pin and thrum ratio in the progeny is 1:1. In a pin $x$ pin intramorph cross, all progeny would be pins. In the thrum $\mathrm{x}$ thrum phenotype cross in which the thrum originally cont the ss genotype, the expected pin: thrum ratio in the progeny wou: The occurrence of either self- or intramorph thrum pollinations result in the presence of the SS genotype. This genotype would al expected phenotypes from the thrum $\mathrm{x}$ thrum cross, resulting in 1( thrums in the progeny. Although distyly in A. grandiflora appear controlled by the $\mathrm{S}$ allele system, it appears to be only partially disassortative (Weller and Ornduff, 1977), with significant seed from intramorph crosses.

A. tessellata is a common weedy annual that has spread througl much of the western United states from its phytogeographic center coastal ranges of California (Ray and Chisaki, 1957a). A. tessel homostylous (the anthers and stigma are opposite each other), sel compatible species exhibiting a high degree of assortative matinç A. grandiflora and A. tessellata both belong to the Tessellatae s within the Amsinckia genus (Ray and Chisaki, 1957b). As members Boraginaceae family, flowers of each species can produce a maxim four seeds, called nutlets. Ray and Chisaki (1957b) presented ev: A. grandiflora ( $\mathrm{n}=6$, smooth nutlets, heterostylous) gave rise $t$ A. douglasiana A. DC ( $\mathrm{n}=6$, rough nutlets, heterostylous), whicl 
gave rise to A. tessellata ( $\mathrm{n}=6$, rough nutlets, homostylous). occurs sympatrically with A. grandiflora in the field.

\section{A. grandiflora pollination studies}

During the 1993-94 and 1994-95 growing seasons, greenhouse studie conducted on A. grandiflora and A. tessellata to examine the pott nutlet output of both species. However, given the more complex heterostylous mating system of A. grandiflora, it was first neces examine the different possible pollination regimes for this specj greenhouse studies were conducted at the Lawrence Livermore Natic Laboratory in Livermore, California. A. grandiflora nutlets for pollination studies were obtained from a 1988 common garden study conducted at the University of California at Davis by Drs. Daniel and Ronald Kelley (Pavlik et al., 1993). These nutlets were desc؛ collections by Dr. Robert Ornduff of the University of California in the mid-1960s from the Drop Tower natural population at Site 30 Nutlets from this common garden source are referred to as the DA source. Nutlets had been stored at $4{ }^{\circ} \mathrm{C}$. On 27 November 1993, A. grandiflora nutlets were germinated in petri plates as descrik for germination Trial A. Seedlings were established in 15.25-cm. with native soil from site 300. Seedlings were maintained in an temperature greenhouse and irrigated with tap water through a dr: system. Beginning in March 1994, all plants received weekly irri $50 \%$ strength Hoagland's solution.

In early March 1994, 40 uniform-size A. grandiflora plants wer randomly selected (20 pins and 20 thrums). Plants were divided i] blocks (arranged in an east-to-west orientation), each containinç 
and four thrum individuals. The greenhouse was completely sealer external pollinators, and airflow and disturbance were minimized Flowers on each plant received one of four pollination treatments manual manipulation ("passive self-pollination", abbreviated ps), manually-assisted self-pollination ("active self-pollination", ak (3) manually-assisted intramorph pollination (abbreviated intra), manually-assisted intermorph pollination (abbreviated inter). $\mathrm{Tr}$ resulted in a total of eight treatments (four treatments for each morph). Pollinations were conducted on newly opened flowers on 2 29, 30 and 31 March 1994. This resulted in at least three flowers treatment per plant, with totals between 56 and 64 individual flov treatment. Nutlets were carefully collected from each labeled fl 15 through 28 April 1994. Nutlets were air dried, weighed and thє at $4{ }^{\circ} \mathrm{C}$.

Nutlets from each pollination treatment were germinated during 1994-95 winter (8 months after collection). On 29 December 1994, nutlets from each treatment were grouped into three or four repli dishes of approximately 20 nutlets. Nutlets from each treatment a minimum of five plants. Germination under ambient greenhouse temperature was recorded for 24 days.

\section{Germination Trials}

Germination trials were conducted to compare germinability of A. grandiflora nutlets to that of A. tessellata nutlets. Trial P. 27 November 1993 using A. grandiflora nutlets from the DA88 sourc A. tessellata nutlets came from volunteer plants growing with A. grandiflora in the 1988 common garden study, and thus are alsc 
referred to as the DA88 source. All nutlets had been stored at 4 were placed into petri plates containing Whatman 40 filter paper with distilled water, with 20 nutlets per plate. Each plate was c foil and replicated three times for a total of 60 nutlets per spec Germination at room temperature (approx. $22^{\circ} \mathrm{C}$ ) was recorded over days. Petri plates were remoistened with distilled water as nece

Trial B was conducted in August 1993. A. grandiflora nutlets 1 this trial were collected in June 1993 from a Site 300 experimenté population founded from the DA88 source. A. tessellata nutlets v collected in June 1993 from a natural population near the A. grar. experimental population. These nutlets are referred to as the EX Nutlets were collected unusually late in the spring because of pr rainfall and delayed senescence. After collection, nutlets from were air dried in paper bags at room temperature (about $22{ }^{\circ} \mathrm{C}$ ). $\mathrm{C}$ August 1993, 120 Steuwe tubes were filled with native soil from sit had been premoistened with distilled water. Each tube was sown w single nutlet of either species at a depth of $0.5 \mathrm{~cm}$. After sowi was irrigated with $0.5 \mathrm{~cm}$ of distilled water, placed into racks, organized into replicates of 10 tubes each. Replicates were arra four blocks (arranged in an east-to-west geometry to remove the e differing light intensity) and placed in a warm greenhouse (apprc daytime). Each block contained one A. tessellata replicate (10 t two A. grandiflora replicates (20 tubes). Tubes were kept moist I distilled water, and germination was recorded through 22 septembe On 22 september 1993, apparently ungerminated A. grandiflora nutl، were excavated from 38 tubes and examined for evidence of germine 
Trial C was conducted in January 1995. The A. grandiflora nut: sources were: (1) nutlets collected in the spring of 1994 from th Canyon natural population (labeled CC94), and (2) nutlets collect spring of 1994 from a Site 300 experimental population (founded fy Davis source) located near the Drop Tower natural population (lab Ex94). A. tessellata nutlets were obtained in the spring of 1994 greenhouse-grown plants (labeled GR94) founded from the Davis sor After air drying at room temperature, the nutlets were stored at plates were prepared on 23 January 1995 as described above for Tr: except that each plate contained 10 nutlets. Plates containing n. source CC94 were replicated three times, and plates containing ni from sources EX94 and GR94 were replicated six times. These were in a cool, ambient temperature (approx. $5{ }^{\circ} \mathrm{C}$ daytime) head house. Germination was recorded over a 10-day period. After 10 days, an ungerminated nutlets were allowed to air dry for an additional 10 After drying, the remaining nutlets were again placed into prepas plates and observed for 15 days to determine the occurrence of adi germination

\section{Interspecies comparisons in the greenhouse}

Growth and reproductive attributes were compared between greenhor grown A. grandiflora and A. tessellata during the 1994 and 1995 winter/spring growing seasons. In January 1994, four germinules A. grandiflora and A. tessellata from germination Trial A were transplanted into $10.15-\mathrm{cm}$. pots containing native site 300 soil. maintained in an ambient temperature greenhouse, drip-irrigated, water, and given weekly irrigations with 50\% strength Hoagland's 
during the flowering period. Once all flowers had senesced, the number of inflorescences per plant (inflorescence output) and tot of flowers per plant (floral output) were determined. Any availa A. tessellata nutlets were collected, air dried and weighed (how' nutlets were lost). Due to the lack of pollinators, A. grandiflo not produce a significant number of nutlets. Above- and below-gr biomass was then separated, oven-dried at $60{ }^{\circ} \mathrm{C}$, and weighed for plant.

In February 1995, fifteen germinules each of A. grandiflora EX! A. tessellata GR94 from germination Trial C were transplanted int cm. pots containing standard greenhouse potting soil. Plants we: maintained in an ambient temperature greenhouse, drip-irrigated, water, and given weekly irrigations with 50\% strength Hoagland's during the flowering period. Seven A. grandiflora plants were $\mathrm{m}$ inter-morph pollinated. Once all flowers had senesced, inflores output and floral output were determined for each plant. Above-ç biomass was oven-dried at $60^{\circ} \mathrm{C}$ and weighed for each plant.

Interspecies comparisons in the field

In October 1994, thirty-six 0.25-m² plots were established in two One location was near the native Drop Tower population (location ] second location was on an ecological reserve adjacent to site 300 the California Department of Fish and Game (location CDFG). Each was seeded with nine A. grandiflora nutlets from the EX94 source. were sown in three rows of three, equidistantly spaced at $10 \mathrm{~cm}$. onset of winter rains, the germinating A. grandiflora nutlets we along with an A. tessellata of the same age from the plot's ambit 
bank. A total of 29 species pairs were marked at the DT location pairs at the CDFG location. Plants were periodically checked for survivorship and inflorescence output throughout the growing sea After each individual flower senesced, the sepals were marked, al fully-filled, green nutlets counted. This provided an accurate $\epsilon$ floral output and floral seed cache (number of nutlets per flower plant. As we wished to allow all A. grandiflora nutlets to enter bank and potentially assist in propagating the species, final abc biomass was not collected. Nutlet collection was limited to coll mature nutlets from five A. tessellata (one from CDFG and four $f$ : location) and ten A. grandiflora plants (four from CDFG and six 1 location).

Data analysis

Percentage data were arcsine square-root transformed prior to stá analysis (Krebs, 1989). Analysis of variance (ANOVA) statistical were conducted using the GLM (General Linear Model) procedure, a linear regressions were conducted using the REG (Regression) prc both of SAS (SAS 1990). Mean separation between treatments was conducted using Dunnet's test. Slopes of the regression lines we compared between the two species. Results were considered signif the alpha value was less than or equal to 0.05 , although nearly s results ( $p$ less than 0.1 but greater than 0.05) are also presentec 
RESULTS

Pollination Studies

Intermorph pollinations of A. grandiflora in the greenhouse prod highest floral seed cache (> 2.5 nutlets/flower) regardless of th morph of the parental plant (Figure 1a). The intramorph and acti pollinations also produced a significant floral seed cache (> 1.5 nutlets/flower). Passive self-pollinations produced essentially Statistically significant block and treatment effects were detect significant block-treatment-morph and date-treatment-morph interi (Table 1). The block effect was a result of all three blocks loce eastern greenhouse windows generally producing a higher floral s cache than the two blocks located in the interior of the greenhou Analyzing each floral morph data separately revealed a block by $t$ interaction in the pin morph data. This was a result of the int] pollination treatment, in which the block effect was not observed the three window blocks. The date by treatment interaction was d only maternal thrum treatments. In both the intra- and active se pollinations, there were two pollinations dates which produced ar floral seed cache approaching or greater than 2 nutlets/flower. other pollination dates, floral seed cache was approximately 1.5 nutlets/flower for both treatments.

Although no difference in floral seed cache was detected betwe and thrums, there was a significant difference in nutlet weight nutlet weight in mg/nutlet, Figure 1b). Nutlet weight of pins wa approximately $1.2 \mathrm{mg} /$ nutlet greater than thrum nutlet weight. Fc comparison, nutlet weight of the limited number of A. tessellata collected from plants growing in the greenhouse at the same time 
pollination study is also presented. Nutlet weight of thrum plan significantly different from that of A. tessellata. The nutlet $w$ A. grandiflora pin plants, as well as the combined average nutlet pin and thrum plants was significantly different from A. tessell Germination of the 6-month-old nutlets resulting from the poll treatments was in general very low (Figure 2a). Germination was for nutlets produced from the active self-pollination $(10-18 \%) \mathrm{k}$ for all other treatments. The floral morph of the progeny plants consistent with that expected for the type of cross (Figure 2b). number of progeny plants resulting from each treatment was low, floral morph did not differ significantly from that expected base phenotypic disassortative mating of the $s$ allele system $\left(\chi^{2}=3.0\right.$, Due to the extremely low sample number, however, caution should $k$ in interpreting these results. All progeny plants resulting fron active self- or intramorph pollination of maternal pin plants wer themselves, providing evidence for the lack of cross contaminatic the manual pollinations.

\section{Germination Trials}

Table 3 summarizes the results of the germination trials. Germi: was highest in Trial A in which A. grandiflora and A. tessellata had been stored at $4{ }^{\circ} \mathrm{C}$ for 5.5 years and germinated at $22{ }^{\circ} \mathrm{C}$. Aft days, A. grandiflora germination averaged $75.0 \%$ ( S.E. = 2.9\%) anc A. tessellata germination averaged $73.3 \%(\mathrm{~S} . \mathrm{E} .=10.1 \%)$. As part separate study, in 26 plates each containing 20 A. grandiflora nu the Davis nutlet source, germination averaged $77.8 \%$ with a standi of $2.7 \%$ within the first 3 days (unpublished data). 
In contrast, Trial B exhibited the lowest observed germination three trials. This trial examined A. grandiflora and A. tessell that had been collected 2 months previously from field-grown plan air dried in warm conditions, and germination attempted under wa conditions in soil. No A. grandiflora or A. tessellata germinul observed breaking the soil surface during the course of the trial A. grandiflora nutlets subsequently excavated, seven (18\%) showed evidence of germination. Six of these exhibited radicle extrusic had completely germinated, although the fully-developed cotyledon to break the soil surface and subsequently died.

Trial C examined the germination of 9-month-old seed sources $n$ had been stored for several months at $4{ }^{\circ} \mathrm{C}$, and germinated under conditions (Figure 3). Germination for all three seed sources o slowly and sporadically over the first 10-day period. Nutlets co the A. grandiflora experimental population (EX94) had significant germination compared with nutlets from both the natural populatic (CC94) and greenhouse-grown A. tessellata (GR94). However, aftes allowing the nutlets to air dry for 10 days, the nutlets from the A. grandiflora population experienced significantly more germina during the second germination period compared with the greenhous produced A. tessellata nutlets. The natural A. grandiflora popu experienced a substantial amount of germination during this peri، germination during this second period occurred extremely slowly sporadically. Although the total amount of germination for all $t$ sources was not significantly different, A. tessellata nutlets hi average percent germination, followed by A. grandiflora nutlets 1 
natural population, with nutlets from the A. grandiflora experim population having the lowest average percent germination.

\section{Greenhouse interspecies comparisons}

In both 1994 and 1995, floral output of greenhouse-grown A. grand was twice that of $A$. tessellata (Figure 4a). Floral output in pl species in 1994 was twice that of plants grown in 1995, although 1 of similar size with respect to above-ground (aerial) biomass (Fi Plants in 1994 were grown from nutlets obtained from the DA88 sou whereas the plants in 1995 were grown from nutlets collected from the GR94 (A. tessellata) or EX94 (A. grandiflora) source. As di: above, germination of both the GR94 and EX94 nutlet sources was $1 \epsilon$ that observed for the DA88 nutlets. These nutlets sources may hat produced seedlings which were less robust compared with those pr in 1994, and thus directed the majority of their resources into $v \epsilon$ structures at the expense of reproductive structures. In additic were grown in $10.15-\mathrm{cm}$ pots in 1994, and in 15.25-cm pots in 1995. larger pot in 1995 may have encouraged biomass allocation to root: expense of aerial organs. Unfortunately, root biomass was not det in 1995 .

When grown in a greenhouse without pollinators, A. grandiflori seed cache was zero (Figure 1 ). It is possible that A. grandiflo increase floral output more than A. tessellata because resources allocated to floral output instead of floral seed cache. However the case. Floral output in hand-pollinated A. grandiflora plants twice that of A. tessellata (Figure 4b). Floral output of the po: A. grandiflora was significantly greater than that of A. tessell 
this trial. This was not the case for the unpollinated A. grandi due to greater variability in floral output (CV of 76\% vs 37\% for A. grandiflora and $44 \%$ for A. tessellata). The destructive analy small number of plants in 1994 (Figure 5a) suggested that under $\mathrm{C}$ of unlimited water and soil nutrients, A. grandiflora apparently its resources into additional shoot and root biomass, which in ti produced more inflorescences and flowers. However, in terms of output and below-ground biomass, A. grandiflora showed much more statistical variation compared with A. tessellata.

For an equivalent amount of aerial biomass, A. grandiflora flo was also twice that of $\mathrm{A}$. tessellata in the greenhouse in 1995 ( $\mathrm{F}$ Using the floral seed cache observed in the field in for each spe nutlets/flower for A. tessellata, and 0.8 for A. grandiflora, Fic output for the greenhouse grown plants was estimated. Estimated output per unit of aerial biomass was similar for A. grandiflora A. tessellata (Figure 6b). If inflorescence output is used inst $\epsilon$ biomass (Figures 6c and 6d), similar relationships are observed, the slopes of the resulting lines are not as steep.

\section{Field interspecies comparisons}

Mortality for both species was very high at both sites (Table 4). A. grandiflora and A. tessellata seedlings was equal at the DT si However, A. tessellata mortality (75\%) was higher than that of A. grandiflora (50\%) at the CDFG site. Most of the mortality ocC within the first month of the growing season. The cause and tim: mortality did not appear to differ between the two species. 
Under field conditions, floral seed cache in both A. grandiflo A. tessellata was less than the maximum of four nutlets per flow 7a). (Because there was no statistical difference in reproductiv between the two sites, the data were combined.) A. tessellata pr nutlets/flower (S.E. 0.19), which was a little more than twice th. A. grandiflora (0.8 nutlets/flower, S.E. 0.12). Floral output wa A. grandiflora, but this difference was not statistically signifj 7b). Seed output in A. tessellata was greater than A. grandiflor 7b), but again this difference was not significant. Floral outpu inflorescence was greater in A. grandiflora (Figure 7c), resulti similar seed output per inflorescence between the two species (Fi This was similar to the results observed in the greenhouse. Thus A. grandiflora appears to be able to compensate for the low flora producing more flowers per inflorescence.

Nutlet weight for field grown A. tessellata plants was consist, that of the combined nutlet weight of pin and thrum A. grandiflor by 1.1 to $1.4 \mathrm{mg} /$ nutlet (Table 5). Nutlets produced by A. grandif plants weighed much more than A. tessellata nutlets, by as much mg/nutlet. Nutlets from thrum A. grandiflora plants also genera weighed more than A. tessellata nutlets, although by only 0.5 to mg/nutlet. The field results were similar to those observed in $t$ greenhouse. Nutlet weight of both species was lower in 1993 when compared to 1995. A. tessellata nutlet weight was reduced to a $g$ extent than A. grandiflora (a reduction of $0.83 \mathrm{mg} / \mathrm{nutlet}$ as comp $0.50 \mathrm{mg} / \mathrm{nutlet)}$. 


\section{DISCUSSION}

Our pollination study results indicate that A. grandiflora is not self-incompatible. Although differential pollen-tube growth is a cause of A. grandiflora's cryptic self-incompatibility (Weller a] 1989), our data suggest that in the absence of pollen competition

nutlet production can occur from illegitimate (intramorph) polles was also observed by Weller and Ornduff (1977), whose results are in Figure 1a. In their study, the highest floral seed cache was the intramorph pollinations (2.2 nutlets/flower for pins, 1.3 nut for thrums), with a floral seed cache in the intermorph pollinatj and 1.3 nutlets/flower for pins and thrums, respectively. In cor results, self-pollinations (which we assume to be active self-po] produced less than 1 nutlet/flower. Deviations from disassortati by intramorph pollination in the field could account for the devi the expected morph ratio of 1:1 that has been observed, particula populations sizes are small (Ornduff, 1976; Pavlik, 1994). Our g grown and intermorph hand-pollinated A. grandiflora plants produ floral seed cache ( $>2.5$ nutlets per flower) that was much higher observed by Ornduff (1976), and was comparable to that of the fiel A. tessellata observed by Ornduff (1976) in 1967 (3.02 nutlets/flor (2.49 nutlets/flower). It is possible our higher intermorph pol] seed cache was a result of applying all four pollination treatmen each individual plant. Our passive self- and intramorph pollinat produced lower seed caches, which could have made additional mat reserves available for intermorph pollination seed set. However, flowers on an individual plant received the same pollination trec (which was presumably done in Weller and Ornduff, 1977), there wc 
equal competition for maternal reserves. If this is the case, hc results of Weller and Ornduff (1977) imply that intramorph pollin more effective at obtaining maternal reserves to convert into nut possibility, and its implications, should be further explored.

Our results suggest that the floral seed cache of A. grandiflo approach that of A. tessellata under conditions of unlimited wat, nutrients, and maximum pollination. Therefore, it is important field populations to maximize the presence of pollinators. This important, if not more, than ensuring an equal pin: thrum ratio, even intramorph pollination can result in significant seed set. I fact that we detected a significant block effect suggests that fl، is sensitive to environmental conditions, such as light. Resour is known to reduce seed number, usually through seed abortion (Hé Westoby, 1988). Competition for light could therefore negatively A. grandiflora floral seed cache.

The results of the germination trials indicate that both A. gri and A. tessellata have germination responses typical of many ann species native to the California grasslands. Although many of tr introduced grasses can germinate as early as August, native spec generally do not respond until October (Chiariello, 1989). Tempe water availability can interact in complex ways to determine gern timing (Young and Evans, 1989). Our results suggest that A. grar and A. tessellata may have an after-ripening requirement which $i$ summer dormancy and delays germination until autumn. Such an af ripening requirement has been observed in other winter annuals (' al., 1968; Baskin and Baskin, 1976). Attempts to germinate fresh] A. grandiflora nutlets in petri plates in July 1994 were also uns 
(unpublished data), further suggesting that the response observec due to this after-ripening requirement, and not due to a light in a result of being covered with soil.

Although our germination trials were not extensive enough to determine the type of dormancy and the exact physical requirement light, temperature and precipitation) for germination initiation nutlet maturation, in general we observed similar germination re in A. grandiflora and A. tessellata. This was true in spite of $t$ the average nutlet weight of A. grandiflora was generally greater of A. tessellata. Both species appear to have the ability to resk of precipitation throughout the cool winter months, thus increasj germination. However, there did appear to be a difference in ger response from nutlets collected from an experimental population c A. grandiflora (EX94) and nutlets collected from the large, nativ population (CC94). Germination was greater for the CC94 nutlets the first 10 days (Trial C, Figure 3). After 10 days of air-dryir germination during the second 15 days was greatest for nutlets fr This resulted in roughly equal germination for the two groups by the trial. We cannot say whether this is due to different enviro conditions experienced by the maternal plants between the two pop or to a genetic difference between the large, native population a] small, experimental population. Nutlets used to found the small $\epsilon$ experimental population can be traced to the Drop Tower natural population. If this germination response is genetically based, $j$ appear that the Drop Tower population may have developed the capac delay germination until after several rain events. 
Such diversified germination may be a risk-spreading strategy some seedling establishment occurs even if early germinating coh lost due to a return of unfavorable conditions (Haig and Westoby, Silvertown and Doust, 1993). This was apparently observed in the Tower population in the 1990-91 growing season. At this time, Ca was under severe drought conditions. Rain in the fall of 1990 st small amount of germination of A. grandiflora. However, there wi subsequent rain until March of 1991. During the "March Miracle" rain fell to stimulate additional germination and establish matuj reproducing plants (Pavlik, 1991).

Our interspecies comparisons indicate that A. grandiflora can compensate for low floral seed cache by increasing floral output compared with A. tessellata under greenhouse conditions. This d appear to be a function of simply larger plants, but a result of per inflorescence for similar sized plants. However, this is ver floral seed cache. Field floral seed cache for A. tessellata in twice that of A. grandiflora (1.7 nutlets per flower for A. tesse A. grandiflora) . Pantone et al. (1995) found A. menziesii var. floral seed cache to be 2.6 nutlets per flower vs. 0.6 for A. gra whereas Ornduff (1976) reported a field floral seed cache for A. between 2.5 and 3.0 and for A. grandiflora of between 0.7 and 1.5 . observed a similar floral seed cache distribution in our experime output of A. grandiflora could not have equaled that of A. tessel although A. grandiflora floral output was greater than A. tessel: field, this difference was not statistically significant. As a r observed greater seed output for A. tessellata compared with A. ( was also not statistically significant. While these results sugg 
output in A. grandiflora can be comparable to A. tessellata, it i questionable as to whether or not A. grandiflora can consistently compensate for low floral seed cache by increasing floral output. year variation could result in significantly greater A. tessellat output compared with A. grandiflora.

The average weight of nutlets collected from both field- and g] grown plants of the common A. tessellata species was consistentl: that of the rare A. grandiflora. This might initially seem surp seed size is generally thought to be advantageous in terms of eme and growth, at least within a species (Haig and Westoby, 1988; Fe 1985). In a study of rare and common prairie grasses, the rare, lighter caryopses, where as the common grasses had heavier caryo (Rabinowitz, 1978). However, a study on mariposa lilies of the gr Calochortus showed two of the three rare species examined to have seeds compared to the common species (Fiedler, 1987). In the cas graminoids, it was suggested that the rare species were colonize thus had light caryopses for dispersal to suitable but rare sites of Calochortus and Amsinckia, both the common and rare species $h$ highly overlapping habitats. Also, in at least the Amsinckia gel common species is a highly aggressive colonizer. It would appea both Calochortus and Amsinckia, the common species has successfl made the trade-off between seed size and seed number (Haig and We 1988; Fenner, 1985). Our data show that germination was not negat affected by A. tessellata's lower nutlet weight. However, field mortality did appear to be greater in A. tessellata compared to A. grandiflora, which might be related to the lower seed reserves A. tessellata nutlet weight showed a greater change between 1993 ; 
than did A. grandiflora, although germination of the 1993 nutlets similar. This again suggests A. tessellata can "get away with" less maternal reserves into each nutlet, responding to environme limitations through reduction in nutlet weight while still produc nutlets. A. grandiflora nutlet weight, on the other hand, is rel plastic, and A. grandiflora appears to respond to environmental through a reduction in nutlet number.

What was more surprising than the difference between A. grandi and A. tessellata's nutlet weight was the greater A. grandiflora progeny nutlet weight when compared to thrum progeny nutlet weigr progeny nutlets weighed from 0.76 up to $1.14 \mathrm{mg} /$ nutlet more than progeny nutlets (Table 5, Fig. 1b). Although the number of mater progeny nutlets germinating was somewhat less than that of mater progeny nutlets (Fig. 2b), the overall number of nutlets germinat small to reach any meaningful conclusion. The evolutionary and restoration implications of such a difference in pin and thrum $p$ nutlet weight remain to be explored.

Our field results may have been confounded by the fact that the were growing in a community dominated by exotic annual grasses. Although we carefully paired the two species in an attempt to mir confounding impact of the community, it is possible that A. granc affected to a greater extent by the presence of exotic annual gra. A. tessellata. It has been shown that A. grandiflora competes pr exotic grasses (Pavlik et al., 1993) and performs better in a mat: perennial bunch grasses (Carlsen et al., 1996). The greater root of A. grandiflora may provide a competitive edge in the relativel undisturbed perennial bunch grass community, where substantial r 
competition may occur (Wilson and Tilman, 1993). In the case of grasses, it appeared that competition for light was the primary $f$ which reduces the number of inflorescences, and thus number of $f$ (Carlsen et al., 1996). Our data suggests that A. grandiflora mu resources into additional floral structures to produce an equal $\mathrm{r}$ nutlets compared with A. tessellata, even under conditions of un resources. That A. grandiflora does not simply increase floral when presented with unlimited resources is probably a consequence reliance on pollinators. By increasing the number of flowers pre pollination, overall pollination probability may be increased. T selfing $A$. tessellata could reduce the number of flowers producec relying on pollinators. Fewer number of flowers produced, along lower nutlet weight, means maternal investment for an equal numbs progeny nutlets is lower for A. tessellata than A. grandiflora. suggests that competition for resources with exotic grasses may A. grandiflora to a greater extent compared to A. tessellata. Ir environment in the absence of other competitors, it was found tha A. grandiflora competed effectively with A. menziesii with respec biomass accumulation, but was not effective in converting those: into seeds (Pantone and Pavlik, 1996). This was likely due to the natural pollinators. Extrinsic factors such as parasitic nemator been shown to be important in the competitive ability of $\mathrm{A}$. menzi intermedia (Pantone et al., 1989). A controlled field competiti experiment comparing the impact of exotic annual grasses on both A. grandiflora and A. tessellata is required. 
We conclude that under conditions of unlimited resources, it i that A. grandiflora fitness is intrinsically limited when compart weedy relative, A. tessellata. Under field conditions, it appear reproductive ecology of A. grandiflora may result in lower seed C A. tessellata. However, this may be a result of an interaction $w$ extrinsic factor of competition with exotic plants.

\section{ACKNOWLEDGMENTS}

The authors thank Steve Gregory, Erin Espeland, Merry Jones and P Beesley for technical assistance. We also thank Drs. John Menke Kevin Rice for technical input throughout the project, as well as of the manuscript. Work performed under the auspices of the U.S. Department of Energy by Lawrence Livermore National Laboratory un Contract W-7405-Eng-48 and funded by a grant from the Laboratory D Research and Development program. Publication number UCRL-ID123356.

\section{REFERENCES}

Baskin, J. M. and Baskin, C. C. (1976). High temperature requirem after-ripening in seeds of winter annuals. New Phytol., 77, 61! Carlsen, T. M., Menke, J. W., and Pavlik, B. M. (1996). Competiti suppression of a rare annual forb by native perennial and exot grasses. Ecology, submitted.

Chiariello, N. R. (1989). Phenology of California grasslands. Ir Structure and Function: California Annual Grassland. Tasks fol Vegetation Science 20, ed. L. F. Huenneke and H. A. Mooney. Kl Academic Publishers, Dordrecht, The Netherlands, pp. 47-58. 
Cody, M. L. (1986). Diversity, rarity, and conservation in Medite climate regions. In Conservation biology: the science of scarc diversity, ed. M. E. Soule. Sinauer Assoc., Inc., Sunderland, Massachusetts, pp. 122-152

Darwin, C. (1872). On the origin of species. 6th edition. Mentor, Evans, R. A. and J. A. Young. (1989). Characterization and analy: abiotic factors and their influences on vegetation. In Grassl Structure and Function: California Annual Grassland. Tasks fc Vegetation Science 20, ed. L. F. Huenneke and H. A. Mooney. K Academic Publishers, Dordrecht, The Netherlands, pp. 13-28.

Fenner, M. (1985). Seed Ecology. Chapman and Hall, New York, NY. Fiedler, P. L. (1987). Life history and population dynamics of ra common mariposa lilies (Calochortus Pursh: Liliaceae). J. Eco: $977-995$

Fiedler, P. L. and Ahouse, J. J. (1992). Hierarchies and cause: * understanding of rarity in vascular plant species. In Conserve Biology: the theory and practice of nature conservation, prese management, ed. P. L. Fiedler and S. K. Jain. Chapman and Hil: York, NY, pp. 23-47

Ganders, F. R. (1976). Pollen flow in distylous populations of An (Boraginaceae). Can. J. Bot., 54,2530-2535.

Ganders, F. R. (1979). The biology of heterostyly. N. Z. J. Bot., Gaston, K. J. (1994). Rarity. Chapman and Hall, New York, NY, 205 Haig, D. and Westoby, M. (1988). Inclusive fitness, seed resource maternal care. In Plant Reproductive Ecology: Patterns and Str ed. J. L. Doust and L. L. Doust. Oxford University Press, New pp. 60-79. 
Heady, H. F. (1988). Valley grassland. In Terrestrial Vegetation California, ed. M. G. Barbour and J. Major. California Native Society, Sacramento, California, pp. 491-514.

Krebs, C. J. (1989). Ecological Methodology. Harper Collins, New pp. 449-451.

Knudsen, M. and Tarp, K. (1994). Draft large-flowered fiddleneck (Amsinckia grandiflora (Gray) Kleeb. ex Greene) Recovery Plan 1. U. S. Fish and Wildlife Service Portland, Oregon.

Ornduff, R. (1976). The reproductive system of Amsinckia grandif] distylous species. Syst. Bot., 1, 57-66.

Pantone, D. J. and Pavlik, B. M. (1996). Plant population ecology endangered plant and a weedy congener: relative competitive abj reproductive biology. Submitted to Biol. Conserv.

Pantone, D. J., Pavlik, B. M. and Kelly, R. B. (1995). The reprodi attributes of an endangered plant as compared to a weedy conge] Biol. Conserv., 71, 305-311.

Pantone, D. J., Williams, W. A., and Maggenti, A. R. (1989). An approach for evaluating the efficacy of potential biocontrol ac weeds. I. Inverse Linear Model. Weed Sci., 31, 771-777.

Pavlik, B. M. (1991). Reintroduction of Amsinckia grandiflora to across its historic range. Prepared for the Endangered Plant I California Department of Fish and Game, Sacramento, Californic Pavlik, B. M. (1994). Tales of success and failure: trends in nat reintroduced populations of Amsinckia grandiflora under diffe: management regimes. Prepared for the Endangered Plant Program California Department of Fish and Game, Sacramento, Californic 
Pavlik, B. M. (1995). The recovery of an endangered plant. II. A phased approach to restoring populations. In Restoration Ecolo Europe, ed. K. M. Urbanska and K. Grodzinska. Geobotanical Ins SFIT Zurich, pp. 49-69

Pavlik, B. M., Nickrent, D. L. and Howald, A. M. (1993). The reco endangered plant. I. Creating a new population of Amsinckia grandiflora. Conserv. Biol., $7(3), 510-526$.

Rabinowitz, D. (1978). Abundance and diaspore weight in rare and prairie grasses. Oecologia 37, 213-219.

Rabinowitz, D. (1981). Seven forms of rarity. In The Biological a rare plant conservation, ed. H. Synge. John Wiley and Sons, Ne NY, pp. 205-217.

Ray, P. M. and Chisaki, H. F. (1957a). Studies of Amsinckia. I. i of the genus, with a study of heterostyly in it. Amer. J. Bot., Ray, P. M. and Chisaki, H. F. (1957b). Studies of Amsinckia. II. Relationships among primitive species. Amer. J. Bot., 44, 537-

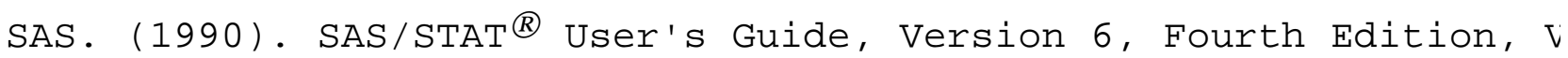
2. SAS Institute Inc., Cary, NC, pp. 891-996.

Silvertown, J. W. and Doust, J. L. (1993). Introduction to Plant Biology. Blackwell Scientific Publications, London, England, pr 170 .

Weller, S. G. and Ornduff, R. (1977). Cryptic self-incompatibilit Amsinckia grandiflora. Evol., 31, 47-51.

Weller, S. G. and Ornduff, R. (1989). Incompatibility in Amsinck: grandiflora (Boraginaceae): Distribution of callose plugs and tubes following inter- and intramorph crosses. Amer. J. Bot., 282. 
Wilson, S. D. and Tilman, D. (1993). Plant competition in relatio: disturbance, fertility and resource availability. Ecology 74,59 Young, J. A. and Evans, R. A. (1989). Seed production and germin. dynamics in California annual grasslands. In Grassland struct Function: California Annual Grassland. Tasks for Vegetation S 20, ed. L. F. Huenneke and H. A. Mooney. Kluwer Academic Publj Dordrecht, The Netherlands. pp. 39-45

Young, J. A., Evans, R. A. and Eckert Jr., R. E. (1968). Germina: medusahead in response to temperature and afterripening. Weed $16,92-95$. 
Table 1. Summary of analysis of variance on floral seed cache of A. grandif different greenhouse pollination treatments.

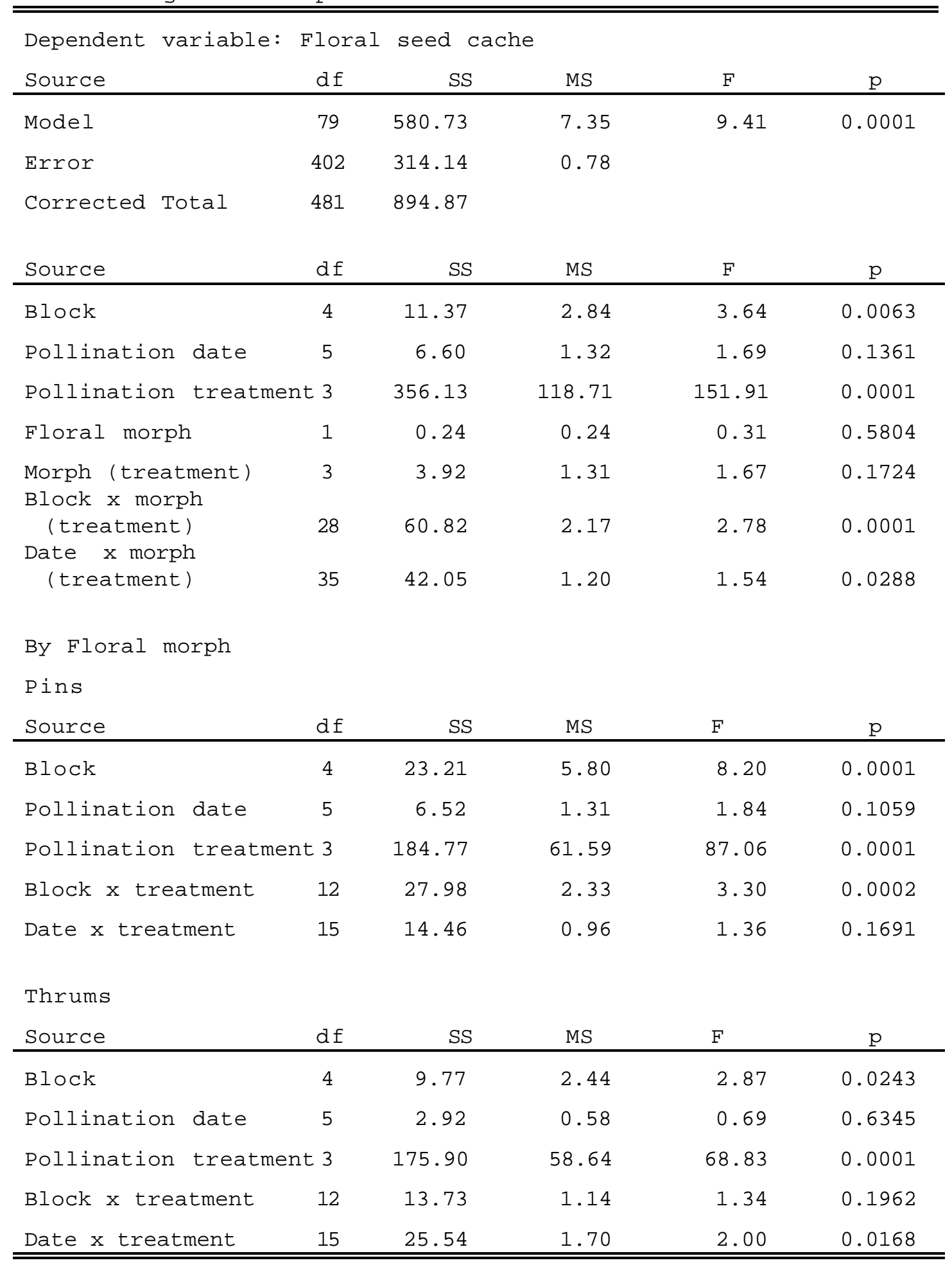


Table 2. Representation of floral morphs in progeny grown from nutlets obtain artificial pollinations in the greenhouse during spring 1994.

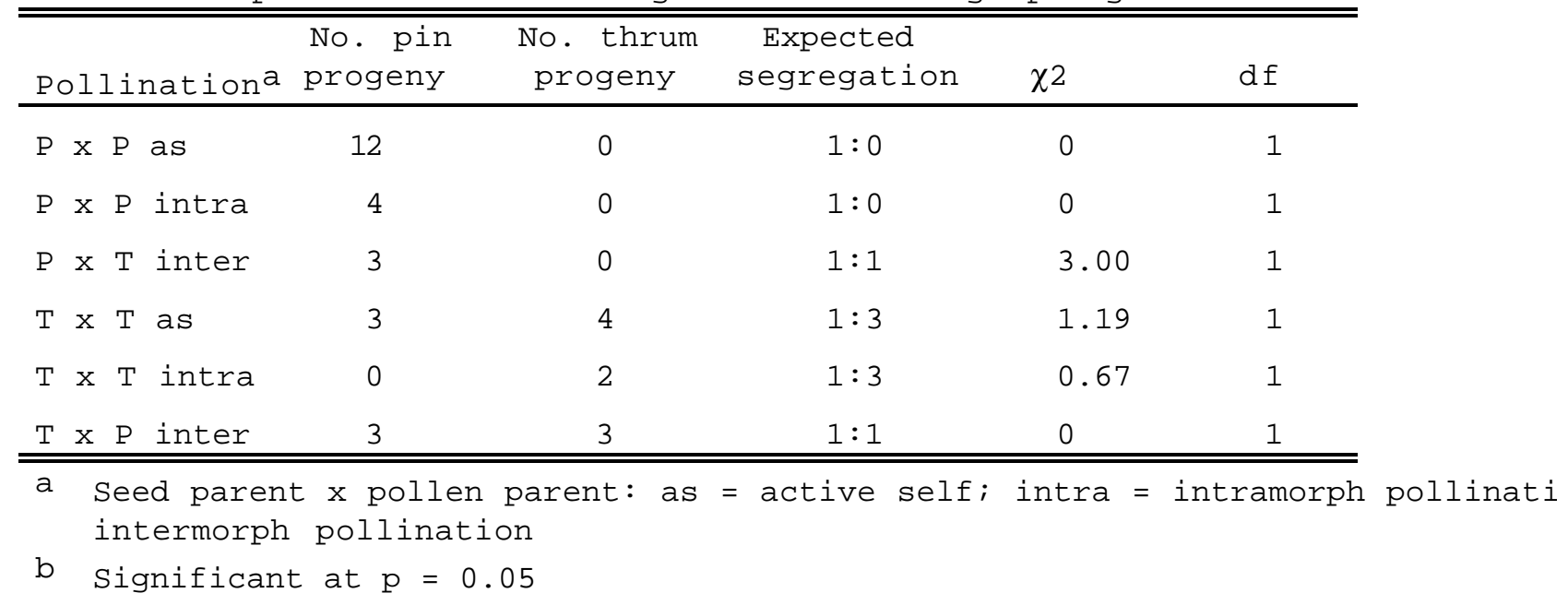


Table 3. Summary of germination trial results.

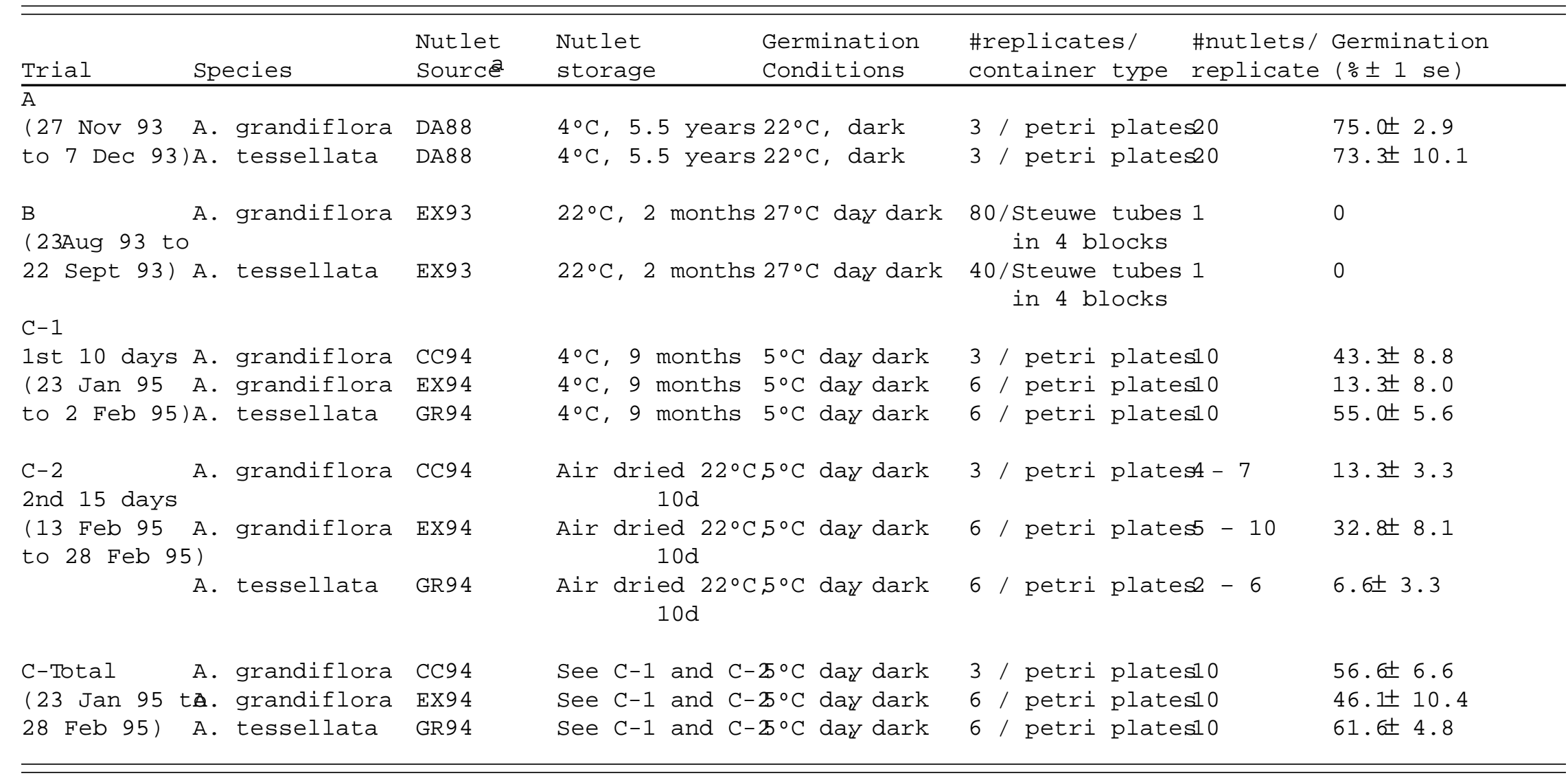

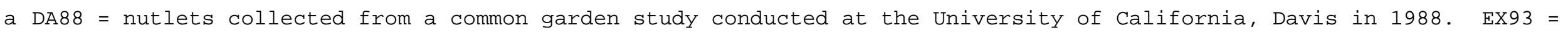

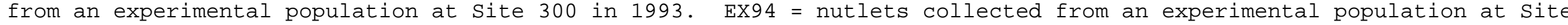

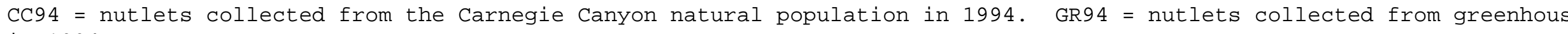
in 1994. 
Table 4. Survivorship of pairs of A. grandiflora and $A$. tessellata marked in the field during the 1994-95 growing season.

\begin{tabular}{|c|c|c|}
\hline \multirow[b]{2}{*}{ Site ${ }^{a}$} & & Mortality (\%) \\
\hline & $\begin{array}{l}\text { No. marked } \\
\text { pairs }\end{array}$ & $\begin{array}{cc}\mathrm{A} \cdot \mathrm{A} \cdot \\
\text { tessellata grandiflora }\end{array}$ \\
\hline $\mathrm{CDFG}$ & 24 & 75 \\
\hline $\mathrm{DT}$ & 29 & 55 \\
\hline $\begin{array}{l}\text { CDFG } \\
\text { Game } \\
300\end{array}$ & $\begin{array}{l}=\text { California } \\
\text { Reserve; DT }\end{array}$ & $\begin{array}{l}\text { Department of Fish and } \\
=\text { Drop Tower Site on Site }\end{array}$ \\
\hline
\end{tabular}

Table 5. Average nutlet weight (mg/nutlet) of field grown A. grandiflora anc A. tessellata plants with greenhouse plant results provided for comparison.

\begin{tabular}{|c|c|c|c|c|}
\hline \multirow[b]{2}{*}{ Yearb } & & grandiflor & & \multirow[b]{2}{*}{ A. } \\
\hline & $\operatorname{Pins}{ }^{C}, e$ & Thrums $\mathrm{C}$, e & Combined ${ }^{d}$ & \\
\hline 1993 (1) & $\begin{array}{c}4.15 \pm 0.140 \\
(21)^{a_{\neq}}\end{array}$ & $\begin{array}{c}3.39 \pm 0.297 \\
(11)^{b_{\neq}}\end{array}$ & $\begin{array}{c}4.00 \pm 0.829 \\
(48)^{a}\end{array}$ & $\begin{array}{c}2.58 \pm 0.072 \\
(7)^{b \neq}\end{array}$ \\
\hline 1994 (2) & $\begin{array}{c}4.79 \pm 0.345 \\
(10)^{a}\end{array}$ & $\begin{array}{c}3.82 \pm 0.109 \\
(10)^{b}\end{array}$ & $\begin{array}{c}4.31 \pm 0.209 \\
(20)^{a}\end{array}$ & ND \\
\hline 1995 (3) & $\begin{array}{c}4.73 \pm 0.217 \\
(6)^{a \neq}\end{array}$ & $\begin{array}{c}3.89 \pm 0.325 \\
\text { (3) } \mathrm{b}\end{array}$ & $\begin{array}{c}4.50 \pm 0.203 \\
(10)^{a}\end{array}$ & $\begin{array}{c}3.41 \pm 0.347 \\
(5) \mathrm{b}_{\neq}\end{array}$ \\
\hline$\Delta 1995-1993$ & 0.58 & 0.50 & 0.50 & 0.83 \\
\hline 1994 (4) & $\begin{array}{c}4.99 \pm 0.076 \\
(129)^{a \neq}\end{array}$ & $\begin{array}{c}3.85 \pm 0.079 \\
(130)^{b_{\neq}}\end{array}$ & $\begin{array}{c}4.42 \pm 0.065 \\
(259)^{a}\end{array}$ & $\begin{array}{c}3.13 \pm 0.038 \\
(14)^{b_{\neq}}\end{array}$ \\
\hline
\end{tabular}

a Results are presented \pm one standard error. Number in parentheses indicate number of plants, except in the case of 1993 A. tessellata and 1994 greenhous where it indicates number of nutlet sub-samples. Combined A. grandiflora p do not equal the sum of pin and thrum plants due to inclusion of plants that senesced prior to floral morph determination.

b Nutlets collected from (1) Ex93 A. grandiflora experimental population with naturally occurring A. tessellata, (2) Ex94 A. grandiflora experimental po] with naturally occurring A. tessellata, (3) Combined A. grandiflora experi plots at DT and CDFG locations with naturally occurring A. tessellata, and grandiflora plants in greenhouse pollination study and A. tessellata green grown plants.

C Different letters indicate significant difference between pins and thrums at

d Different letters indicate significant difference between combined A. gran and $A$. tessellata at $\mathrm{p}=0.05$

e $\neq$ indicates significant difference between A. tessellata and different flo of A. grandiflora at $p=0.05$. 
a.

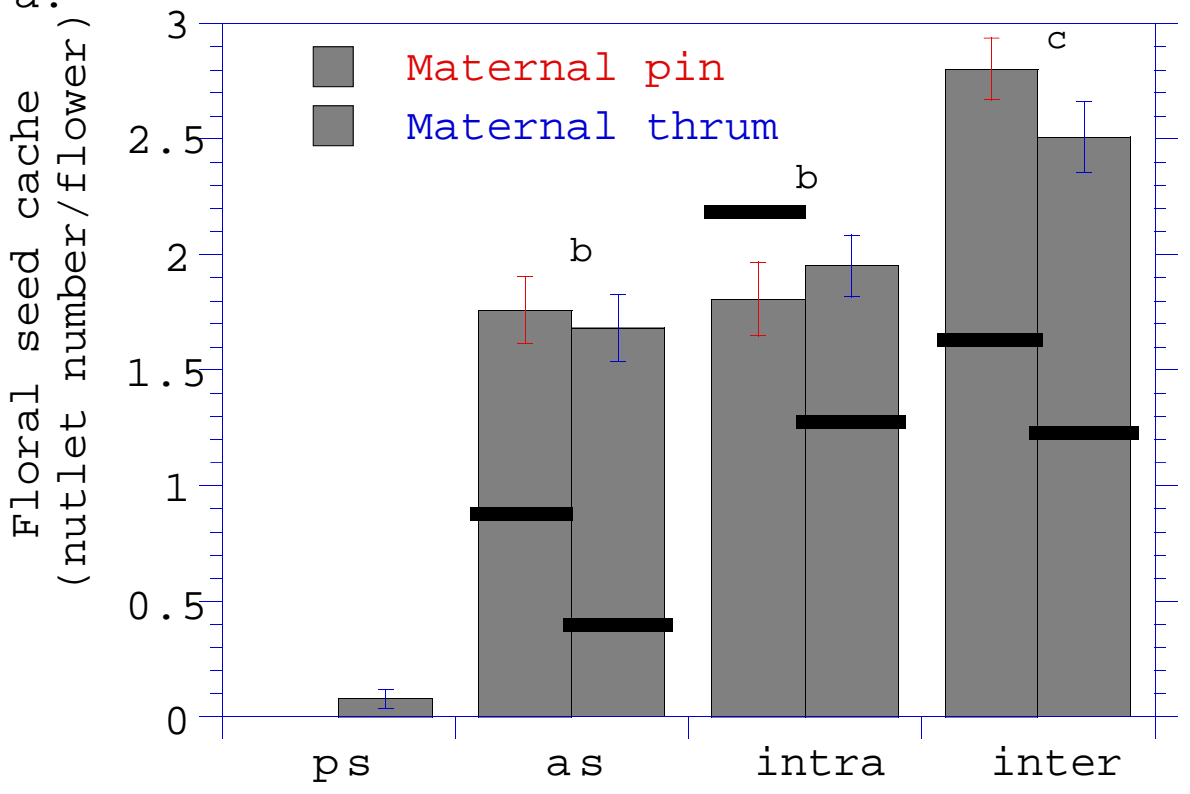

Treatment

b.

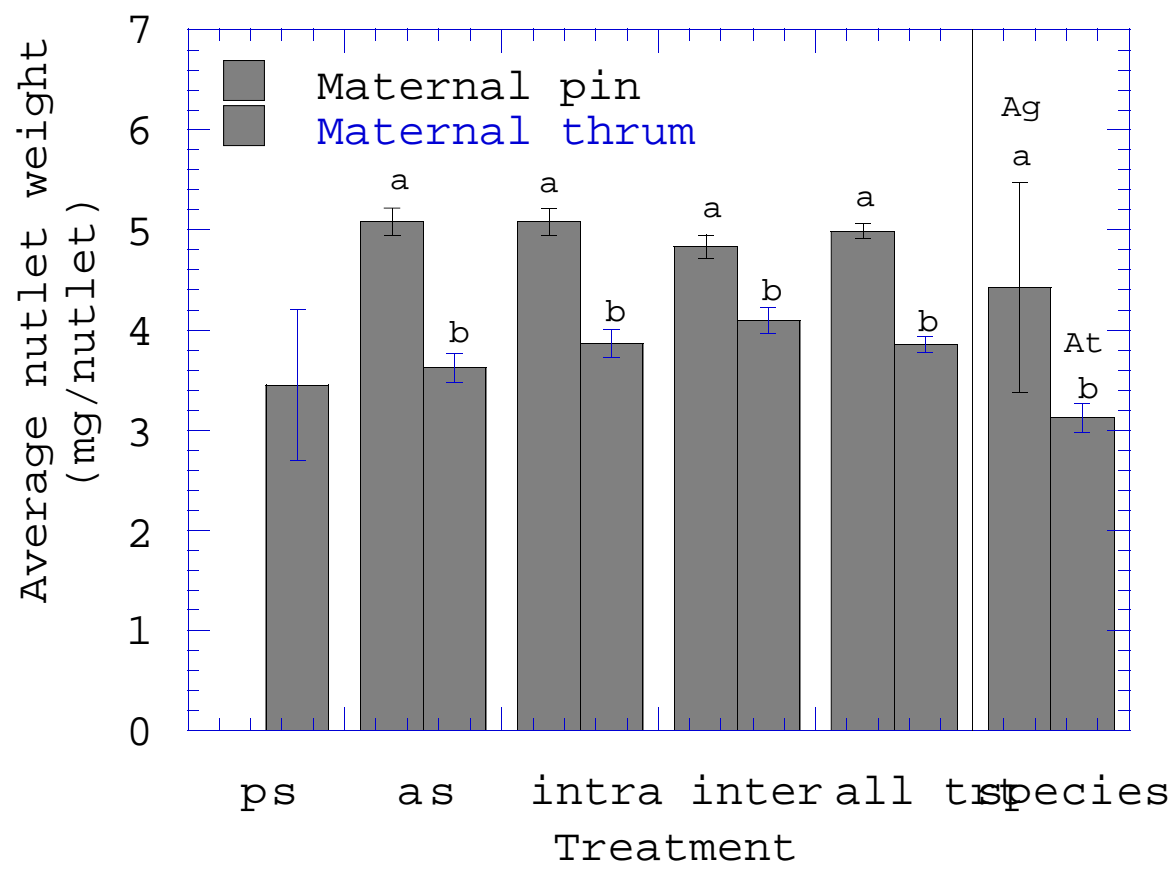

Figure 1Average floral seed cache (1a) and average nutlet Awe gghatnd(ffldorin from artificial pollinations in the greenhouse invesnorgiengultgles. weight of tessellaparesented for comparison. ps = passive self-pollination; as = active self-p intra = intramorph pollination; inter = intermorph pollination; all trt = treatments for individual morphs; same letter are not significantly фiffer@rst atsolid bar represents reblets of $W$ and Ornduff (1977) assuming their self-pollination treatment is equivalent to our ac pollination treatment. Error bars are one standard error 

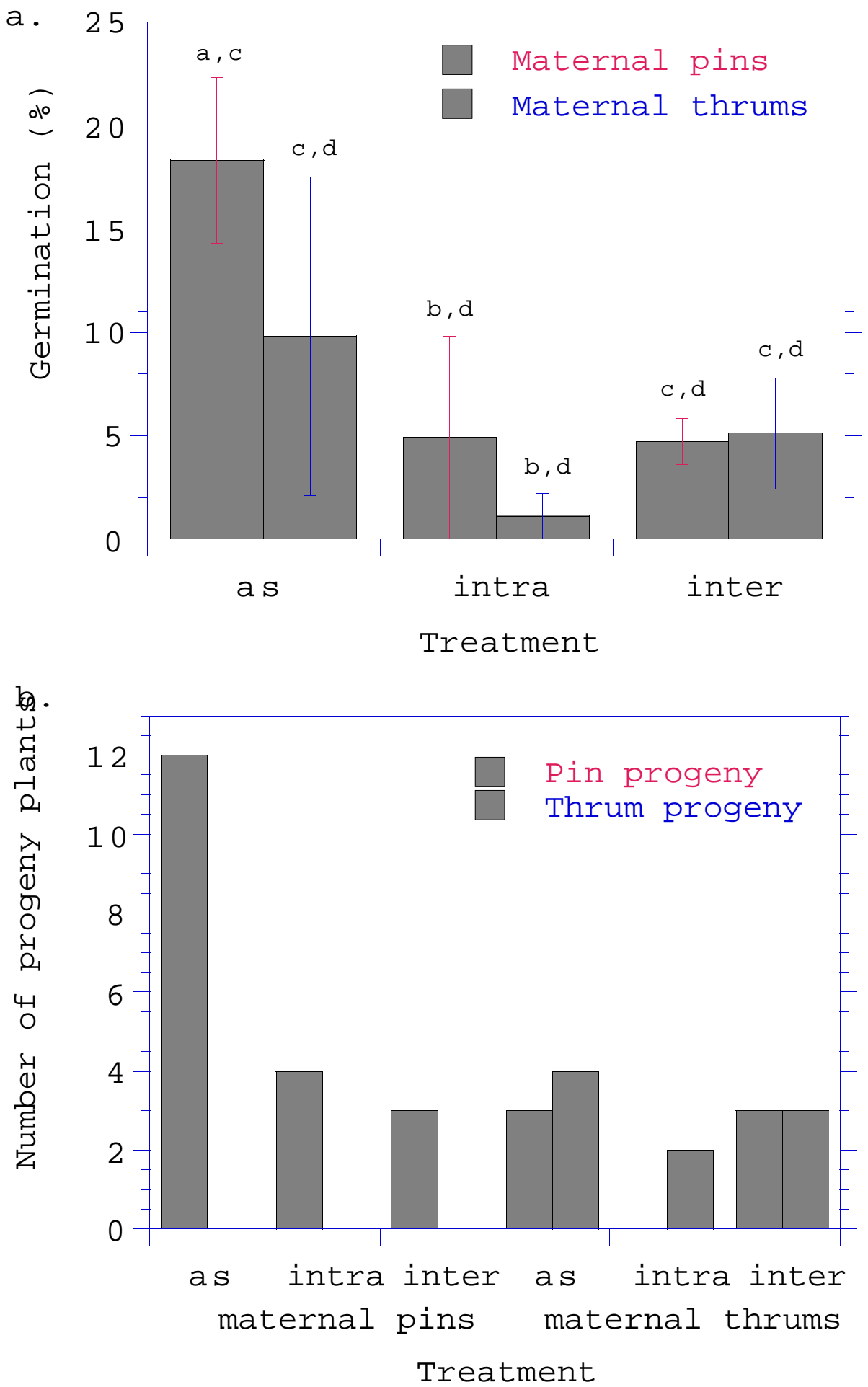

Figure 2. January 1995 percent germination (a) and floral morph (b) of nutlets from spring 1994 pollination studies. as = progeny from active self-pollination; intra = from intramorph pollination; inter = progeny from intermorpmeathimatimith $T$ different letters are significantlyp diffeelent faitror bars are one standard error 


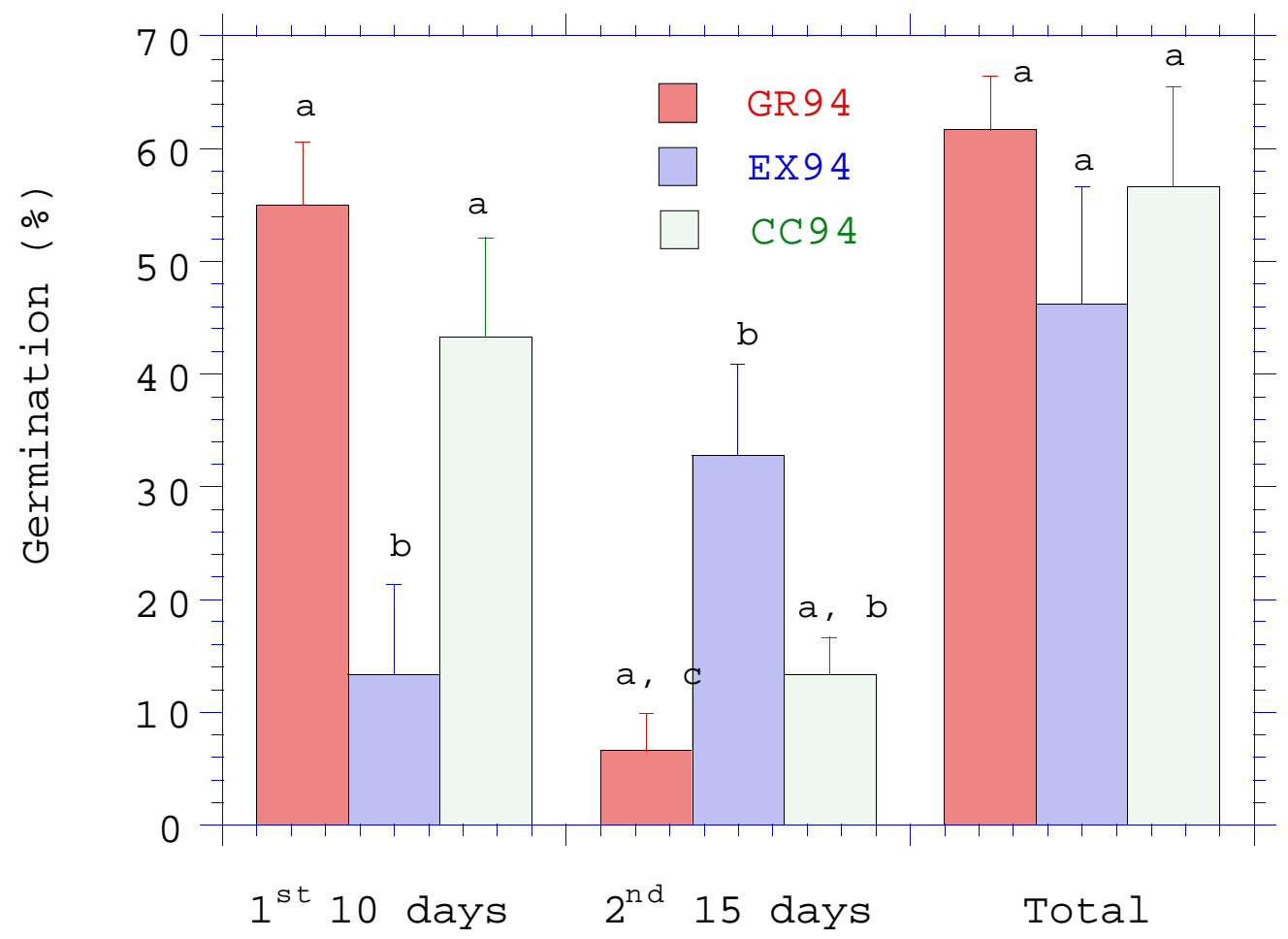

Figure 3.ritil C germination of three nutlet sources collected in the spring of 1994 .

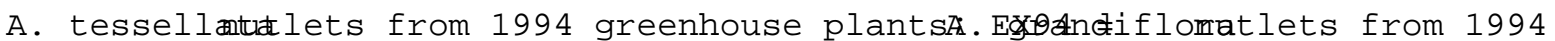
experimental population; C\&94gmandiflopiants from 1994 Carnegie Canyon natural population. For each separate germination period, nutlet sources with different let significantly diffepeft0at5. Error bars are one standard error 

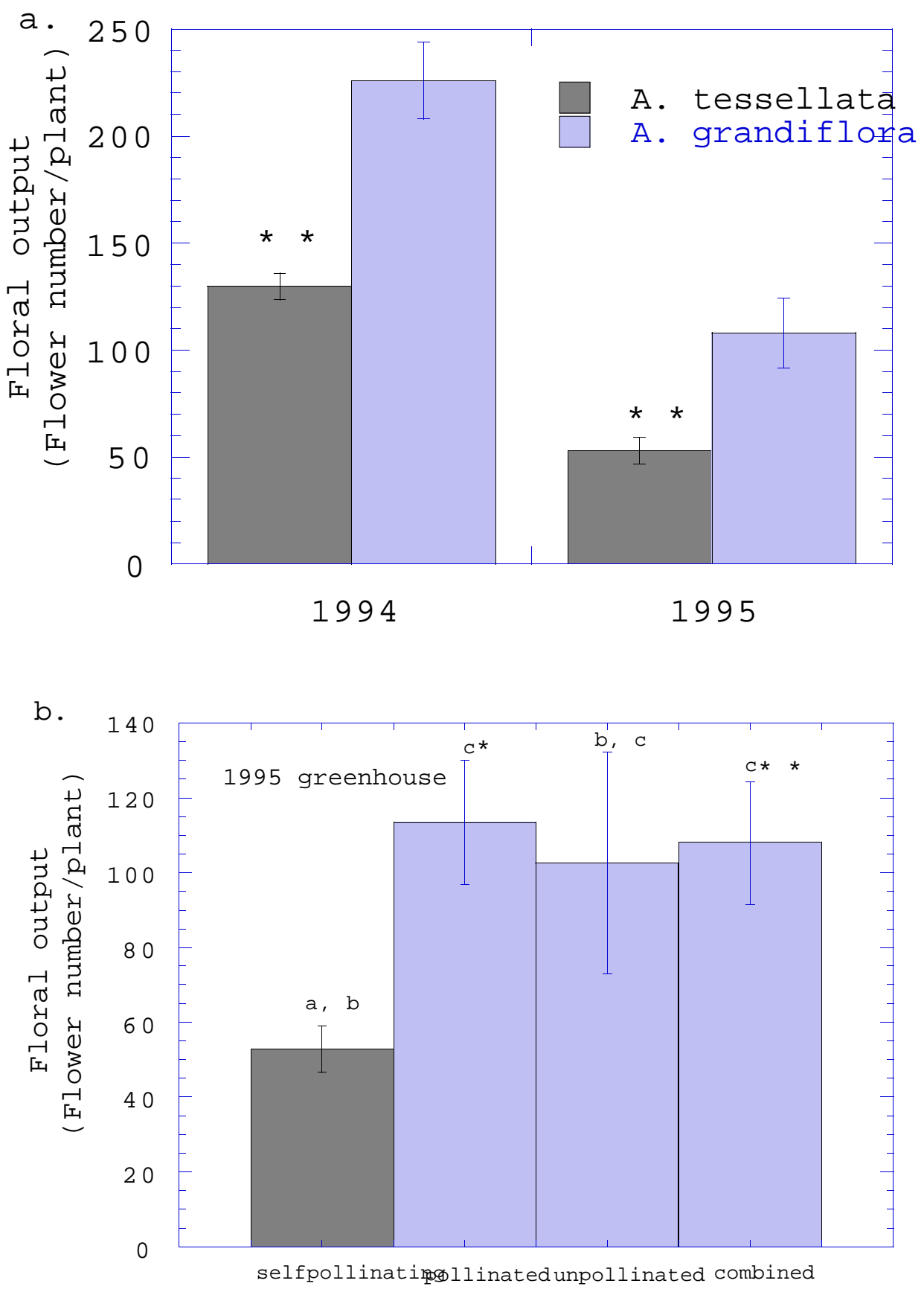

Figure 4. Floral output by greenhouAse-tgersosenl latnelA. grandiflora) Results of 1994 and 1995 comparisons. b) 1995 results in which. 5ofrarofifhopants were hand intemorph pollinated. * Significantly qi eereerte *t * Significantly different atp $=0.005$. Error bars are one standard error 


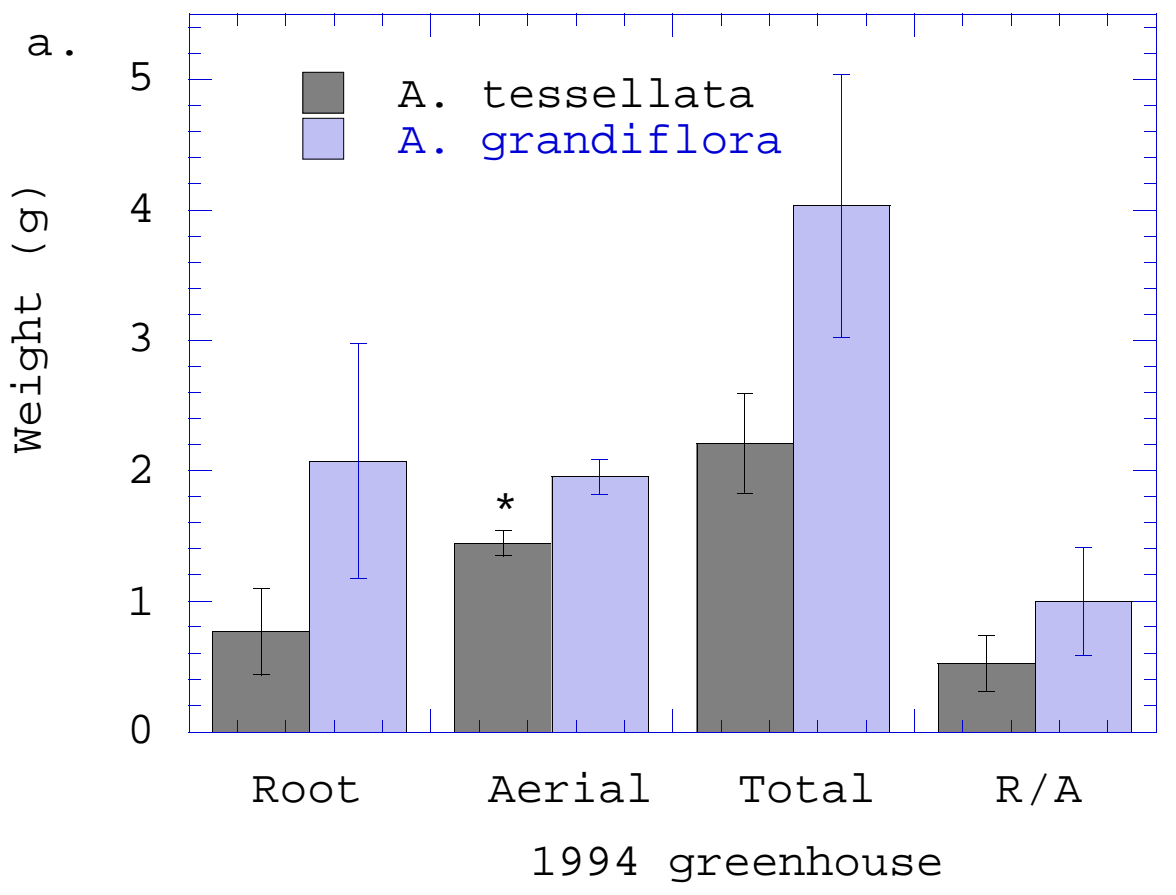

b.

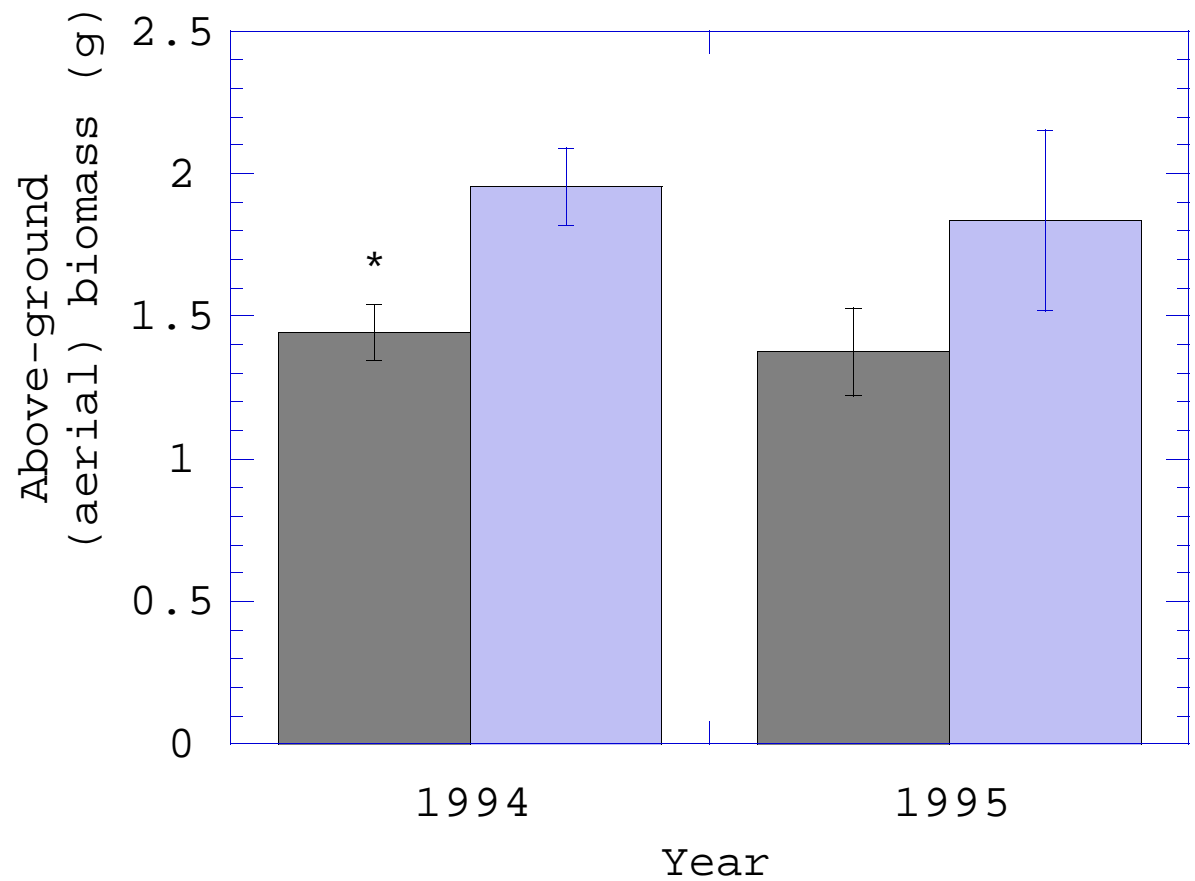

Figure 5. Distribution of dry biomass of greenhotesegldma. grandiflora plants. a) Root and above-ground (aerial) biomass grown in 1994, R/A = root:aerial b ratio; Ab)ove-ground (aerial) biomass in 1994 and 1995. * Significaptzy0d(1tferent at Error bars are one standard error 

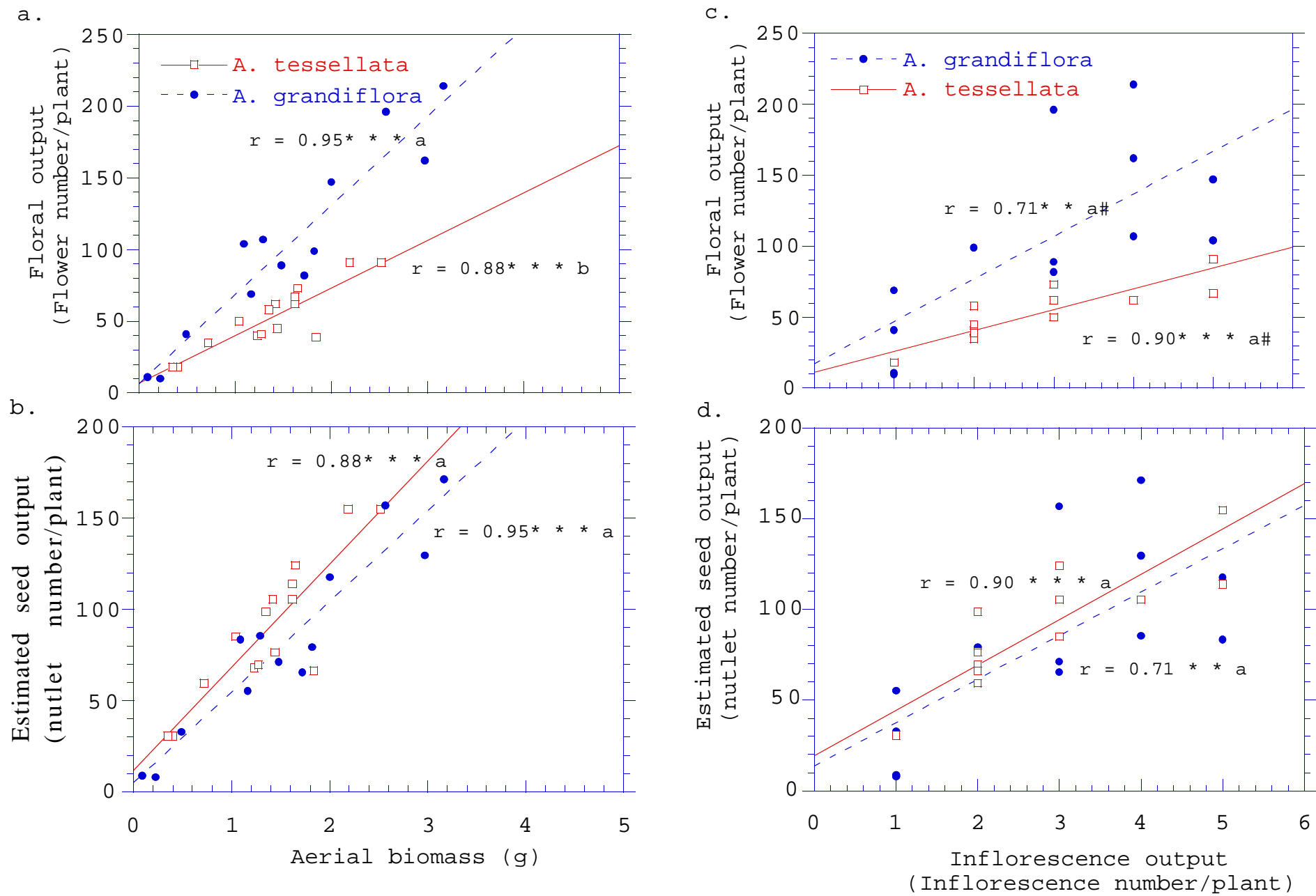

Figure 6. Reproductive attributes of 1995 gree hou b) Estimated seed output per aerial biomass. c) Floral output per inflorescence output. d) Estimated seed output per inf * * * Slope of line significantly differemt= foromolerosbopes with different letters are significantly different from each $\mathrm{p}=0.005$. Slopes with \# are significantly different prem0e日eh other at 

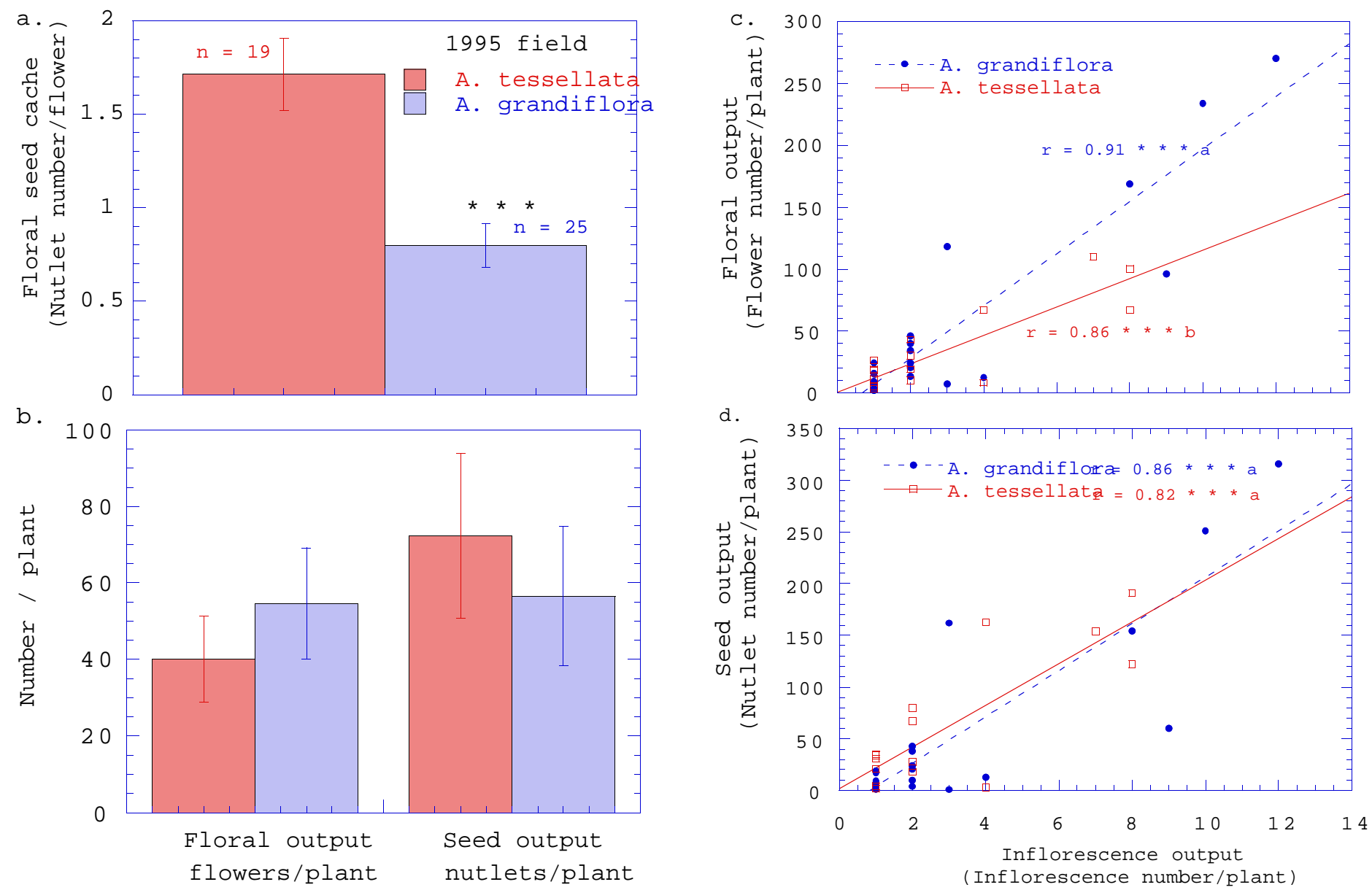

Figure 7. Reproductive attributes of 1995AfitedsgldmalA. grandiflopiants. a) Floral seed cache. b) Floral output and seed output. C) Floral output per inflorescence output. d) Seed output per inflorescence output. Error bars are one stan

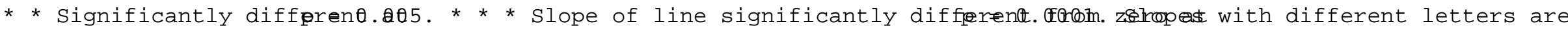
significantly different from each øthecont 


\title{
EFFECT OF LITTER AND SEED PREDATION ON THE GERMINATION OF A RARE ANNUAL FORB
}

\author{
TINA M. CARLSEN \\ Environmental Restoration Division, Lawrence Livermore Nation \\ Laboratory, Livermore, CA 94551 USA
}

Prepared for submission to Ecological Applications 
Abstract. The poor germination of A. grandiflora after a cont suggested that changes in microclimate or predation may control establishment of this endangered plant. A field experiment was $t$ conducted over two growing seasons to investigate the role of lit. and post-dispersal seed predation on A. grandiflora. The main t: consisted of either manually clearing all litter, or leaving the Two sub-treatments were established within each main treatment pl the cleared main plot, sub-treatments consisted of either coverin with aviary netting, or leaving the plot open. Within the litter 1 sub-treatments consisted of clipping the standing litter and repl the subplot, or leaving the standing litter intact. A subset of 1 instrumented to a depth of $1 \mathrm{~cm}$ with thermocouples to measure soi temperatures. During the 1993-94 growing season, litter cover (c standing) increased A. grandiflora germination. Soil temperatur moderated by litter cover. Some predation was detected, but its 1 not significant. In contrast, germination success during 1994-9. greatly affected by predation, and high germination was confined netted sub-treatment. Soil temperature extremes were not as grea this year, with little influence by litter cover. Thus, both mic alteration and predation can affect A. grandiflora germination, $k$ relative importance could vary depending on the timing of litter and germination, and the environmental conditions peculiar to a particular growing season.

Keywords: A. grandiflora, microclimate, soil temperature, germ: litter, predation. 


\section{INTRODUCTION}

The use of fire to manage grasslands and rangelands is becomir increasingly common (Humphrey 1949, Howe 1994, Glitzenstein et al In California, fire has been used to control exotic annual grass introduced from the Mediterranean region and to re-establish nati perennial bunch grasses (Menke 1992, George et al. 1992). Howeve: use of controlled burns in the late spring or early fall essentia all litter cover that may be present. This has the potential to a microclimate during the critical initial rains of the California which typically begins in late fall or early winter. The first $s$ rainfall (approx. $1.3 \mathrm{~cm}$, Heady 1956) stimulates annual seeds to and establish seedlings that grow vegetatively throughout the win months (Heady 1990). The lack of an insulating layer of litter u: results in extremes in soil temperatures and may result in reduct germination or post-germination seedling establishment (Heady 195 Evans and Young 1970, Evans and Young 1989).

If fire was a natural component of the original California per grasslands (Heady 1990), then native annual species probably evoli mechanisms to tolerate such microclimate variation. One such mechanism may be ample seed production or prolonged seed longevit ensures a sufficient number of seeds are present in the seed bank year of poor germination. There is evidence that germination anc germination seedling establishment of exotic grass species in the California grasslands is reduced as a result of unfavorable micr due to lack of litter cover, but sufficient seeds remain in the st maintain the population (Evans et al. 1975). Alternatively, the l litter layer may not result in lower seed germination. Many alie 
unaffected by the lack of a litter layer (Evans and Young 1970). annual species actually have higher seed germination without lit use the greater temperature extremes as an indication of the lack competitors in order to germinate (Evans et al. 1974, Rice 1985).

Invasive exotic species, agricultural conversion and suburban have placed many native annual species in peril. Many such taxa of conservation concern, and some have been formally listed as tr and endangered. In their most recent inventory of rare and enda] vascular plants of California (Skinner and Pavlik 1994), the Cali Native Plant Society (CNPS) listed 216 annual plant taxa found in grassland, foothill woodland, and cismontane woodland communitie California. Of these, 121 are on the CNPS list of most threatenec with 9 taxa federally listed as threatened or endangered. Ninety. highly threatened annual taxa occur in valley grassland or footh: woodland communities. Consequently, restoration efforts are cur: underway for several of these rare annual species (Skinner and $\mathrm{P}$ c 1994) .

There is evidence that competition by invasive exotic annual gl reduces some measure of fecundity in both annual and perennial ni species (Gordon and Rice 1993, Guerrant 1992, Pavlik et al. 1993). Therefore, the use of fire to control exotic annual grasses woulc appropriate. But it is during early restoration efforts, when pr rare annual plants may be limited, that poor germination as a res unfavorable microclimate may be particularly important. During period, there would likely be a lack of a significant seed bank tc species to span a year of low germination. Failure of the seeds could result in the loss of a significant percentage of the extar 
A loss of propagules occurred during restoration efforts on $\mathrm{Ar}$ grandiflora (Gray) Kleeb. ex Greene (Boraginaceae), a rare forb $\mathrm{n}$ the California grasslands. As part of a study on the competitive native perennial and exotic annual grasses on A. grandiflora, on 1992, a site selected for reintroduction of A. grandiflora underw controlled burn of $625 \mathrm{Btu} / \mathrm{ft}^{3}$ (heat per unit area), with a fireli $48 \mathrm{Btu} / \mathrm{ft} / \mathrm{s}$ (Carlsen et al. 1996). After the burn, 3800 A. grandi (seeds) were sown into the site. Significant rainfall did not oc December, at which point daytime temperatures were at or below fr Germination at both sites was below 5\%. This was very unexpected nutlets from the same source had laboratory germination of $80 \%$, reintroduction efforts using this nutlet source had field germini exceeding 60\% (Pavlik et al. 1993). The reintroduction site was s based on similar criteria, and was near the site where A. grandi naturally (Carlsen et al. 1996).

The low germination of A. grandiflora nutlets observed in the $f$ suggested that the fire created an unfavorable microclimate as a the total removal of the overlying litter. However, it could alsc result of predation, some unknown effect of the burn, or the site been unfavorable for A. grandiflora germination for other unknow: reasons. Therefore, a set of field experiments were conducted to the role of litter cover in the germination of A. grandiflora.

METHODS

Plot selection and design

In the fall of 1993, a $64-\mathrm{m}^{2}$ site was selected just outside of $t$ was burned in the fall of 1992. This site (elevation $\approx 320 \mathrm{~m}$ ) is i 
canyon where the originally described natural population of A. g: exists, located in the Altamont Hills of the inner Coastal Range, miles southeast of San Francisco, California. The property is pa Lawrence Livermore National Laboratory's Site 300, a high-explosi testing facility operated by the University of California for the Department of Energy. The site was selected to mimic the locatio A. grandiflora occurs naturally, in annual grassland bordered by woodland and coastal sage scrub. The aspect is north-west facinc slope ranging from 25\% to 72\% (average 56\%). The soil consists 0 drained, deep (about $1 \mathrm{~m}$ ) sandy clay loam. Herbaceous cover cons primarily of the annual exotic grasses Bromus hordeaceus L. and myuros (L.) C. Gmelin, with lesser amounts of B. diandrus Roth, B. madritensis ssp. rubens (L.) Husnot, Avena barbata Link, and $t$ forb Erodium cicutarium (L.) L'Hér. Native species include the ] bunch grass Poa secunda J. S. Presl, and several forbs and legum including Clarkia spp., miniature lupine (Lupinus bicolor Lindle purple owl's clover (Castilleja exserta (A. A. Heller) Chuang \&

On 9 November 1993 the site was split into two 4 x $8 \mathrm{~m}$ main plot main plot cover treatments consisted of clearing the litter (desi "cleared" main plot treatment), or retaining the litter (designat "litter" main plot treatment). Litter is defined as the previous leaves, and inflorescences of plants (primarily herbaceous) sens and Young (1970). The treatments were assigned to the main plots randomly. The "cleared" treatment was applied by manually remov of the litter down to the bare mineral soil. Six $0.25-\mathrm{m}^{2}$ sub-plot established in each main plot. Within each main plot, two sub-tr were assigned to the six sub-plots, replicated three times. The 
treatments within the litter main plot consisted of 1) the litter standing litter (the "standing" sub-treatment), and 2) the litter then placed back onto the plot (the "clipped" sub-treatment). Wit cleared main plot treatment, the two sub-plot treatments consistec plots covered with aviary netting (the "netted" sub-plot treatment plots left open (the "open" sub-plot treatment). Because of a lir A. grandiflora nutlet supply, the main plot treatments were not $r$ The experiment was repeated in the fall of 1994. This time, tw were selected. The first site was located at site 300 within the was burned in the fall of 1992 (the "S300" site). The second site on an ecological reserve adjacent to site 300 belonging to the Ca: Department of Fish and Game (the "CDFG" site). Efforts to establ A. grandiflora at this site had been underway for several years ( 1994). The experimental design for each site was identical to thi for the previous year's experiment except that each main treatmer replicated three times in a randomized complete block design. A used to remove litter from the cleared main plot treatments.

\section{Nutlet source and sowing}

The nutlet source used in 1993-94 was the same as used in the $f$ 1992. These nutlets were originally collected from the nearby na population, and further propagated at the University of Californi. in 1988 (known as the DA88 source). Each plot was sown with nine A. grandiflora nutlets at a depth of $1 \mathrm{~cm}$ equidistantly spaced at intervals in 3 rows. There had been no fall rain up to the time. establishment. The following day (10 November 1993), there was 1. rainfall. 
The A. grandiflora nutlets used in 1994-95 were obtained in the of 1994 from plants established as part of a competition experime] the site that had been burned in the fall of 1992 (the "Ex94" nutl Nutlets were air dried after collection and maintained at room t $\epsilon$ throughout the summer. Nutlets were sown on 5 October 1994 at S3C on 6 October 1994 at CDFG. The first significant rain $(1.52 \mathrm{~cm}) \mathrm{c}$ 7 November 1994.

Microclimate instrumentation and data collection

In 1993, all plots, with the exception of the netted plots, wert instrumented to a depth of $1 \mathrm{~cm}$ with thermocouples on 15 November Campbell Scientific CR-7 data logger was used to obtain soil temp data. Temperature data were collected once per hour over a 24-ho for one set of standing, clipped and open sub-plots on 29 November again on 29 December 1993. A. grandiflora germination data were through 30 November 1993. At this time the aviary netting was ren The number of established reproductive plants was recorded on 15 1994. On 5 May 1994, neighbor biomass was collected from $0.1 \mathrm{~m}^{2} \mathrm{i}$ center of each plot, dried at $65{ }^{\circ} \mathrm{C}$ and weighed.

In 1994, all subplots at the s300 site were instrumented with thermocouples at a depth of $1 \mathrm{~cm}$. Germination was carefully recr from 7 November 1994 through 13 December 1994. A Campbell Scienti CR-7 data logger was used to continuously read the soil temperatu rate of once per hour. The aviary netting was removed at the end period. The number of established reproductive plants was recor March 1995. Neighbor biomass was collected from the $0.1 \mathrm{~m}^{2}$ in th 
of each plot on 30 May 1995 at the CDFG site, and on 1 June 1995 at site. All biomass was dried at $65{ }^{\circ} \mathrm{C}$ and weighed.

Daily minimum and maximum temperatures were also obtained for both 1993 and 1994 from the nearby Castle Rock Radiation Lab meteorological station (Station number B80 1583-00). This station maintained at Site 300 for the State of California Department of $W$ Resources. Although the station is not collocated at the experim temperature data from this station were used to evaluate relative differences in air temperature between the two years.

\section{Data analysis}

Because each main treatment did not contain identical sub-trea the experiment could not be analyzed as a traditional split-plot Therefore, the main treatments (litter and cleared) were first ar. two separate experiments, each containing two treatments (that is and standing treatments within the litter experiment, and open an treatments within the cleared experiment). While this makes com. across "experiments" difficult (such as comparing the open treatr clipped treatment), some general observations are possible. Next investigate the effect of cover (the main treatment, that of litt $\epsilon$ if no significant differences were observed between sub-treatment each main treatment "experiment", then all sub-plots within a ma: were pooled and considered sub-samples of the main plot. The exr was then analyzed as a two treatment (litter vs. cleared) randomi complete block with each block containing 6 sub-samples per treat However, if significant differences were observed between the sub treatments within the main treatment, then only the open sub-plot 
the cleared main plot, and the standing sub-plots within the main main plot were used in the analysis. This resulted in a two trea randomized complete block experiment, with each block containing samples per treatment. Because the main plots were not replicat $\epsilon$ the 1993-94 season, treatment in this case is confounded with loc, possible that any observed treatment effect is actually a locatior. small study site in 1993-94 was uniform with respect to aspect, $\mathrm{s}$ vegetation cover and soil type. Therefore, we believe any "treatn to be meaningful. Statistical analyses were conducted using the (General Linear Model) procedure of SAS (SAS 1990). All percenta were arcsine square-root transformed prior to statistical analysi 1989). Results were considered significant if the alpha value wa or equal to 0.05 .

\section{RESULTS}

On 30 Nov 1993 the germination of A. grandiflora nutlets was no significantly different between sub-treatments within each main $t$ (Fig 1a). The open sub-treatment resulted in the lowest amount 0 germination (4\%), whereas the clipped sub-treatment resulted in $t$ highest amount of germination (52\%). The litter main treatment $\mathrm{r}$ significantly greater A. grandiflora germination (48\%) compared $t$ cleared main treatment (9\%, Fig. 1b) using the pooled sub-treatme as sub-samples of each main treatment (Table 1).

There was no significant difference in A. grandiflora nutlet germination between the two sites in 1994, and therefore the data pooled to increase the power of the analysis. This resulted in $s$ each main treatment. At the end of the germination monitoring pr 
A. grandiflora nutlet germination in the netted sub-treatment wit cleared main treatment was significantly greater than that observ open sub-treatment (33\% vs. 24\%, Fig. 1C). Sub-treatments within main treatment were not significantly different at the end of the germination monitoring period (Table 1), although they were sign: different earlier in the germination period (Fig. 1c). The nette treatment resulted in the greatest amount of A. grandiflora nutle germination (33\%), whereas the standing sub-treatment resulted ir. lowest amount of germination (16\%). Because significant differer detected between sub-treatments, only the open sub-plots within tr main plots and the standing sub-plots within the litter main plot used in the statistical analysis on the effect of cover on A. gra germination. Although the cleared main treatment had greater A. grandiflora nutlet germination compared to the litter main tre (24\% vs. 16\%, Fig. 1d), this difference was not significant at the germination monitoring period (Table 1). However, significant d between these two treatments were detected earlier in the germina period (Fig. 1d). The difference in nutlet germination between $t$ treatments observed in 1994 was not as great as that observed in 1 maximum amount of A. grandiflora nutlet germination observed in: was lower than that observed in 1993 (33\% vs. 52\%), whereas the m amount of germination was greater (16\% vs. 4\%). A significant b] sub-treatment interaction was observed in 1994, which was the res. netted sub-plots in one block at each site exhibiting lower A. gr nutlet germination than observed in the open sub-treatments in th block. 
Differences in soil temperature between the sub-treatments wert detected (Fig. 2). In 1993, 19 days after initial rainfall, thes clipped sub-treatments resulted in cooler temperatures during the part of the day (by approx. $-1.5^{\circ} \mathrm{C}$ ), and warmer temperatures dur coldest part of the day (by approx. $+1{ }^{\circ} \mathrm{C}$ ) as compared to the open treatment (Fig. 2a). This difference could still be detected $49 \dot{c}$ initiating rainfall, although the temperature differential durinç part of the day had reduced to $0.5{ }^{\circ} \mathrm{C}$ (Fig. 2b). In general, this observed in 1994 although the temperature differential was not as One day after the germination initiating rainfall, the clipped su was approximately $1{ }^{\circ} \mathrm{C}$ cooler than the netted sub-treatment durinc warmest part of the day, with the open and standing sub-treatment between (Fig. 2C). This differential was maintained 9 days latte In both years, the clipped sub-treatment produced more uniform sc temperatures than the standing sub-treatment, as indicated by the variation. In general, minimum air temperatures in 1994 were not as in 1993 during the first 25 days after the germination initiat (Fig. 3). During this period, the average minimum air temperatu 1993 was $1.3{ }^{\circ} \mathrm{C}\left(\mathrm{SE} 3.9^{\circ} \mathrm{C}\right)$, while in 1994 it was $2.8{ }^{\circ} \mathrm{C}\left(3.8{ }^{\circ} \mathrm{C}\right)$.

The percentage of reproductive A. grandiflora plants establish following spring was not significantly affected by the main treat either year (Fig. 4, Table 2). The percentage of established plal generally lower in the spring of 1995 as compared to the spring of Again, there were no site differences in 1995. In 1994, the clipl treatment resulted in the greatest establishment (63\%), with the, treatment exhibiting the lowest (22\%), although these differences statistically significant (Fig. 4a). However, in 1995, there wer 
differences in adult establishment between sub-treatments within treatments (Fig. 4b). The netted sub-treatment resulted in the gr amount of adult establishment (25\%), with the standing sub-treatm exhibiting the lowest (12\%). The significant block $\mathrm{X}$ sub-treatme: interaction was again the result of the same two blocks within th sub-treatments which exhibited low germination, this time exhibit establishment compared to the open sub-treatments within the same blocks.

The main cover treatments did not significantly affect the amor final dry neighbor biomass collected from the plots in 1994 (Fig. However, in 1995, the litter main treatment had significantly gre. biomass than the cleared main treatment (33 vs. $20 \mathrm{~g} / 0.1 \mathrm{~m}^{2}$, Fig. 3). Sub-treatments within the main treatments were not significa different. In general, a greater amount of final dry biomass wa: in 1995 as compared to 1994 (an average maximum of $37 \mathrm{vs}$. 10 g/0.1

\section{DISCUSSION}

Litter cover has been shown to be an important factor in the $g \epsilon$ and establishment of annual plants in grassland communities. It reduce high temperatures during the day which could result in the critical soil moisture. During the night, litter helps prevent $t$ from dropping below levels which could inhibit cellular metaboli: promote dormancy. Evans and Young (1970) found litter cover to $r$ surface soil temperatures $9{ }^{\circ} \mathrm{C}$ lower during the warmest part of $t$ and $5{ }^{\circ} \mathrm{C}$ higher at the coldest part of the day. At a depth of 1.5 temperature differentials were $2{ }^{\circ} \mathrm{C}$ and $1{ }^{\circ} \mathrm{C}$, respectively. They germination of alien grasses to be generally enhanced by litter c 
the germination of alien forbs was unaffected. In contrast, litt apparently can increase the germination of the native forb, A. g] as was observed in the fall of 1993. Litter cover, either clippec increased germination during the first few weeks after the initic Soil temperatures at $1 \mathrm{~cm}$ was in the range of that observed by Eve Young (1970) and is consistent with the hypothesis that litter cor moderates extremes in soil temperature. Clipped litter apparentl moderates soil temperatures more effectively than standing litter due to more even coverage of the soil surface. In 1993, the soil data were not collected until 19 days after the initial rainfall minimum air temperatures were fairly high (Fig. 3). Had soil te data been collected earlier (when air temperatures were colder), possible the soil temperature differential between the sub-treatms during the coldest part of the day would have been even greater. temperatures are a major limiting factor in annual grass germiné (Evans and Young 1970, Evans and Young 1989). Although many anni species (particularly exotics) will germinate over a wide range c temperatures, temperatures below $2{ }^{\circ} \mathrm{C}$ are generally inhibitory (E. Young 1989, Young et al. 1973).

The apparent reversal of the litter cover effect on germinatior. in the fall of 1994 (in which greater germination was observed in main plots compared to the litter plots) could have been the resu: factors. First, temperatures were slightly warmer during the 19c germination period as compared to 1993 (Fig. 3). Second, the sma of litter left after using a hoe to clear the main plots may have sufficient to prevent temperature-induced reductions in germinati of these factors could have contributed the smaller temperature $\dot{c}$ 
observed between the sub-treatments during 1994 as compared to 199 Finally, the initial rainfall did not occur for a full month afte were sown, whereas in 1993 it occurred the following day. This p longer opportunity for predation of A. grandiflora nutlets by gra birds and small rodents.

Nutlet predation was more important than soil temperature duri 1994-95 as compared to 1993-94. Herbivory on seedlings was also v evident in the non-netted sub-plots in 1994-95. Although plots we frequently during the initial germination period, the lower appar germination observed in the open sub-plots as compared to the nett plots may have been due to a combination of nutlet predation and herbivory. Predation of seeds and grazing on shoots and roots by common in western grasslands (Borchert and Jain 1978, Detling anc Painter 1983, Hoffmann et al. 1995). There was also a suggestion predation in 1993-94, as the netted sub-plots resulted in a large of germination compared to the open sub-plots, however, this diff was not statistically significant. In 1994-95, the standing sub-] exhibited both the lowest amount of A. grandiflora germination an lowest number of reproductive plants. Seed-eating birds such as sparrows (Passerculus sandwichensis) and towhees (Pipilo ssp.) h observed foraging in the study area. Granivorous mammals such a mice (Peromyscus maniculatus), Heermann's kangaroo rats (Dipodol heermanni) and valley pocket-gophers (Thomomys bottae) have been trapped out of this and other A. grandiflora reintroduction sites rodents often preferentially forage in areas that provide some pr from predators (Bartholomew 1970), and may have preferred the sta cover sub-treatment plots over the other sub-treatment plots. In 
the relatively large A. grandiflora nutlets (approx. $4 \mathrm{mg}$ ), would attractive to granivores (Hoffmann et al. 1995).

During the 1993-94 growing season, germination of A. grandiflo nutlets continued after the initial germination period, as eviden increase in established adult reproductive plants relative to the seedling cohort. In contrast, there were fewer established adult during 1994-95 compared with to the initial seedling cohort. The adult population was due in part to ongoing seedling herbivory an due to greater mortality because of the more intense neighbor com (there was significantly greater neighbor biomass in 1994-95 than 94, composed mostly of exotic annual grasses). A. grandiflora hi shown to compete poorly with exotic annual grasses (Pavlik et al. Carlsen et al. 1996). Although in both years there was a lack of statistically significant main treatment effect on adult plant es there were large differences in the mean values. Removal of the enclosures after the initial germination period subjected all A. plants to potential herbivory. This may have increased the varia observed in the final plant establishment.

The generally lower germination observed in 1994-95 as comparec 1993-94 may have also been an effect of nutlet source. The nutlet 1993-94 had been stored for several years, and had laboratory gerl exceeding 70\% (Carlsen and Pavlik 1996). This germination was hi synchronous, with most of the germination occurring during the $f$ days. The 1994-95 nutlet source had been collected in the spring These nutlets were kept at room temperature, and did not experien extremely warm summer temperatures typical of the in situ seed bi Such warm temperatures are often necessary to complete afterripe 
winter annuals (Baskin and Baskin 1976). Laboratory germination nutlet source, conducted in January 1995, was approximately 45\% a occurred over a period of 28 days (Carlsen and Pavlik 1996). Becé large amount of replication conducted in the 1994-95 experiment, unlikely the nutlet source impacted the cover effects, although i undoubtedly added to the variation observed in the resulting data.

These data suggest that both microclimate alteration, nutlet pu and seedling herbivory can affect germination and establishment c reproductive plants after litter cover removal. The existing cli conditions at the time of litter removal, the timing of germinati condition of the predator population can determine the levels of mortality that affects A. grandiflora nutlets and seedlings. It both factors operated during the fall and winter of 1992-93 when A. grandiflora germination and plant establishment was less than Nutlets were exposed to predation for well over a month, and wher. finally occurred, air temperatures were extremely low. Thus, ca be exercised when using fire as a tool for the restoration of rar forbs. In the context of California annual grasslands, fire is $c$ control exotic annual grasses. Consideration should be given to surrogate for the litter cover after a controlled burn, particula of a rare plants seeds occurs subsequent to the burn. The use of other comparable mulching material could both moderate temperatu possibly reduce the risk of predation, particularly from birds. Unfortunately, straw may provide cover for rodent populations, th potentially increasing the risk of rodent predation. However, pr litter lying on the ground surface appears to provide less protec rodents than standing litter. In very cold years, the risk from 
microclimate conditions may outweigh the risk from rodent predatj a meaningful way of predicting such a climate does not readily cc mind.

If the restoration goal is focused solely on the establishment forbs, an alternative to the use of fire, at least on a fairly smi application of a dilute solution of grass-selective herbicide. W mid-winter, this has been shown to reduce annual grass competiti without completely removing the protective litter layer (Pavlik et However, unless applied manually in a very careful, precise mann use of grass-selective herbicides can reduce native perennial gri limits the utility of such herbicides on a large scale, and cleas them inappropriate if the restoration goal is to maintain native along with native forbs. However, the combined use of grass-sele herbicides, fire and appropriate mulch may prove a powerful rest, tool. Herbicides could be used initially on a small-scale to est forb populations. Once the rare forb population has developed a large seed bank to buffer against the occasional poor germinatior. could be periodically used on a larger scale to maintain native 


\section{ACKNOWLEDGMENTS}

I would like to thank Steve Gregory, Erin Espeland, Merry Jones Peter Beesley for technical assistance. I also thank Drs. Bruce Menke and Kevin Rice for technical input throughout the project, for review of the manuscript. Work performed under the auspices

S. Department of Energy by Lawrence Livermore National Laboratory under Contract W-7405-Eng-48 and funded by a grant from the Labori Directed Research and Development program.

\section{LITERATURE CITED}

Bartholomew, B. 1970. Bare zone between California shrub and gras communities: the role of animals. Science 170:1210-1211.

Baskin, J. M. and C. C. Baskin. 1976. High temperature requiremer. afterripening in seeds of winter annuals. New Phytology 77:619Bouchert, M. I. and S. K. Jain. 1978. The effect of rodent seed p four species of California annual grasses. Oecologia 57: 406-4:

Carlsen, T. M. and B. M. Pavlik. 1996. The role of intrinsic fact reproductive ecology of an endangered plant. Submitted to Biolc Conservation.

Carlsen, T. M., J. W. Menke, and B. M. Pavlik. 1996. Competitive suppression of a rare annual forb by native perennial and exot grasses. Submitted to Ecology.

Detling, J. K. and E. L. Painter. 1983. Defoliation responses of, wheatgrass populations with diverse histories of prairie dog $\subseteq$ Oecologia 57: 65-71. 
Evans, R. A., B. L. Kay and J. A. Young. 1975. The microenvironm dynamic annual community in relation to range improvement. Hilgardia 43: 79-102.

Evans, R. A., J. A. Young and B. L. Kay. 1974. Germination of wil annual species from a rangeland community treated with paraque Weed Science $22(2): 185-187$.

Evans, R. A. and J. A. Young. 1970. Plant litter and establishmer. annual weed species in rangeland communities. Weed Science 18 ( $697-703$

Evans, R. A. and J. A. Young. 1989. Characterization and analysi: abiotic factors and their influences on vegetation. Pages 13-28 Huenneke and H. A. Mooney, editors. Grassland Structure and Function: California Annual Grassland. Tasks for Vegetation S, 20. Kluwer Academic Publishers, Dordrecht, The Netherlands.

George, M. R., J. R. Brown and W. J. Clawson. 1992. Application , nonequilibrium ecology to management of Mediterranean grasslar Journal of Range Management 45:436-440.

Glitzenstein, J. S., W. J. Platt and D. R. Streng. 1995. Effects, and habitat on tree dynamics in North Florida longleaf pine sa Ecological Applications 65(4): 441-476.

Gordon, D. R. and K. J. Rice. 1993. Competitive effects of grassl on soil water and blue oak (Quercus douglasii) seedlings. Ecol 74 (1) : 68-82. 
Guerrant, E. O. 1992. Genetic and demographic considerations in t sampling and reintroduction of rare plants. Pages 321-344 in $P$ Fiedler and S. K. Jain, editors. Conservation Biology: the thec practice of nature conservation, preservation and management. Chapman and Hill, New York, New York, USA.

Heady, H. F. 1956. Changes in a California annual plant community induced by manipulation of natural mulch. Ecology 37(4): 798-81 Heady, H. F. 1990. Valley grassland. Pages 491-514 in M. G. Barbr J. Major, editors. Terrestrial Vegetation of California. Calif Plant Society, Sacramento, California, USA.

Hoffmann, L. A., E. F. Redente and L. C. McEwen. 1995. Effects of seed predation by rodents on shortgrass establishment. Ecologi, Applications $5(1): 200-208$.

Howe, H. F. 1994. Response of early- and late-flowering plants to in experimental prairies. Ecological Applications 4(1): 121-13: Humphrey, R. R. 1949. Fire as a means of controlling velvet mesqu burroweed, and cholla on southern Arizona ranges. Journal of Management 2: 175-182.

Krebs, C. J. 1989. Ecological Methodology. Pages 449-451. Harper ( Publishers, New York, NY, USA.

Menke, J. 1992. Grazing and fire management for native perennial restoration in California grassland. Fremontia 20(2):22-25.

Pavlik, B. M., D. L. Nickrent and A. M. Howald. 1993. The recover endangered plant. I. Creating a new population of Amsinckia grandiflora. Conservation Biology $7(3): 510-526$. 
Pavlik, B. M. 1994. Tales of success and failure: trends in natur reintroduced populations of Amsinckia grandiflora under differ management regimes. Prepared for the Endangered Plant Program California Department of Fish and Game, Sacramento, CA, USA.

Rice, K. J. 1985. Responses of Erodium to varying microsites: the germination cueing. Ecology 66:1651-1665.

SAS. 1990. SAS/STAT ${ }^{\circledR}$ User's Guide, Version 6, Fourth Edition, Vo Pages 891-996. SAS Institute Inc., Cary, NC, USA.

Skinner, M. and B. M. Pavlik. 1994. Inventory of rare and endange vascular plants of California, 5th edition. California Native I Society, Sacramento, CA, USA.

Young, J. A., R. A. Evans and B. L. Kay. 1973. Temperature requi for seed germination in an annual-type rangeland community. Agronomy Journal 65: 656-659. 
TABLE 1. ANOVA on A. grandiflora percent germination at end of germination monitoring period. All data were arcsine transformed prior to analysis.

\begin{tabular}{|c|c|c|c|c|c|}
\hline Source & $\mathrm{DF}$ & SS & MS & F & $\mathrm{p}$ \\
\hline Germination on 30 & November & $1993^{a}$ & & & \\
\hline Cover & 1 & 2923.44 & 2923.44 & 14.34 & 0.0036 \\
\hline Error & 10 & 2037.75 & 203.78 & & \\
\hline Germination on 13 & December & $1994^{\mathrm{b}}$ & & & \\
\hline Cover & 1 & 243.64 & 243.64 & 1.84 & 0.1880 \\
\hline $\mathrm{Block}$ & 5 & 848.04 & 169.61 & 1.28 & 0.3056 \\
\hline Block X Cover & 5 & 596.83 & 119.37 & 0.90 & 0.4965 \\
\hline Error & 23 & 3043.31 & & & \\
\hline \multicolumn{6}{|c|}{ Cleared Experiment } \\
\hline Subtrt & 1 & 572.17 & 572.17 & 7.12 & 0.0135 \\
\hline $\mathrm{Block}$ & 5 & 831.38 & 166.28 & 2.07 & 0.1049 \\
\hline Block $\mathrm{X}$ subtrt & 5 & 1663.40 & 332.68 & 4.14 & 0.0075 \\
\hline Error & 24 & 1929.87 & 80.41 & & \\
\hline \multicolumn{6}{|l|}{ Litter Experiment } \\
\hline Subtrt & 1 & 353.54 & 353.54 & 3.25 & 0.0866 \\
\hline $\mathrm{Block}$ & 5 & 330.93 & 66.19 & 0.61 & 0.6948 \\
\hline Block $\mathrm{X}$ subtrt & 5 & 481.05 & 96.21 & 0.88 & 0.5101 \\
\hline Error & 20 & 2177.54 & 108.88 & & \\
\hline
\end{tabular}

a All sub-plots within each main plot were combined.

b only open and clipped sub-plots were considered. 
TABLE 2. ANOVA on A. grandiflora percent establishment of reproductive plants All data were arcsine transformed prior to analysis.

\begin{tabular}{|c|c|c|c|c|c|}
\hline Source & $\mathrm{DF}$ & SS & MS & $F$ & $\mathrm{p}$ \\
\hline \multicolumn{6}{|c|}{ Establishment on 15 March 1994a } \\
\hline Cover & 1 & 461.28 & 461.28 & 1.87 & 0.2016 \\
\hline Error & 10 & 2469.26 & 246.93 & & \\
\hline \multicolumn{6}{|c|}{ Establishment on 25 March $1995^{\text {b }}$} \\
\hline Cover & 1 & 388.15 & 388.15 & 2.07 & 0.1645 \\
\hline $\mathrm{Block}$ & 5 & 429.65 & 85.93 & 0.46 & 0.8032 \\
\hline Block X Cover & 5 & 1023.62 & 204.72 & 1.09 & 0.3933 \\
\hline Error & 22 & 4130.06 & 187.73 & & \\
\hline \multicolumn{6}{|l|}{ By Cover: Cleared } \\
\hline Subtrt & 1 & 403.01 & 403.01 & 3.78 & 0.0637 \\
\hline $\mathrm{Block}$ & 5 & 339.49 & 67.90 & 0.64 & 0.6738 \\
\hline Block X subtrt & 5 & 2244.82 & 448.96 & 4.21 & 0.0069 \\
\hline Error & 24 & 2559.32 & 106.64 & & \\
\hline \multicolumn{6}{|l|}{ By Cover: Litter } \\
\hline Subtrt & 1 & 1000.20 & 1000.20 & 6.47 & 0.0198 \\
\hline $\mathrm{Block}$ & 5 & 601.74 & 120.35 & 0.78 & 0.5772 \\
\hline Block $X$ subtrt & 5 & 445.48 & 89.10 & 0.58 & 0.7174 \\
\hline Error & 19 & 2936.19 & 154.54 & & \\
\hline
\end{tabular}

a All sub-plots within each main plot were combined.

b only open and clipped sub-plots were considered.

TABLE 3. ANOVA on final dry neighbor biomass.

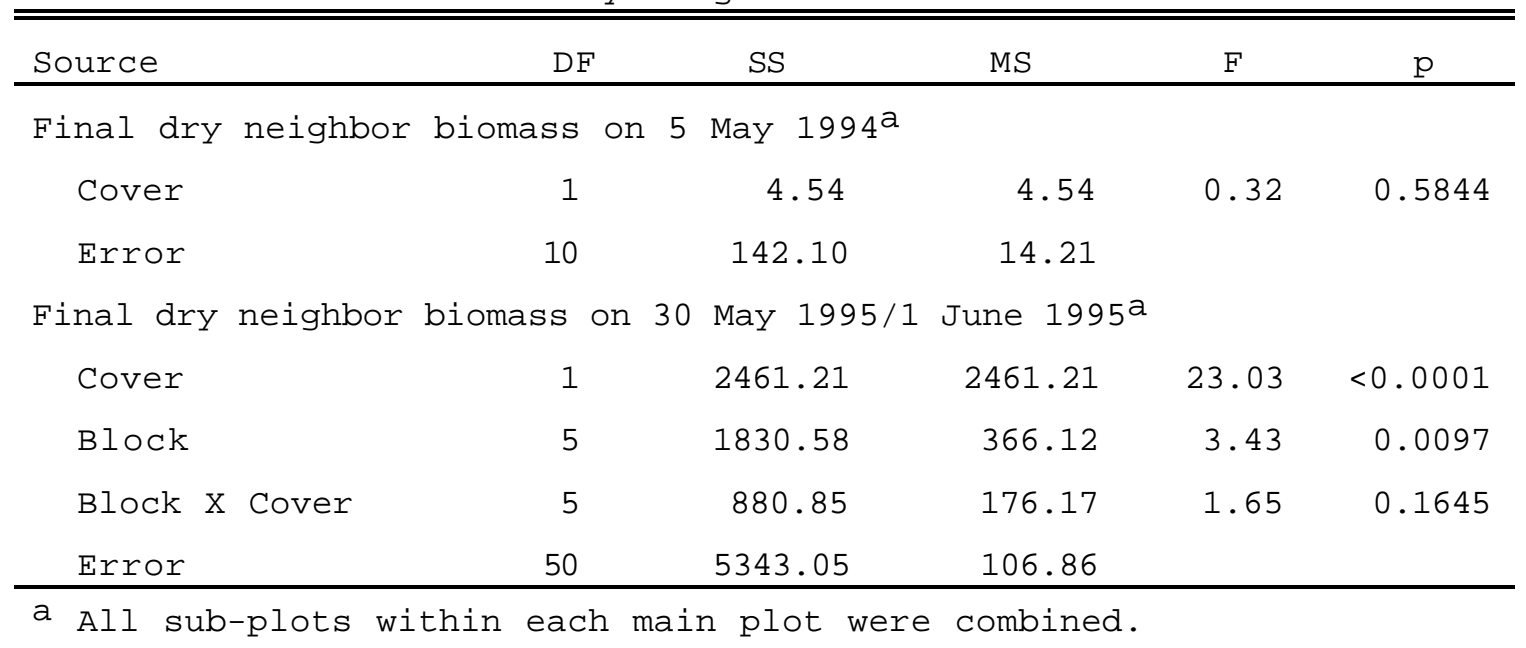



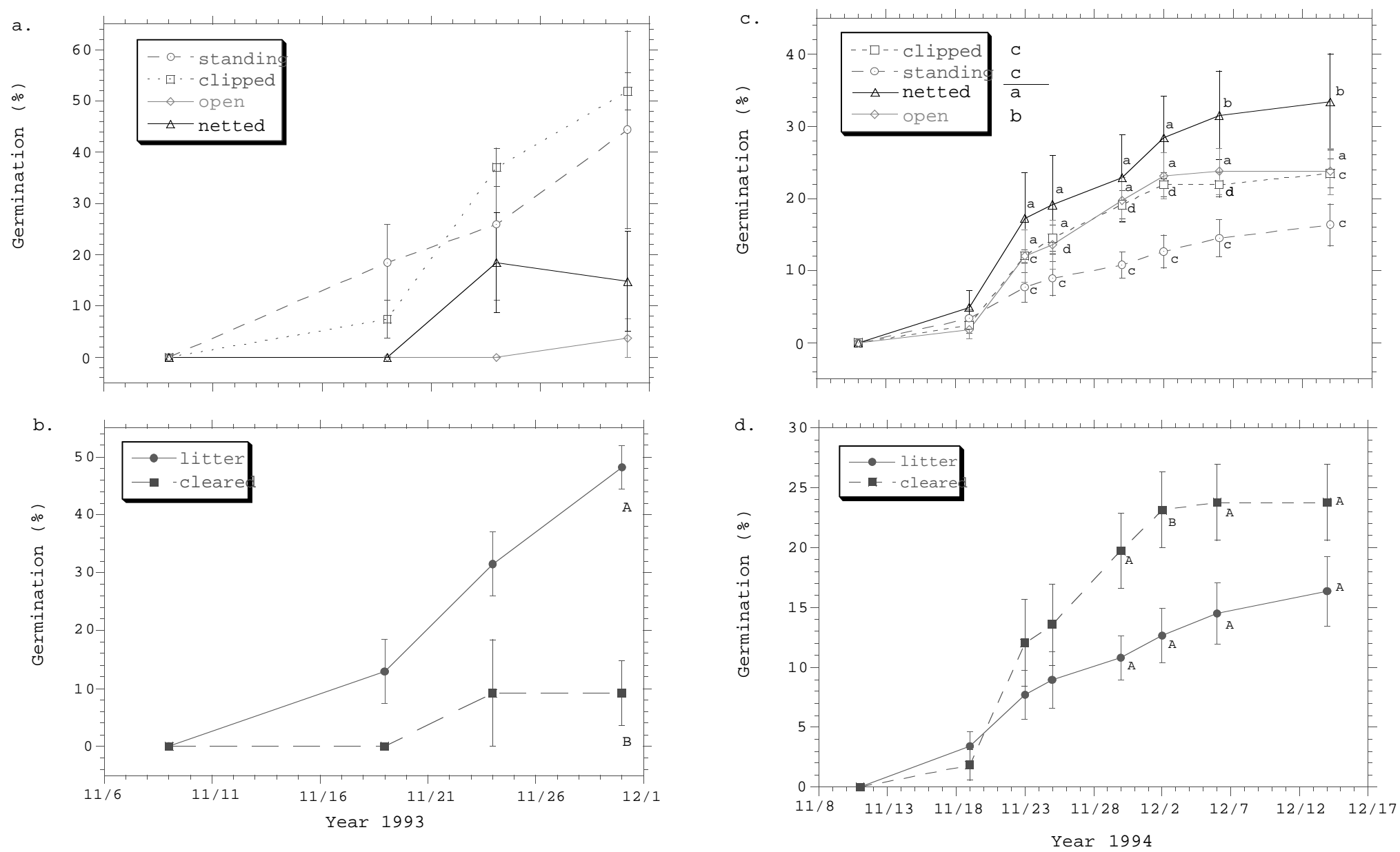

FIG. 1A. grandiflogarmination in (a) the fall of 1993 by sub-treatments ( $n=3$ ), (b) the fall of 1993 by main treatments of 1994 by sub-treatments $(\mathrm{n}=18)$, and (d) the fall of 1994 by main treatment using only the open and standing sub-treatm Error bars are one standard e\$rloxtreatments within main treatments with different lower case letters are significantly d p=0.05. Main treatments with different capital letters are signipfilabht.ly different at 

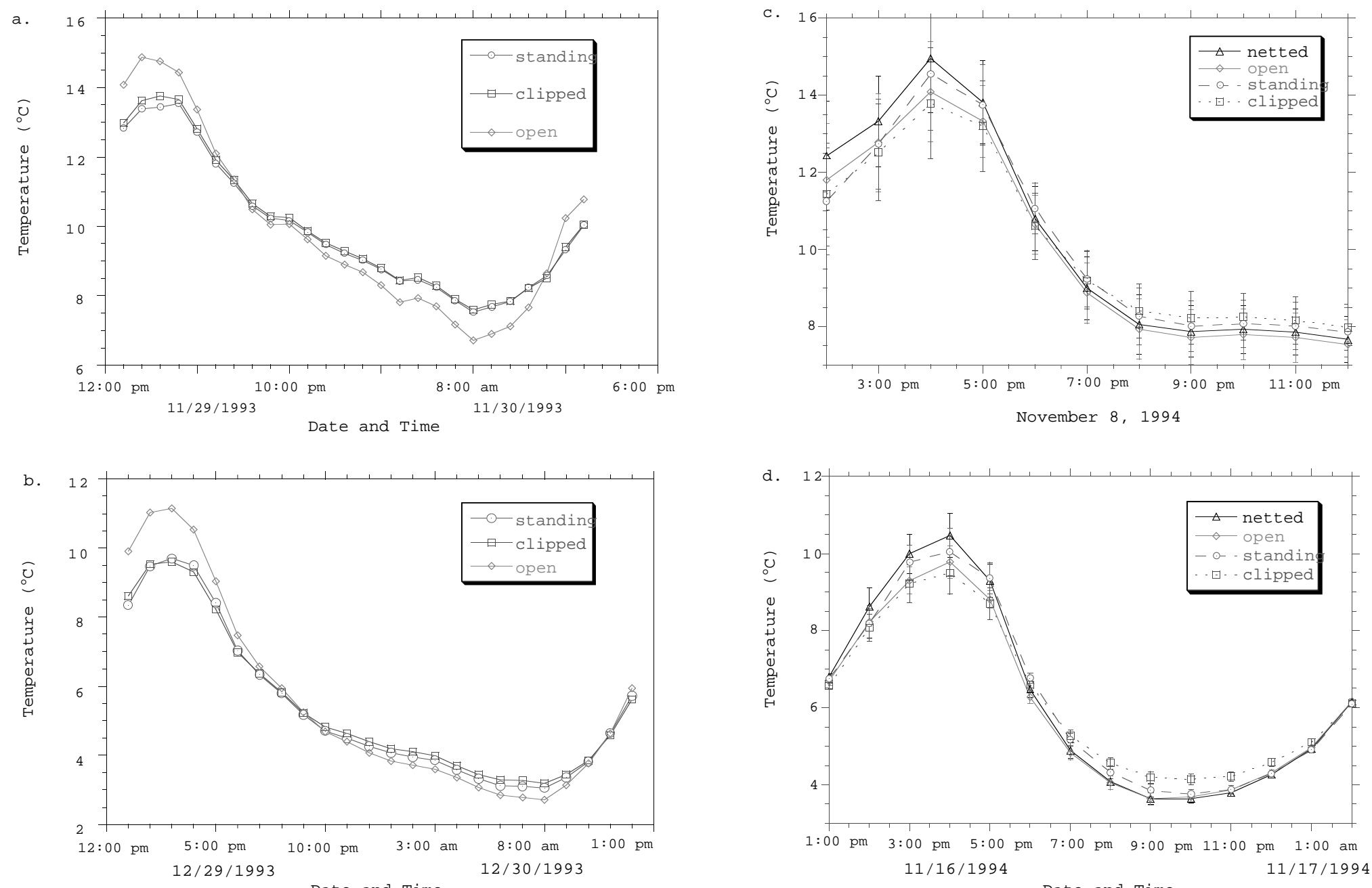

FIG. 2. Effect of sub-treatments on soil temperature at $1.5 \mathrm{~cm}$. (a) 19 days after initial rainfall (29 November 1993 ), rainfall (29 December 1993), (c) 1 day after initial rainfall (8 November 1994) (n=9) and (d) 9 days after initial rainf $(\mathrm{n}=9)$. Error bars are one standard error 


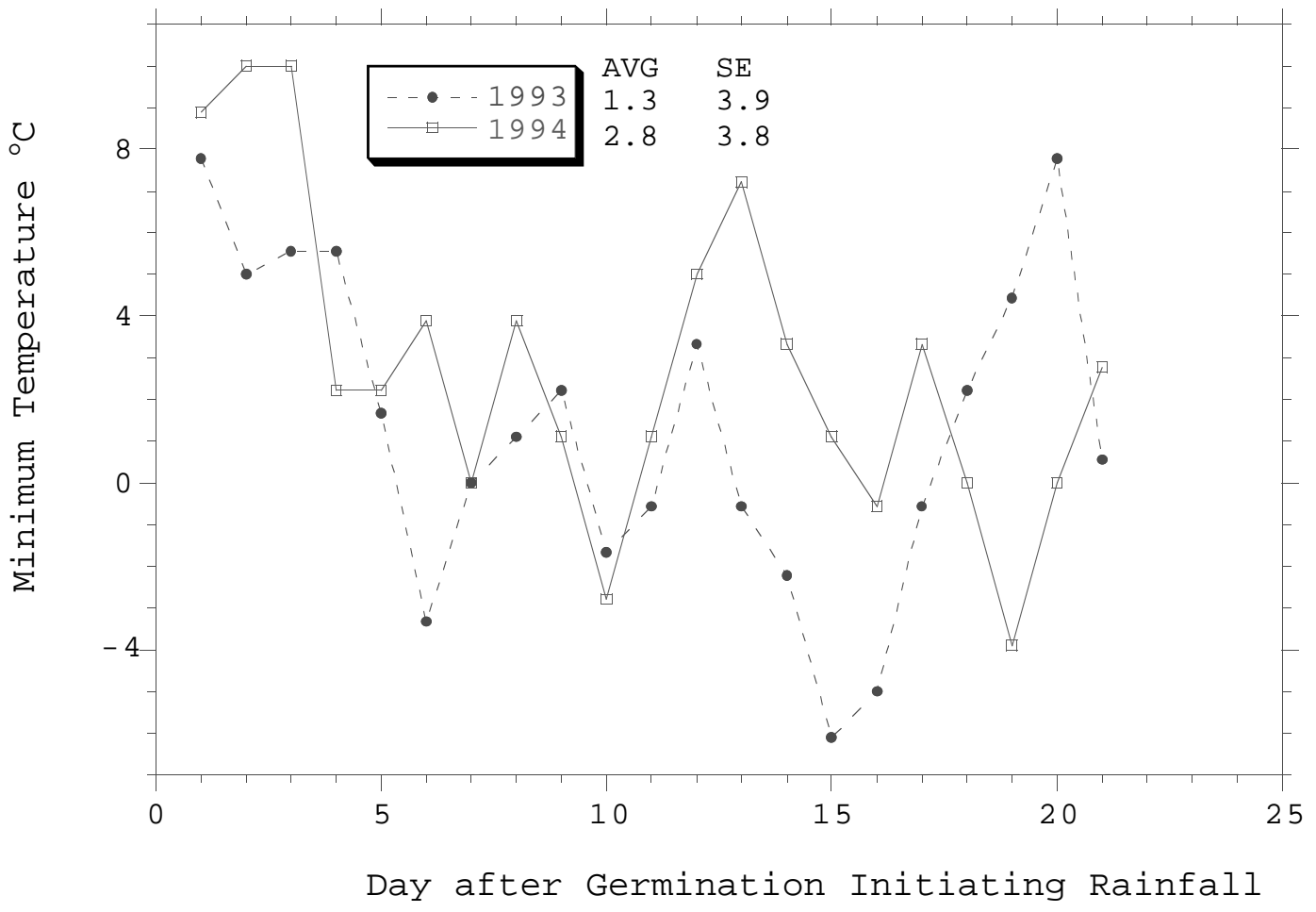

FIG. 3. Minimum daily temperäureluring. grandiflogarmination period in the fall of 1993 and 1994 . 

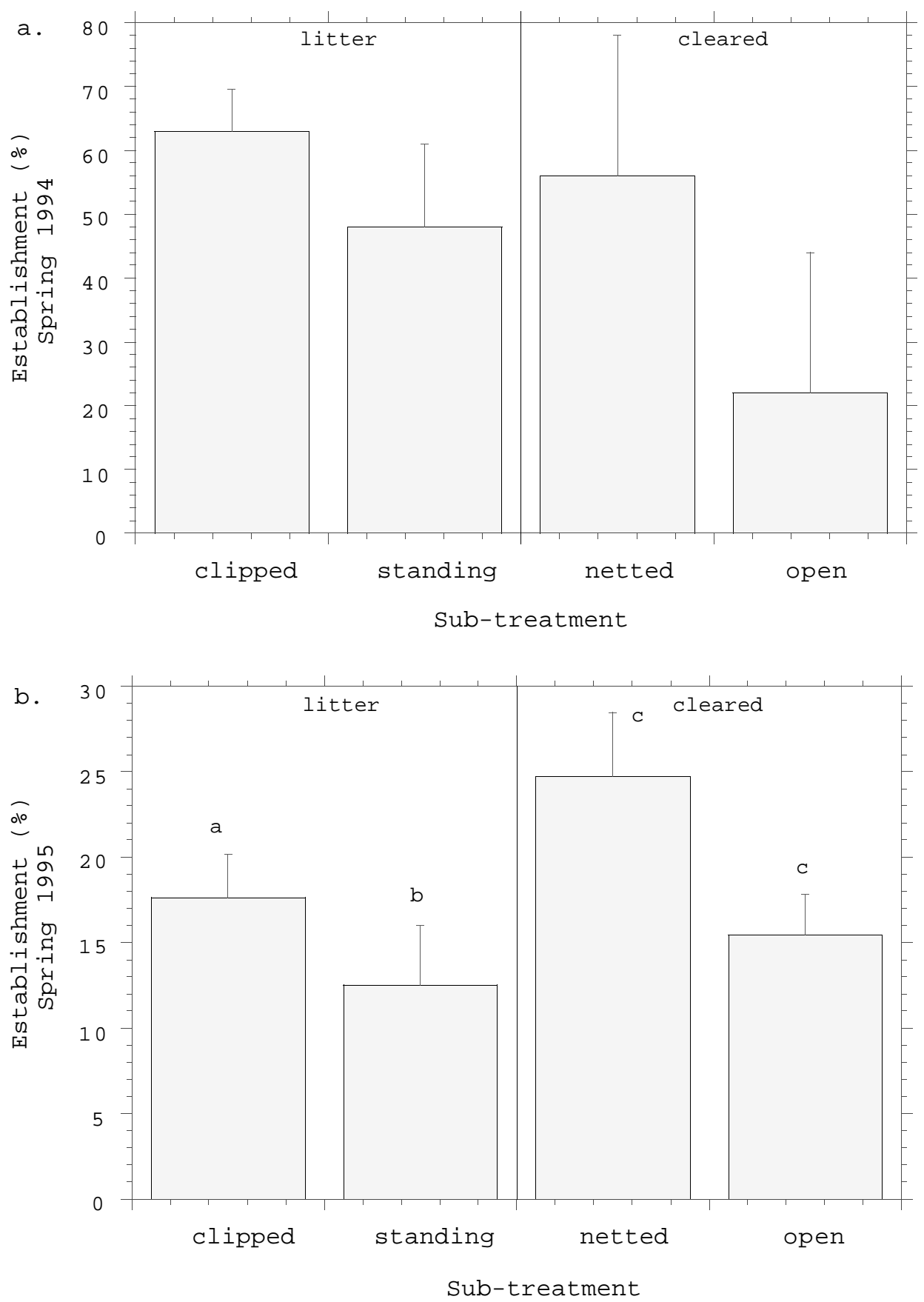

FIG. 4. Effect of main treatments and sub-treatments on establishment of reproducti plants def grandifloir (a) the spring of $1994 \quad(n=3)$ and (b) the spring of $1995 \quad(n=18)$ Error bars are one standard effom treatments with different capital letters are sign cantly different=0ato5. Sub-treatments within main treatments with different lower ca letters are significantly dipfeferent.t at 

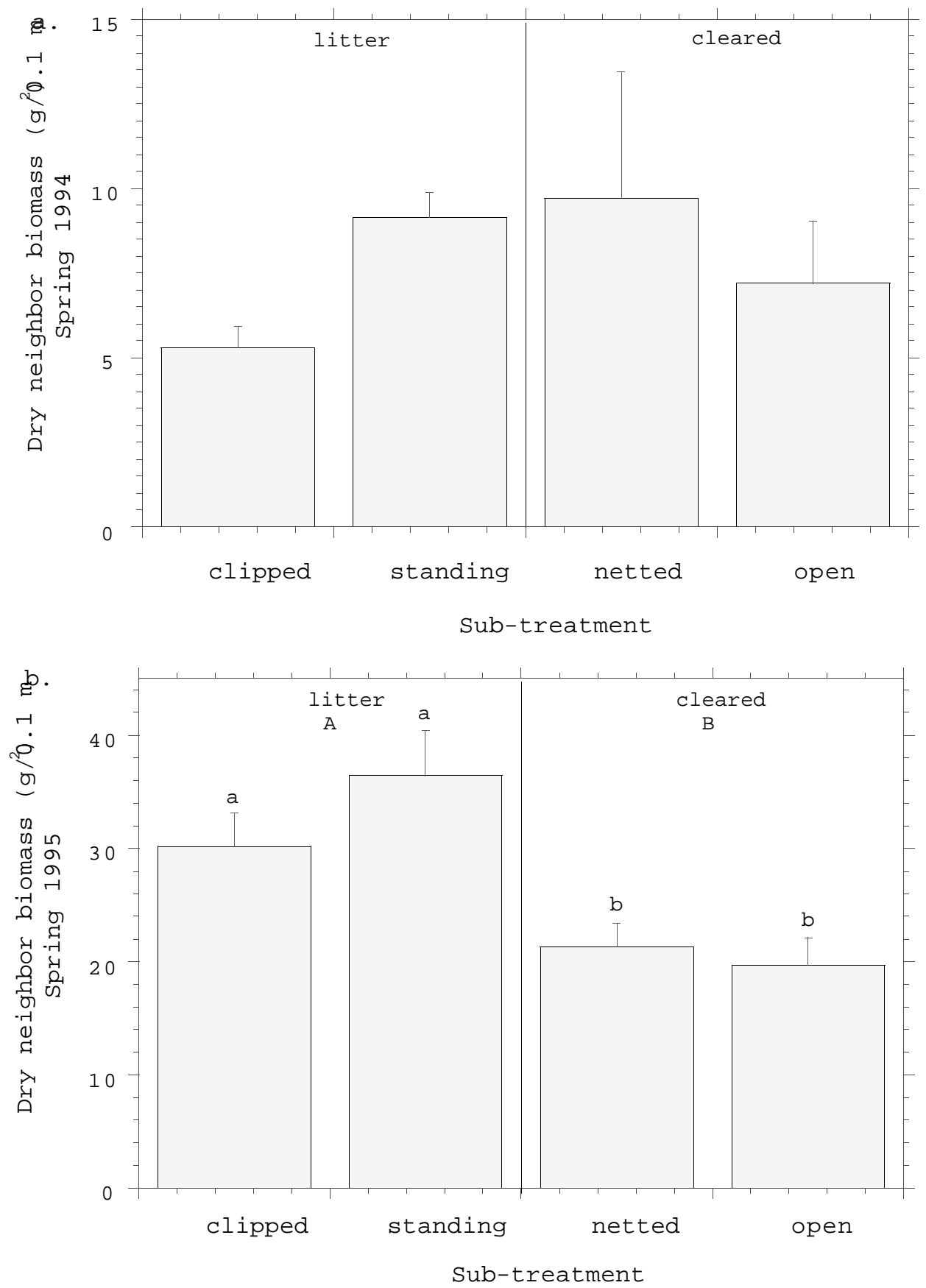

FIG. 5. Effect of main treatments and sub-treatments on final dry neighbor biomass the spring of $1994(n=3)$ and (b) the spring of $1995(n=18)$. Error bars are one stan Main treatments with different capital letters are signifipabtQj.different at Sub-treatments within main treatments with different lower case letters are signifi different pat.05. 


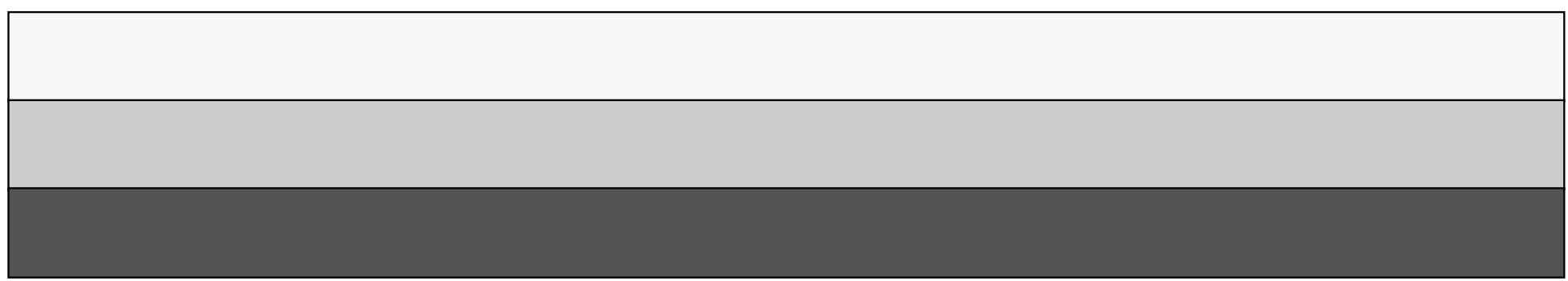

